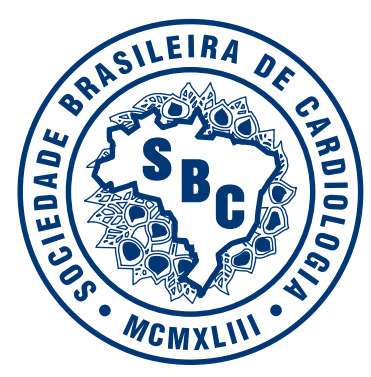

\title{
I DIRETRIZ DE AVALIAÇÃO PERIOPERATÓRIA
}

\section{Idealização e Organização}

\author{
Bruno Caramelli \\ Cláudio Pinho \\ Daniela Calderaro \\ Danielle Menosi Gualandro
}

Pai Ching Yu

\section{Comissão de Redação}

Danielle Menosi Gualandro, Claudio Pinho, Gilson Soares Feitosa-Filho, Bruno Caramelli

\section{Autores}

Alina Coutinho Rodrigues Feitosa, Beatriz Ayub, Bruno Caramelli, Carisi A. Polanczyk, Carolina L. Zilli Vieira, Claudio Pinho, Daniela Calderaro, Danielle Menosi Gualandro, Denise lezzi, Dirk Schreen, Dimas T. Ikeoka, Elbio Antonio D’Amico, Elcio Pfeferman, Emerson Quintino de Lima, Emmanuel de Almeida Burdmann, Fábio Santana Machado, Filomena Regina Barbosa Gomes Galas, Gilson Soares Feitosa-Filho, Heno Ferreira Lopes, Henrique Pachón, João César Nunes Sbano, José Augusto Soares

Barreto Filho, José L. Andrade, Roberto Henrique Heinisch, Luciana Moraes dos Santos, Luciana

S. Fornari, Ludhmila Abrahão Hajjar, Luis Eduardo P. Rohde, Luiz Francisco Cardoso, Marcelo Luiz Campos Vieira, Maristela C. Monachini, Pai Ching Yu, Paula Ribeiro Villaça, Paulo Grandini, Renato

S. Bagnatori, Roseny dos Reis Rodrigues, Sandra F. Menosi Gualandro, Walkiria Samuel Avila,

Wilson Mathias Jr.

\section{Coordenador de Normatizações e Diretrizes}

Anis Rassi Jr.

\section{REALIZAÇÃo}

Comissão de Avaliação Perioperatória (CAPO) - Sociedade Brasileira de Cardiologia 


\section{1) DEFINIÇÃO DO PROBLEMA}

\section{A) Objetivo da diretriz}

A prática médica vem incorporando de maneira surpreendentemente rápida os novos conhecimentos relacionados à cirurgia. Os recursos tecnológicos e o aprimoramento técnico das equipes aumentaram o grau de confiança de médicos e pacientes. Êxitos consecutivos associados ao menor índice de complicações pós-operatórias, resultaram na ampliação da população cirúrgica. Com a disponibilização de estratégias menos invasivas, mais rápidas e eficientes, casos antes considerados como inoperáveis passaram a ingressar nos centros cirúrgicos. Em conseqüência, um número crescente de intervenções passou a ser realizado em uma população progressivamente mais idosa e de maior risco.

Tornou-se necessário organizar o conhecimento a respeito dos fenômenos que acontecem antes, durante e depois da intervenção cirúrgica. Esta tarefa demanda grande esforço considerando-se a enorme variabilidade das características dos pacientes nestas condições e a dificuldade de estabelecer critérios comuns e referências para observação e comparação, a metodologia básica para o acúmulo de conhecimento científico. Para esta área de conhecimento, alguns autores propuseram o nome de Avaliação Perioperatória.

Para os pesquisadores e para os profissionais envolvidos na prática clínica diária da avaliação perioperatória alguns fundamentos foram estabelecidos e constituem os objetivos gerais deste documento:

- Aprimorar e unificar a linguagem utilizada por toda a equipe multiprofissional, incluindo o paciente e sua família;

- Estabelecer novas rotinas, modificar a indicação cirúrgica em função das informações da avaliação perioperatória;

- Não contra-indicar a intervenção cirúrgica, mas informar sobre os seus possíveis riscos. Com estes dados, sua experiência pessoal e conhecendo o outro lado da história, a doença de base, seus riscos e o risco atribuível à operação em si, o cirurgião poderá decidir em conjunto com o paciente e sua família se a relação risco/benefício é favorável à intervenção.

- Nem sempre há dados ou evidências científicas disponíveis para analisar todas as situações que se apresentam. Como em muitos casos na prática médica, a análise minuciosa do paciente, do problema e o bom senso da equipe devem prevalecer.

- A intervenção cirúrgica não termina no curativo ou na saída da sala operatória. O conceito de perioperatório inclui a necessidade de uma vigilância pós-operatória, tanto mais intensa quanto maior o risco individual do paciente.

Ao invés de substituir o raciocínio clínico, esta diretriz pretende complementá-lo, tornando-se uma referência para o estabelecimento de novas estratégias de tratamento e linhas de pesquisa.

\section{B) Metodologia e evidências}

Os participantes desta diretriz foram selecionados entre especialistas das ciências da saúde com experiência assistencial e acadêmica, o que os caracteriza como pesquisadores clínicos. Foram estabelecidos os fundamentos da avaliação perioperatória e as normas e recomendações atuais, tendo em vista a redução da taxa de complicações. Infelizmente não chegamos ao limite de anular o estresse provocado pela intervenção cirúrgica nem todas as suas consequências, mas o leitor perceberá que há muito que pode ser feito para tornar mais tranqüilo e bem sucedido o procedimento cirúrgico, sem ferir a verdade científica. A metodologia e os níveis de evidência adotados foram os mesmos utilizados em documentos anteriores pela Sociedade Brasileira de Cardiologia.

\section{Recomendações:}

- As diretrizes deverão ser baseadas em evidências;

- Quando aplicável, deverá ser utilizada a divisão em classes;

- Quando aplicável, deverá ser utilizada a divisão em graus de recomendação, segundo os níveis de evidência;

\section{Grau ou Classe de Recomendação:}

- I: Quando existe um consenso sobre a indicação;

- Ila: Quando existe divergência sobre a indicação, mas a maioria aprova;

- Ilb: Quando existe divergência sobre a indicação, com divisão de opiniões;

- III: Quando existe um consenso na contra-indicação ou quando não for aplicável;

\section{Níveis de Evidência:}

- A: Grandes ensaios clínicos aleatórios e metas-análises;

- B: Estudos clínicos e observacionais bem desenhados;

- C: Relatos e séries de casos;

- D: Publicações baseadas em consensos e opiniões de especialistas;

\section{2) AVALIAÇÃO GERAL}

\section{A) História}

A anamnese é o primeiro passo na avaliação perioperatória. Deve ser realizada em ambiente confortável, com o paciente ou com um de seus familiares quando a presença do primeiro não for possível. Em intervenções eletivas deve preceder o procedimento cirúrgico em pelo menos uma semana para que, eventualmente, medicamentos possam ser introduzidos para otimização da condição clínica ou outros possam ser retirados por eventual interferência no sucesso de operação. Por outro lado, nas intervenções de urgência, a anamnese realizada com o próprio paciente ou com seus familiares pode trazer à luz informações importantes para decidir, por exemplo, que o pós-operatório deverá ser realizado em UTI ou que existem condições clínicas que poderão influenciar o pós-operatório imediato.

Entre os itens que compõe a essência de anamnese estão:

- Investigação da doença de base, que indicou o procedimento cirúrgico; 


\section{Diretriz}

- Investigação minuciosa de antecedentes cirúrgicos ou anestésicos que pode revelar complicações potencialmente evitáveis, alergias ou existência de co-morbidades;

- Investigação do estado clínico e da necessidade de compensação de doenças co-existentes;

- Medicamentos em uso e potencial interferência com o ato operatório;

- Conhecimento do ponto de vista do cirurgião, da urgência e do risco do procedimento;

- Grau de ansiedade e dúvidas do paciente e seus familiares com relação ao procedimento e seus riscos.

\section{B) Exame físico}

O exame físico é útil durante o processo de avaliação de risco perioperatório e não deve ser limitado ao sistema cardiovascular. Os objetivos são: identificar cardiopatia pré-existente ou potencial (fatores de risco), definir a gravidade e estabilidade da cardiopatia e identificar eventuais co-morbidades.

Os pacientes com doença cardíaca cujo estado geral está comprometido por outras afecções tais como doenças neurológicas, insuficiência renal, infecções, anormalidades hepáticas, desnutrição ou disfunção pulmonar, apresentam risco mais elevado de complicações cardíacas porque essas condições exacerbam o estresse cirúrgico ${ }^{1}$.

Pacientes com doença vascular periférica têm elevada incidência de doença isquêmica do coração que representa um fator preditivo de complicação no perioperatório. Informações no exame físico como alterações de pulsos arteriais ou sopro carotídeo devem ser pesquisados. Por outro lado, jugulares túrgidas indicando pressão venosa central (PVC) elevada na consulta pré-operatória indicam que o paciente poderá desenvolver edema pulmonar no pós-operatório ${ }^{2,3}$. O achado de terceira bulha (B3) na avaliação pré-operatória é indicador de mau prognóstico com um risco aumentado de edema pulmonar, infarto do miocárdio ou morte cardíaca ${ }^{4}$.

Quadro 1 - Exame físico e risco de complicações no perioperatório

\begin{tabular}{|c|c|c|c|}
\hline Sinal & Sensibilidade (\%) & Especificidade (\%) & $\begin{array}{l}\text { Razão de } \\
\text { Verossimilhança } \\
\text { positiva }\end{array}$ \\
\hline B3 predizendo edema pulmonar & 17 & 99 & 14,6 \\
\hline B3 predizendo IAM ou morte cardíaca & 11 & 99 & 8,0 \\
\hline Aumento da PVC predizendo edema pulmonar & 19 & 98 & 11,3 \\
\hline Aumento da PVC predizendo IAM ou morte cardíaca & 17 & 98 & 9,4 \\
\hline \multicolumn{4}{|c|}{$\begin{array}{l}\text { Fonte: modificado de McGee, } 2001^{4} \text {. B3: terceira bulha cardíaca; PVC: pressão venosa central; IAM:infarto agudo do miocárdio. Razão de verossimilhançá } \\
\text { positiva: os valores indicam o quanto que um resultado de um teste diagnóstico aumentará a probabilidade pré-teste de uma condição alvo, podendo } \\
\text { se estimar que a chance de ocorrência do fenômeno analisado é alta (valores maiores do que 10), moderada (valores maiores do que } 5 \text { e menore } \\
\text { do que 10), pequena (valores de } 2 \text { a 5) e insignificante (valores de } 1 \text { a 2). } .^{5}\end{array}$} \\
\hline
\end{tabular}

O achado de edema de membros inferiores (bilateral) deve ser analisado em conjunto com a presença ou não de distensão venosa jugular. Se há aumento da PVC, visualizado pela altura da oscilação do pulso da veia jugular interna, então cardiopatia e hipertensão pulmonar são pelos menos parcialmente responsáveis pelo edema do paciente. Se a PVC não está aumentada outra causa deve ser a responsável pelo edema, tais como hepatopatia, síndrome nefrótica, insuficiência venosa periférica crônica ou uso de alguma medicação. O achado de edema por si só e sem o conhecimento da PVC do paciente não é um sinal definitivo de doença cardíaca ${ }^{6}$. $\mathrm{Na}$ presença de sopros cardíacos o médico deve ser capaz de distinguir sopros orgânicos de funcionais, significativos ou não, e a origem do sopro para determinar se há necessidade de profilaxia para endocardite ou de avaliação da gravidade da lesão valvar.

\section{Referências}

1. Eagle KA, Berger PB, Calkins H, Chaitman BR, Ewy GA, Fleischmann KE, Fleisher LA, Froehlich JB, Gusberg RJ, Leppo JA, Ryan T, Schlant RC,Winters WL Jr. ACC/AHA guideline update for perioperative cardiovascular evaluation for noncardiac surgery: a report of the American College of Cardiology/ American Heart Association Task Force on Practice Guidelines (Committee to Update the 1996 Guidelines on Perioperative Cardiovascular Evaluation for Noncardiac Surgery) 2002. American College of Cardiology Web site. Available at: http:/www.acc.org/clinical/guidelines/perio/dirlndex.htm.

2. Goldman L, Caldera DL, Nussbaum SR, Southwick FS, Krogstad D, Murray B, Burke DS, O' Malley TA, Goroll AH, Caplan CH, Nolan J, Carabello B, Slater EE. Multifactorial index of cardiac risk in noncardiac surgical procedures. $\mathrm{N}$ Engl J Med 1977; 297:845-850.
3. Goldman L, Caldera DL, Nussbaun SR, Southwick FS. Cardiac risk factors and complications in noncardiac surgery. Medicine 1978; 57:357-70.

4. McGee SR. Evidence-based physical diagnosis.Philadelphia: W.B. Saunders Company, 2001.

5. Jaeschke R, Guyatt G, Sackett DL for the Evidence-Based Medicine Working Group. Users' guides to the medical literature, III: how to use an article about a diagnostic test, $\mathrm{B}$ : what are the results and will they help me in caring for my patients? JAMA 1994; 271: 703-707.

6. Butman SM, Ewy GA, Standen JR, Kern KB, Hahn E. Bedside cardiovascular examination in patients with severe chronic heart failure: importance of rest or inducible jugular distension. J Am Coll Cardiol 1993; 22: 968-974. 


\section{C) Co-morbidades}

\section{I) Doenças da tireóide}

A doença de tireóide é uma situação clínica muito comum sendo que em áreas endêmicas a incidência de bócio é de $15-30 \%$ da população adulta. Por este motivo é importante considerar algumas peculiaridades no contexto perioperatório desta população. Além das dificuldades técnicas no manejo das vias aéreas dos pacientes com bócio, os distúrbios hormonais podem ser fonte de considerável morbi-mortalidade ${ }^{1}$. A tetraiodotironina (T4) representa $80 \%$ da produção hormonal tireoideana e $40 \%$ dela é convertido perifericamente para triiodotironina (T3) que é cinco vezes mais potente. Outros $50 \%$ do T4 são convertidos em 3,5-triiodotironina (T3 r) que não tem ação biológica. Apenas $0,2 \%$ de T3 e 0,3\% de T4 circulam na forma livre e biologicamente ativa e o restante se liga a proteínas do plasma (albumina, pré-albumina, tireoglobulina). O T3 e o T3r são convertidos no fígado, rins e SNC em compostos inativos. Doenças sistêmicas graves, trauma e drogas podem bloquear a conversão periférica de T4 a T3 levando à síndrome eutireoideana do doente crítico, que representa um mecanismo fisiológico de economia energética em situações críticas.

\section{1) Hipotireoidismo}

A prevalência de hipotireoidismo é estimada em 5 para 1000 pacientes e a de hipotireoidismo subclínico três vezes maior. $\mathrm{O}$ acometimento é 10 vezes maior no sexo feminino. A causa mais freqüente é iatrogênica (radioiodoterapia ou ressecção cirúrgica), sendo a segunda causa a tireoidite auto-imune (Hashimoto). Além do quadro clínico (Quadro 1) as dosagens de TSH, T4 livre e T3 livre são necessárias para diagnóstico.

No período perioperatório as complicações são raras quando o hipotireoidismo é sub-clínico, leve ou moderado.

Quadro 1 - Manifestações clínicas relevantes de hipotireoidismo no perioperatório

\section{Hipotermia}

Depressão miocárdica

Diminuição da freqüência respiratória e dificuldade no desmame ventilatório

Diminuição da freqüência cardíaca

Resposta anormal de barorreceptores

Hipotensão ou hipertensão

Angina, infarto do miocárdio

Redução de volemia

Anemia

Hipoglicemia

Hiponatremia (síndrome de secreção inapropriada de

hormônio antidiurético)

Distensão abdominal

Diminuição da metabolização hepática de drogas
Especial atenção deve ser dada aos casos graves, cuja chance de complicações é maior ${ }^{1-6}$.

\section{Recomendações:}

Grau de recomendação I, Nível de evidência D

- Avaliar todos os fatores de risco do paciente;

- Não valorizar hipotireoidismo subclínico quando o valor de $\mathrm{TSH}<10 \mathrm{mU} / \mathrm{dl}$;

- O procedimento eletivo só deverá ser realizado quando o paciente estiver eutireoideano;

- Pacientes com idade $<45$ anos devem receber a dose plena que costuma ser 1,6 a $2,2 \mathrm{mcg} / \mathrm{kg}$ de L-tiroxina ou 100 a 200 mcg ao dia. Os níveis de TSH só normalizam após 4 a 6 semanas do início da dose adequada;

- Pacientes com mais de 45 anos devem iniciar com 25-50 mcg/dia e a dose vai sendo aumentada a cada 2 semanas;

- Os pacientes coronarianos devem receber $15 \mathrm{mcg} / \mathrm{dia}$ e a dose deve ser aumentada a cada semana até a aquisição de TSH normal;

- Não adiar procedimento em pacientes com quadro de hipotireoidismo leve, porém iniciar reposição hormonal oral;

- Em procedimentos cirúrgicos na vigência de hipotireoidismo deve ser realizada profilaxia de hipotermia, monitorização cardiovascular e administrada hidrocortisona $100 \mathrm{mg}$ a cada 8 horas em 24 horas pela chance de insuficiência adrenal;

- O T4 tem meia-vida de 7 dias e o T3 de 1,5 dia. Por este motivo, o usuário de T4 não precisa tomá-lo no dia da operação enquanto o usuário de T3 deve fazê-lo;

- Avaliar a chance de intubação difícil por bócio por meio de radiografia da região cervical;

Recomendações para cirurgia de urgência em pacientes com hipotireoidismo grave ou coma mixedematoso:

Grau de recomendação I, Nível de evidência $D$

- Administrar 200-500 mcg de L-tiroxina ou 40 mcg de T3 endovenoso ou 10-25 mcg de T3 a cada 8 horas no préoperatório, o que corrige as alterações hemodinâmicas e eletrocardiográficas.No perioperatório dividir a dose em 50\% de T4 e $50 \%$ de T3;

- A dose de manutenção deverá ser 40 a 100 mcg de T4 ou 10 a 20 mcg de T3 por via venosa a cada 24 horas;

- Administrar 100 mg a cada 6 horas de hidrocortisona por tempo prolongado;

- Logo que possível, iniciar reposição hormonal por via digestiva nas doses terapêuticas descritas acima;

\section{2) Hipertireoidismo}

A tireotoxicose afeta $2 \%$ das mulheres e $0,2 \%$ dos homens. A prevalência de hipertireoidismo clínico e subclínico nos EUA é, respectivamente, 0,2 e $1 \%$. As causas mais comuns são: Doença de Graves-Basedow, bócio nodular tóxico, tireoidites e iatrogênicas. As manifestações clínicas que tem 


\section{Diretriz}

repercussão no período perioperatório estão representadas no Quadro 2. Os efeitos adrenérgicos são de alto risco para complicações como arritmias cardíacas (10 a 15\% de fibrilação atrial). Eles se relacionam ao aumento do número e/ou da sensibilidade dos receptores beta-adrenérgicos. A mortalidade do hipertireoidismo está relacionada a evento cardiovascular $^{1-6}$.

\begin{tabular}{|c|c|}
\hline \multicolumn{2}{|c|}{$\begin{array}{l}\text { Quadro } 2 \text { - Manifestações clínicas no hipertireoideo } \\
\text { com repercussões no perioperatório }\end{array}$} \\
\hline Cardiovasculares & $\begin{array}{l}\text { Aumento do inotropismo e } \\
\text { cronotropismo cardíacos com queda } \\
\text { da resistência vascular sistêmica } \\
\text { Hipertrofia de ventrículo esquerdo } \\
\text { Maior incidência de angina, } \\
\text { insuficiência cardíaca, arritmias e } \\
\text { eventos embólicos }\end{array}$ \\
\hline Hematológicas & $\begin{array}{l}\text { Anemia, plaquetopenia, neutropenia, } \\
\text { aumento de fator VIII } \\
\text { Diminuição de fatores dependentes } \\
\text { de vitamina K, sangramentos. }\end{array}$ \\
\hline Gastrointestinais & $\begin{array}{l}\text { Absorção inadequada de } \\
\text { medicamentos }\end{array}$ \\
\hline Metabólicas & $\begin{array}{l}\text { Hipercalcemia, hipoalbuminemia, } \\
\text { cetoacidose } \\
\text { Aumento do clearance de } \\
\text { medicamentos } \\
\text { Intolerância à glicose, perda de peso e } \\
\text { catabolismo protéico }\end{array}$ \\
\hline Pulmonares & Miopatia com disfunção ventilatória \\
\hline Endócrinas & $\begin{array}{l}\text { Aumento da produção e utilização de } \\
\text { cortisol }\end{array}$ \\
\hline
\end{tabular}

Para o diagnóstico deve haver confirmação laboratorial em associação à suspeita clínica. O valor de TSH deve ser baixo e o T4 livre normal (hipertireoidismo subclínico) ou alto. Diversas situações podem elevar o T4 total por aumentarem a proteína ligadora de T4, sem todavia afetar o T4 livre que exerce atividade biológica: gravidez, cirrose,acromegalia, síndrome de Cushing, uso de Lítio, anticoncepcionais, propranolol, amiodarona e contrastes iodados.

Em casos de tireoidectomia podem ocorrer complicações específicas: pacientes com grandes bócios podem apresentar complicações na intubação e extubação (até 35\% deles apresentam algum grau de obstrução de vias aéreas), lesão de laríngeo recorrente, traqueomalácea e edema de glote e pode ocorrer hipocalcemia até 36 horas após tireoidectomia em 20\% dos casos. Apenas 3\% ficam hipocalcêmicos permanentemente e o cálcio deve ser reposto por via venosa nesta fase.

\section{Recomendações:}

\section{Grau de recomendação I, Nível de evidência $D$}

- A avaliação paralela de um endocrinologista deve ser fortemente considerada no perioperatório de pacientes com hipertireoidismo;

- Antes do procedimento eletivo o paciente deverá estar adequadamente tratado do hipertireoidismo com medicações;

- Medicamentos antitireoideanos - os mais utilizados são propiltiouracil (PTU) e metimazol. Inibem a síntese de hormônios tireoideanos impedindo a oxidação e organificação do iodo. O PTU possui o benefício adicional de inibir a conversão periférica de T4 a T3 em doses altas, sendo por esse motivo mais utilizado no perioperatório. A dose habitual é de $100 \mathrm{mg}$ a cada 8 horas e a dose máxima é de $400 \mathrm{mg}$ a cada 8 horas. As doses de metimazol variam de 10 a 120 mg ao dia em dose única. A dose deve ser reavaliada a cada 4-6 semanas. Os efeitos adversos raramente são graves: rash cutâneo, febre, prurido e artralgia, elevações transitórias de enzimas hepáticas, leucopenia. Complicações mais graves, menos freqüentes e que exigem a suspensão do medicamento são agranulocitose $(0,5 \%)$, hepatite grave, Síndrome Lupus-Like e trombocitopenia;

- Betabloqueadores - o mais utilizado é o propranolol na dose de 10-80 mg a cada 6-8 horas (1 mg venoso no intra-operatório). O esmolol pode ser administrado no intraoperatório com dose de ataque de $500 \mathrm{mcg} / \mathrm{kg}$ em 1 minuto e manutenção de $25-300 \mathrm{mcg} / \mathrm{kg} / \mathrm{min}$.

Recomendações para procedimentos cirúrgicos de urgência ou emergência:

\section{Grau de recomendação I, Nível de evidência D}

- Drogas antitireoideanas - o medicamento de escolha é o PTU em doses altas (1000 a 1200 mg ao dia divididas em 3 tomadas);

- Betabloqueadores - preferir utilização por via venosa;

- lodo - pode ser usado no máximo por 10 dias já que a inibição da organificação (efeito Wolff-Chaikoff) é transitória e após esse tempo ocorre escape e piora do hipertireoidismo. A solução de Lugol, que contém $5 \%$ de iodo e $10 \%$ de iodeto de potássio é a mais utilizada, sendo a dose de 0,1 a 0,3 ml a cada 8 horas (3 a 5 gotas);

- Contrastes iodados - o Ipodato de sódio e ácido iopanóico são utilizados para compensação, com a vantagem de darem menos escape e inibirem a conversão periférica de T4 a T3. A dose é de 500mg a cada 8 horas;

- Corticosteróide - deve ser administrado quando não houver compensação do hipertireoidismo no intra e pósoperatório por maior degradação periférica do cortisol. A dose é de $100 \mathrm{mg}$ na indução e $100 \mathrm{mg}$ a cada 8 horas nas primeiras 24 horas;

- Anestesia - deve ser dada atenção especial para o aumento de metabolização medicamentos anestésicos e para o risco de intubação difícil por causa de bócio; ${ }^{1}$

- Tempestade Tireotóxica - associa-se a índices de mortalidade de 20-30\%. Diante do quadro clínico abrupto, o tratamento deve se iniciar prontamente, mesmo sem confirmação laboratorial; Quadro 3. 


\section{Tratamento específico}

- Hidratação

- Resfriamento

- Suporte ventilatório

- Controle metabólico

- Inotrópicos
- PTU ataque (1000 mg via digestiva)

- PTU manutenção 200mg cada 6 horas via digestiva

- Hidrocortisona ataque 300 mg via venosa

- Hidrocortisona manutenção de 100 mg a cada 8 horas

- Iodo na forma de Lugol via digestiva ou iodo endovenoso na dose de $1 \mathrm{~g}$ a cada 8 horas

- Se necessário plasmaférese, diálise ou colestiramina para remover hormônios da circulação

\section{Referências}

1. Mostbeck A,Galvan G,Bauer P, et al.The incidence of hypertireoidism in Austria from 1987 to 1995 before and after an increase in salt iodization in 1990. Eur J Nucl Med 1998; 124:367.

2. Bennet-Guerrero $E$, et al. Effect of chronic and acute thyroid hormone reduction on perioperative outcome. Anesth Analg 1997; 85:30.

3. Pronovost $\mathrm{PH}$,et al. Perioperative management of thyroid disease:prevention of complications related to hyperthyroidism and hypothyroidism. Postgrad

\section{Med 1995; 98:83.}

4. Graham GW, et al. Perioperative management of selected endocrine disorders. Int Anaesthesiol Clin 2000; 38:31.

5. Murkin JM. Anaesthesia and hypothyroidism: a review of thyroxine, physiology, pharmacology and anaesthetic implication. Anaesth Analg 1982; 61:371.

6. Stehling LC. Anaesthetic management of the patient with hyperthyroidism. Anesthesiology 1974; 41:585.

\section{II) Insuficiência renal}

Os pacientes portadores de insuficiência renal estão mais predispostos a complicações perioperatórias, tempo de hospitalização prolongado, maiores custos durante a internação e maior mortalidade do que aqueles que não possuem disfunção renal ${ }^{1,2}$. Entre os fatores de risco presentes em modelos prognósticos para complicações cardiovasculares após cirurgias não-cardíacas figura a creatinina pré-operatória maior que $2,0 \mathrm{mg} / \mathrm{dL}$. Mesmo a insuficiência renal crônica moderada (creatinina 1,5 - 3,0 $\mathrm{mg} / \mathrm{dL}$ ou filtração glomerular entre 30 e $60 \mathrm{ml} / \mathrm{min}$ ) é um fator de risco para complicações cardíacas e não-cardíacas no pós-operatório e está associada à mortalidade até duas vezes mais elevada quando comparado com pacientes com função renal normal ${ }^{1,2}$. Os pacientes em programa de terapia substitutiva renal devem ser submetidos à diálise antes da operação para evitar hipervolemia, corrigir os distúrbios eletrolíticos e ácido-básico e reduzir o risco de sangramento associado à uremia. Nos transplantados renais a imunossupressão deve ser cuidadosamente ajustada pelo nefrologista no pré e pós-operatório devido ao risco de rejeição aguda e nefrotoxicidade.

A insuficiência renal aguda (IRA) no pós-operatório ocorre, dependendo do tipo de operação, em 1-30\% dos casos, com mortalidade em torno de $50 \%$. A prevenção de IRA no período perioperatório depende da identificação de fatores de risco para o seu desenvolvimento (principalmente insuficiência renal pré-operatória), evitar o uso de drogas nefrotóxicas, manter hidratação adequada e evitar hipotensão. As tentativas de prevenção da IRA através de diuréticos e aminas vasoativas não mostraram eficácia.
A dopamina em "dose renal" não previne a disfunção renal, não reduz a necessidade de diálise e não diminui a mortalidade por IRA. Medicamentos potencialmente nefrotóxicos devem ser evitados ou utilizados de forma adequada, com correção para o nível de função renal. Antibióticos aminoglicosídeos, anfotericina B, contraste radiológico, inibidores da enzima conversora da angiotensina e antinflamatórios não-hormonais são exemplos de substâncias nefrotóxicas comumente utilizadas no período perioperatório. Os efeitos dos antiinflamatórios com propriedade de inibição seletiva da ciclooxigenase II na função renal não são diferentes dos promovidos pelos antiinflamatórios não seletivos e seu uso deve ser evitado em pacientes de risco para nefrotoxicidade por antiinflamatórios (idade avançada, insuficiência renal prévia, insuficiência cardíaca, desidratação, uso concomitante de inibidores da enzima conversora de angiotensina, diuréticos ou outros agentes nefrotóxicos) ${ }^{3-6}$.

Os riscos de complicações pós-operatórias estão bem definidos em pacientes com insuficiência renal e a avaliação do nefrologista deve ser considerada em todos os pacientes com creatinina pré-operatória maior que 1,5 mg/dL. Deve-se sempre ter em mente que a creatinina é um marcador pouco sensível da função renal. Portanto, creatinina menor que 1,5 $\mathrm{mg} / \mathrm{dL}$ não significa necessariamente função renal normal, particularmente em pacientes idosos ou com massa muscular reduzida. A avaliação perioperatória é uma oportunidade de contato com este paciente e com a equipe clínica-cirúrgica para planejar medidas de prevenção de deterioração da função renal e para seguimento posterior visando retardar a progressão da insuficiência renal crônica. 


\section{Diretriz}

\section{Referências}

1. O'Hare AM, Feinglass J, Sidawy AN, Bacchetti P, Rodriguez RA, Daley J, Khurì $\mathrm{S}$, Henderson WG, Johansen KL. Impact of renal insufficiency on short-term morbidity and mortality after lower extremity revascularization: data from the Department of Veterans Affairs' National Surgical Quality Improvement Program. J Am Soc Nephrol 2003; 14:1287-1295.

2. Chertow GM, Lazarus JM, Christiansen CL, Cook EF, Hammermeister KE, Grover F, Daley J. Preoperative renal risk stratification. Circulation 1997; 95:878-884.

3. Burdmann EA: Epidemiologia. In: Insuficiência Renal Aguda: Fisiopatologia, Clínica e Tratamento. Schor N, Santos O, Boim M, São Paulo, Editora Sarvier,

\section{III) Doenças hematológicas}

Muitas doenças hematológicas podem aumentar a morbidade e mortalidade dos indivíduos submetidos a procedimentos cirúrgicos. A anemia é uma situação que leva à sobrecarga do sistema cardiovascular, aumentando o débito cardíaco. Indivíduos com doenças cardiovasculares apresentam menor tolerância à anemia, de modo que a sua presença pode intensificar uma condição de isquemia miocárdica e de insuficiência cardíaca subjacentes. São limitadas as orientações disponíveis quanto à transfusão de sangue no período perioperatório, porém sempre devem ser questionados os riscos e benefícios desta medida ${ }^{1}$. Na decisão de uma transfusão sangüínea deve-se ainda considerar a duração da anemia, a volemia, a extensão da cirurgia, a probabilidade de hemorragia maciça e a presença de condições associadas, como doenças pulmonares, insuficiência cardíaca, isquemia miocárdica e insuficiência vascular periférica ou cerebral. Deve-se sempre considerar que uma unidade de concentrado de eritrócitos aumenta a taxa de hemoglobina em aproximadamente $1 \mathrm{~g} / \mathrm{dL}$ e o hematócrito em 3\%1.

Recomendações para transfusão de concentrados de hemáceas no perioperatório²:

- Indivíduos com anemia sintomática devem ser transfundidos para um valor de hemoglobina que leve à melhora dos seus sintomas; Grau de recomendação I, Nível de evidência $D$.

- Hemoglobina inferior a 7,0 g/dL em indivíduos com anemia aguda; Grau de Recomendação I, Nivel de Evidência A.

- Nos casos de insuficiência coronariana aguda, recomendase manter a hemoglobina entre 9,0 e 10,0 g/dL; Grau de Recomendação I, Nível de Evidência D.

Existem várias outras condições hematológicas que devem ser consideradas na avaliação perioperatória, sendo que em muitas delas há a necessidade do envolvimento do hematologista na equipe clínico-cirúrgica. Pacientes com contagem plaquetária igual ou superior a $50.000 / \mathrm{mm}^{3}$ usualmente toleram os procedimentos cirúrgicos sem apresentar manifestações hemorrágicas excessivas não necessitando de transfusão de plaquetas $^{2}$.
1997, pp 1-7.

4. Lima EQ, Castro I, Zanetta DMT, Yu L. Mortality risk factors and validation of severity scoring systems in critically ill patients with acute reanl failure. Ren Fail 2005; 27(5):547-56

5. Kellum JA, Decker M: Use of dopamine in acute renal failure: a meta-analysis. Crit Care Med 2001; 29:1526-1531

6. Ott E, Nussmeier NA, Duke PC, Feneck RO, Alston RP, Snabes MC, Hubbard RC, Hsu PH, Saidman LJ, Mangano DT. Efficacy and safety of the cyclooxygenase 2 inhibitors parecoxib and valdecoxib in patients undergoing coronary artery bypass surgery. J Thorac Cardiovasc Surg 2003; 125:1481-1492.

\section{Recomendações para transfusão de plaquetas:} Grau de Recomendação I, Nível de Evidência B

- Contagem plaquetária inferior a 50.000/ $\mathrm{mm}^{3}$;

- Para as intervanções neurológicas e oftalmológicas, contagem plaquetária inferior à 100.000 plaquetas $/ \mathrm{mm}^{3}$;

Recomendações para conduta no perioperatório em pacientes com outras condições hematológicas

\section{1) Doença Falciforme (SS/SC/SBtal)}

\section{Grau de Recomendação I, Nível de Evidência C}

- Elevar a taxa de hemoglobina para $10 \mathrm{~g} / \mathrm{dL}$ através de transfusão de concentrado de hemácias. Em casos com $\mathrm{Hb}$ $\geq 9 \mathrm{~g} / \mathrm{dL}$, consultar especialista;

- Monitorização pre-operatória do hematócrito, perfusão periférica e oxigenação;

- Monitorização intra-operatória das condições de pressão arterial, ritmo e freqüência cardíaca, oxigenação e temperatura, evitando a hipotermia;

- Monitorização pós-operatória da hidratação, oxigenação e manutenção da temperatura ${ }^{3}$;

\section{2) Síndrome antifosfolípide primária}

\section{Grau de Recomendação I, Nível de Evidência C}

- Para pacientes sob terapia anticoagulante, fazer profilaxia anti-trombótica no perioperatório;

- Para pacientes sem uso de anticoagulantes, fazer profilaxia no pós-operatório ${ }^{4}$.

\section{3) Trombofilia hereditária}

\section{Grau de Recomendação I, Nível de Evidência C}

- Em pacientes sob terapia anticoagulante, fazer profilaxia anti-trombótica no perioperatório;

- Para pacientes sem uso de anticoagulantes, fazer profilaxia anti-trombótica no pós-operatório, com dose que irá variar conforme o tipo de trombofilia hereditária ${ }^{4}$;

4) Hemofilia A (deficiência de fator VIII) e B (deficiência de fator IX) 


\section{Grau de Recomendação I, Nível de Evidência B}

- Avaliação laboratorial pré-operatória quanto à presença de inibidores do fator deficiente;

- Para o intra-operatório, correção do nível plasmático do fator deficiente através do uso de concentrado de fator específico;

- No pós-operatório, manter a taxa plasmática do fator deficiente em níveis e tempo que irão variar conforme o tipo e porte da cirurgia;

- Controle laboratorial rigoroso dos níveis plasmáticos do fator deficiente ${ }^{5}$;

\section{Referências}

1. Armas-Loughran B, Kalra R, Carson JL. Evaluation and management of anemia and bleeding disorders in surgical patients. Med Clin North Am $2003 ; 87: 229-242$.

2. Madjdpour C, Spahn DR. Allogenic blood cell transfusions: efficacy, risks, alternatives and indications. British Journal of Anaesthesia 2005; 95(1):33-42.

3. The management of sickle cell disease. National Institute of Health / National Heart, Lung, and Blood Institute / Division of Blood Diseases and Resources. 2002.

4. Middeldorp S, Büller HR, Prins MH, Hirsh J. Approach to the thrombophilic

\section{IV) Insuficiência adrenal}

O aumento dos níveis de cortisol durante o estresse agudo é uma importante resposta protetora. Entretanto, o estresse metabólico causado pelo ato cirúrgico pode precipitar insuficiência adrenal aguda em indivíduos com distúrbios clínicos e subclínicos que acometam o eixo hipotálamohipófise adrenal e os resultados podem ser catastróficos determinando complicações múltiplas e até mesmo a morte do paciente.

O estresse físico aumenta o hormônio adrenocorticotrófico (ACTH) e a secreção de cortisol. O aumento nos níveis de cortisol, noradrenalina e adrenalina caracterizam as alterações hormonais induzidas pelo estresse, sendo mínima no estresse cirúrgico pequeno e progressivamente elevada em estresse moderado e severo, durando não mais que 24 horas em intervenções sem complicações. O período intra-operatório e, principalmente, a recuperação anestésica e a extubação são os maiores determinantes da ativação do eixo com aumento dos níveis de cortisol plasmático que retornam aos valores basais em 24 a 48 horas $^{1}$. Com o aumento do requerimento endógeno de corticóides, indivíduos com prejuízo na função e reserva adrenal comprometida podem ter insuficiência adrenal aguda (IAA), sendo fundamental a identificação precoce destes indivíduos para adequado planejamento perioperatório visando evitar complicações.

\section{1) Quadro Clínico da Insuficiência Adrenal}

- Hipotensão e choque hemodinâmico (que pode ser

\section{5) Doença de von Willebrand}

\section{Grau de Recomendação I, Nível de Evidência B}

- Para o intra-operatório, correção do nível plasmático do fator deficiente através do uso de concentrado de fator VIII com fator von Willebrand;

- No pós-operatório, os níveis de fator VIII e de fator Von Willebrand (quantidade e função) irão variar conforme o tipo e porte cirúrgico;

- Conforme o tipo de procedimento cirúrgico e a resposta laboratorial ao teste com DDAVP, considerar o uso desta medicação ${ }^{6}$;

patient. In: Hemostasis and Thrombosis. Basic principles \& Clinical practice. Colman RW, Hirsh J, Marder VJ, Clowes AW, George JN, eds. 4 ed, Lippincott Williams \& Wilkins, Philadelphia 2001. P. 1085-100.

5. Arun B, Kessler CM. Clinical manifestations and therapy of the hemophilias. In: Hemostasis and Thrombosis. Basic principles \& Clinical practice. Colman RW, Hirsh J, Marder VJ, Clowes AW, George JN, eds. 4 ed, Lippincott Williams \&Wilkins, Philadelphia 2001. P. 815-24.

6. Mannucci PM. Treatment of von Willebrand disease. Haemophilia 1998 4:661-64.

resistente a vasopressores) com disfunção de múltiplos órgãos;

- Hipoglicemia;

- Taquicardia;

- Distúrbios hidroeletrolíticos: hiponatremia, hipercalemia (em IA primária), hipercalcemia, acidose;

- Hipocontratilidade cardíaca;

- Anemia, eosinofilia e neutropenia;

- Náuseas, vômitos, fraqueza, hipotensão ortostática, desidratação, dor abdominal ou em flancos (hemorragia adrenal aguda), fadiga, perda de peso;

- Vitiligo, alteração da pigmentação da pele, hipogonadismo, hipotireoidismo;

Deve-se desconfiar do diagnóstico de IA se no intra ou pós-operatório houver hipotensão ou choque não explicado ou refratário a volume e drogas, discrepância entre a gravidade da doença e o estado do paciente, febre alta sem causa aparente (culturas negativas) ou que não responde à terapia antibiótica, alterações mentais não explicadas, apatia ou depressão sem distúrbio psiquiátrico específico. Nestes casos, deve-se tratar como IAA e obter confirmação posterior. Grau de recomendação I, Nível de evidência C.

\section{2) Identificação de pacientes de risco de IA}

- Pacientes com diagnóstico já estabelecido de $\mathrm{IA}^{2}$;

- Pacientes de risco para $\mathrm{IA}^{3}$ e pacientes com hipoadrenalismo relativo (limitada reserva adrenocortical): 


\section{Diretriz}

Tumores hipofisários (macroadenomas);

Radioterapia da região hipofisária;

Intervenção cirúrgica hipofisária prévia;

Pós-operatório de cirurgia de doença de cushing, adrenalectomia bilateral ou adrenalec-tomia unilateral em caso de outra adrenal acometida;

Usuários crônicos de corticóide (>7,5mg de prednisona ou equivalente por mais de 30 dias ou acima de $20 \mathrm{mg}$ por mais que duas semanas);

Pacientes com diabetes mellitus tipo 1 ou doenças autoimunes (Doença de Hashimoto, falência ovariana ou testicular primária, hipoparatireoidismo, vitiligo);

Indivíduos com clínica sugestiva (escurecimento da pele, fraqueza, fadiga, náuseas, vômitos, depressão, hipotensão, distúrbios eletrolíticos, hipoglicemia, febre);

\section{Recomendações:}

- Confirmar o diagnóstico por meio de testes apropriados para pacientes de risco para IA e considerar o acompanhamento conjunto do endocrinologista; Grau de Recomendação I, Nível de evidência $B$.

- Em casos de necessidade de confirmação da IA por exames, utilizar dexametasona que não interfere com os testes comprobatórios; Grau de recomendação I, Nível de evidência $C$

- Em casos de coexistência de hipotireoidismo e IA não tratados: corrigir primeiro a IA; Grau de recomendação I, Nível de evidência $C$.

- Não há necessidade de suplementação de mineralocorticóides pois as doses de corticóide para suplementação no estresse cirúrgico possuem atividade mineralocorticoide; Grau de recomendação I, Nível de evidência $C$.

- Na impossibilidade de confirmação diagnóstica antes da operação recomendamos a suplementação de corticóide conforme esquemas a seguir; Grau de Recomendação Ila, Nível de evidência $D$.

\section{3) Doses de suplementação de corticóide ${ }^{4-6}$ Recomendações:}

- Não há necessidade de doses elevadas de suplementação de corticóides para prevenção de IAA; Grau de Recomendação Ila, Nível de evidência $B$.
- Doses elevadas podem aumentar a chance de complicações como hipertensão e descompensação de diabetes; Grau de Recomendação Ila, Nível de Evidência C.

\section{A) Estresse cirúrgico leve}

- Dobrar ou triplicar a dose do corticóide nos pacientes com IA estabelecida e usuários crônicos, lembrando que a supressão adrenal pode acontecer rapidamente ao usar doses elevadas ou mesmo após muito tempo sem usar corticoides (até 48 meses); Grau de recomendação lla, Nível de evidência C.

- Se o paciente estiver em jejum, suplementar com hidrocortisona 50mg intramuscular ou intravenoso logo antes da operação e manter $25 \mathrm{mg}$ de hidrocortisona 2 vezes por dia ou equivalente (dexametasona $0,75 \mathrm{mg} 2$ vezes por dia), reduzindo para dose habitual em 24 horas ou assim que cessado o estresse; Grau de recomendação lla, Nível de evidência C.

- Nos pacientes sem diagnóstico estabelecido e com forte suspeita, tratar como se fosse IA estabelecida; Grau de recomendação Ilb, Nível de evidência $C$.

\section{B) Estresse cirúrgico moderado}

- Suplementar 25mg de hidrocortisona ou equivalente, intramuscular ou intravenoso de 08/08 horas, iniciando na manhã da operação, com redução de $50 \%$ da dose por dia até a dose habitual; Grau de recomendação Ila, Nível de evidência $C$.

\section{C) Estresse cirúrgico elevado}

- Suplementar 50mg/dia de hidrocortisona ou equivalente de 06/06 horas com redução de $50 \%$ da dose por dia até a dose habitual quando cessado o estresse metabólico (em geral dura até 48 horas em operações não complicadas por infecções ou outras intercorrências); Grau de recomendação Ila, Nível de evidência C.

\section{D) Situação especial de Síndrome de Cushing}

- Considerar o acompanhamento de médico endocrinologista;

- Iniciar o corticóide logo na chegada ao ambiente de terapia intensiva ou no dia seguinte à operação;

- Nestes casos, alguns grupos administram corticóide apenas se existirem sintomas, sinais ou resultados laboratoriais de IAA;

\section{Referências}

1. Udelsman R, Norton JA, Jelenich SE, Goldstein DS, Linehan WM, Loriaux $\mathrm{DL}$, Chrousos GP. Responses of the hypothalamic-pituitary-adrenal and reninangiotensin axes and the sympathetic system during controlled surgical and anesthetic stress. J Clin Endocrinol Metab 1987 May;64(5):986-94.

2. Oelkers W Adrenal Insufficiency. N Engl J Med 1996; 335:1206-1212.

3. Grinspoon SK, 1994, May ME, Vaughn ED, Carey RM. Adrenocortical insufficiency - clinical aspects. In: Vaughn ED Jr, Carey RM, eds. Adrenal Disorders. New York: Thieme Medical, 1989: 171-89.
4. Salem M, Tainsh RE Jr, Br J, Loriaux DL, Chernow B. Perioperative glucocorticoid coverage. A reassessment 42 years after emergence of a problem. Ann Surg 1994; Apr;219(4):416-25.

5. Cooper MS, Stewart PM. Corticosteroid insufficiency in acutely ill patients. N Engl J Med 2003; Feb 20;348(8):727-34.

6. Axelrod L. Perioperative management of patients treated with glucocorticoids. Endocrinol Metab Clin North Am 2003 Jun;32(2):367-83. 


\section{Obesidade}

A prevalência de sobrepeso e obesidade está aumentando em todo o mundo em taxas alarmantes apresentando aumento de até $50 \%$ na prevalência entre a década de 80 e a atualidade. Estima-se que cerca de $40 \%$ dos indivíduos adultos do país apresentam excesso de peso (índice de massa corporal, IMC, acima de $25 \mathrm{~kg} / \mathrm{m}^{2}$ ) e que $8,9 \%$ dos homens e $13,1 \%$ das mulheres apresentam obesidade, sendo que a prevalência tende a aumentar com a idade.

A gravidade da obesidade pode ser caracterizada em graus:

Obesidade grau 1 IMC 30-34,9 kg/m²

Obesidade grau 2 IMC $35-39,9 \mathrm{~kg} / \mathrm{m}^{2}$

Obesidade grau $3 \mathrm{IMC} \geq 40 \mathrm{~kg} / \mathrm{m}^{2}$

1) Peculiaridades do risco cirúrgico associado à obesidade

- Quanto maior o grau de obesidade, maior o risco cirúrgico, principalmente em relação ao sistema respiratório e cardiovascular;

- Há dificuldade no estabelecimento do risco cirúrgico do obeso porque o exame físico é precário pela obesidade;

- A história clínica pode subestimar os sintomas (grande limitação funcional) e o risco cirúrgico, especialmente nos obesos graus 2 e 3 ;

- Os escores de risco não contemplam a obesidade como fator de risco independente;

- A intubação é difícil;

- Ocorre hipoxemia por hipoventilação, restrição pulmonar, atelectasia no pós-operatório, apnéia central e obstrutiva do sono e hipercapnia;

- Existe risco de aspiração de conteúdo gástrico;

- Pode haver descompensação de ICC subdiagnosticada e precipitação de isquemia miocárdica;

- Maior risco de eventos tromboembólicos;

- Há dificuldade na mensuração da pressão arterial e acesso venoso;

- Maior sensibilidade à opióides e sedativos;

- Risco de infecção na ferida cirúrgica;

- Ocorre rabdomiólise;

- Risco inerente às co-morbidades freqüentes no obeso: hipertensão, diabetes, cardiovasculopatia, hipertrofia ventricular;

2) Recomendações específicas para a avaliação préoperatória de acordo com o IMC e o porte cirúrgico:

A) Obesidade de qualquer grau e cirurgia de porte baixo

- Avaliação semelhante ao indíviduo não obeso; Grau de recomendação lla, Nível de evidência $D$.

B) Obesidade grau 1 e 2 e cirurgia de porte intermediário e alto
- História e exame físico completos;

- Avaliação clínica da apnéia obstrutiva do sono; Grau de recomendação I, Nível de evidência $B$.

- ECG; Grau de recomendação lla, Nível de evidência B.

- Glicemia de jejum; Grau de recomendação Ila, Nível de evidência $B$.

- Creatinina em caso de diabetes, hipertensão ou história de nefropatia; Grau de recomendação IIb, Nível de evidência C.

- Polissonografia em pacientes selecionados; Grau de recomendação Ilb, Nível de evidência $C$.

- Oximetria não invasiva em repouso e durante o sono se escore de apnéia intermediário ou alto nos escores clínicos ou polissonografia com diagnóstico de apnéia do sono; Grau de recomendação IIb, Nível de evidência $D$.

- ECO com avaliação de função diastólica se sinais ou sintomas sugestivos de ICC; Grau de recomendação IIb, Nível de evidência $D$.

\section{e alto}

C) Obesidade grau 3 e cirurgia de porte intermediário

- ECG; Grau de recomendação lla, Nível de evidência B.

- Glicemia de jejum; Grau de recomendação Ila, Nível de evidência $B$.

- Creatinina em caso de diabetes, hipertensão ou história de nefropatia; Grau de recomendação lla, Nível de evidência C.

- ECO com avaliação de função diastólica; Grau de recomendação lla, Nível de evidência $D$.

- Oximetria não invasiva em repouso e durante o sono; Grau de recomendação IIb, Nível de evidência $D$.

\section{Observações:}

- A realização de testes adicionais como estudos de coagulação, testes não-invasivos para isquemia cardíaca, radiografia de tórax, testes pulmonares funcionais não é mandatória e não deve ser rotina na avaliação pré-operatória de indivíduos obesos. Testes adicionais devem selecionados com base na história clínica; Grau de recomendação lla, Nível de evidência $B$.

- Os procedimentos bariátricos de ressecção de estômago (derivações) e bypass gástrico se enquadram em cirurgias de porte intermediário;

\section{3) Recomendações para a redução do risco}

- Cessação do tabagismo 6 semanas antes da cirurgia'; Grau de recomendação I, Nível de evidência $B$.

- Fisioterapia respiratória; Grau de recomendação lla, Nível de evidência $D$.

- Se houver apnéia do sono documentada por polissonografia ou escore de risco alto para apnéia considerar a instalação de CPAP no pré-operatório nos pacientes que não fazem uso e não descontinuar os que já usam; Grau de recomendação lla, Nível de evidência $B$.

\section{A) Cuidados no intra-operatório}




\section{Diretriz}

- Monitorização da pressão arterial com manguito apropriado para obeso ou local alternativo (antebraço) com cálculos de ajuste²; Grau de recomendação I, Nível de evidência $B$

- Posicionamento em Trendelemburg reverso na indução anestésica; Grau de recomendação lla, Nível de evidência $B$.

- O uso do sevoflurano na anestesia geral resulta em extubação mais rápida e melhor recuperação inicial; Grau de recomendação lla, Nível de evidência $B$.

- Pré-oxigenação com cabeceira elevada ou sentada; Grau de recomendação lla, Nível de evidência $B$.

- Rápida seqüência de indução anestésica com pressão cricóide durante a intubação; Grau de recomendação Ila, Nível de evidência $B$.

- Maca apropriada para obeso e cuidados com as lesões por posicionamento na cama cirúrgica; Grau de recomendação Ila, Nível de evidência D.

- Considerar individualmente monitorização invasiva da pressão arterial; Grau de recomendação Ilb, Nível de evidência $D$.

\section{B) Cuidados no pós-operatório}

- CPAP em casos de diagnóstico de apnéia do sono documentada ${ }^{3}$; Grau de recomendação I, Nível de evidência B.

- Monitorização não invasiva de oximetria em pacientes com hipoxemia no pré e intra-operatório e com suspeita de patologias de vias áereas e pulmonares (apnéia do sono, hipoventilação alveolar); Grau de recomendação Ila, Nível de evidência $B$.

- Cuidados pós-operatórios em UTI para pacientes de alto risco devido a comorbidades, que tiveram falência na extubação pós-operatória, sofreram complicações no intra-operatório ou para superobesos $(\mathrm{IMC}>70)^{4}$; Grau de recomendação lla, Nível de evidência $C$.

- Manutenção de normovolemia; Grau de recomendação Ila, Nível de evidência D.

- Oximetria não invasiva contínua durante recuperação anestésica (grau de recomendação IIb, Nível de evidência C), mensuração após recuperação da anestesia (se normal não precisa repetir) e medida contínua durante o sono (em intervenções de porte intermediário a alto); Grau de recomendação Ilb, Nível de evidência $D$.

- Fisioterapia respiratória para todos submetidos à cirurgias de porte intermediário a alto; Grau de recomendação Ila, Nível de evidência $D$.

- Profilaxia para TVP:

- Deambulação precoce e profilaxia medicamentosa; Grau de recomendação I, Nível de evidência $B$.

- Profilaxia medicamentosa com heparina de baixo peso molecular e não fracionada em doses habituais ${ }^{5}$. Para obesos com peso acima de $100 \mathrm{~kg}$ considerar a monitorização da atividade do fator Xa; Grau de recomendação Ila, Nível de evidência $B$.

- Doses mais elevadas (40mg de enoxaparina de 12/12 horas) resultaram em menos eventos tromboembólicos e podem ser úteis ${ }^{6}$; Grau de recomendação Ila, Nível de evidência $B$

\section{Referências}

1. Moller AM, Villebro N, Pedersen T, Tonnesen H. Effect of preoperative smoking intervention on postoperative complications: a randomised clinical trial. Lancet 2002; Jan 12;359(9301):114-7.

2. Pickering TG, Hall JE, Appel LJ, Falkner BE, Graves J, Hill MN, Jones DW Kurtz T, Sheps SG, Roccella EJ; Subcommittee of Professional and Public Education of the American Heart Association Council on High Blood Pressure Research. Recommendations for blood pressure measurement in humans and experimental animals: Part 1: blood pressure measurement in humans: a statement for professionals from the Subcommittee of Professional and Public Education of the American Heart Association Council on High Blood Pressure Research. Hypertension 2005 Jan;45(1):142-61.

3. Lojander J, Maasilta P, Partinen M, Brander PE, Salmi T, Lehtonen H. Nasal-

CPAP, surgery, and conservative management for treatment of obstructive sleep apnea syndrome. A randomized study. Chest 1996 Jul;110(1):114-9.

4. Helling TS. Operative experience and follow-up in a cohort of patients with a BMI > or $=70 \mathrm{~kg} / \mathrm{m}^{2}$. Obes Surg $2005 \mathrm{Apr} ; 15(4): 482-5$.

5. Hamad GG, Choban PS. Enoxaparin for thromboprophylaxis in morbidly obese patients undergoing bariatric surgery: findings of the prophylaxis against VTE outcomes in bariatric surgery patients receiving enoxaparin (PROBE) study. Obes Surg 2005 Nov-Dec;15(10):1368-74.

6. Scholten DJ, Hoedema RM, Scholten SE. A comparison of two differen prophylactic dose regimens of low molecular weight heparin in bariatric surgery. Obes Surg 2002 Feb;12(1):19-24.

\section{D) Exames subsidiários}

A solicitação de exames complementares é um tema polêmico em medicina. Com a evolução tecnológica há um acréscimo exponencial no número de exames que estão disponíveis. É necessário que o médico esteja familiarizado com os atributos de um teste, suas indicações, vantagens, desvantagens, custos, disponibilidade e riscos antes de empregá-lo e tenha sempre em mente que a anamnese e o exame físico continuam sendo instrumentos fundamentais no

diagnóstico clínico.

Freqüentemente, são solicitados exames para a confirmação de diagnóstico, para avaliação da gravidade do problema ou no auxílio do planejamento terapêutico. Contudo, algumas vezes, mesmo um paciente portador de uma cardiopatia grave não apresenta sintomas até atingir um estágio avançado. Exames de "rotina" em uma consulta ao médico por qualquer outro motivo podem revelar essa cardiopatia assintomática. 


\section{I) Eletrocardiograma ${ }^{5,6}$}

A análise do eletrocardiograma (ECG) pode permitir a identificação de pacientes com alto risco cardíaco operatório ${ }^{1}$. O ECG proporciona a detecção de arritmias, defeitos de condução, isquemia ou necrose miocárdica, sobrecargas cavitárias, superdosagem digitálica ou sugere distúrbios eletrolíticos. Além disso, um traçado basal é importante para a avaliação comparativa no perioperatório.

Consideram-se alterações eletrocardiográficas de alto risco as arritmias graves (bloqueio atrioventricular total, arritmias ventriculares sintomáticas com doença cardíaca subjacente, arritmias supraventriculares com freqüência cardíaca elevada), de médio risco a presença de ondas Q patológicas e de baixo risco a detecção de hipertrofia ventricular esquerda, bloqueio do ramo esquerdo, alterações do segmento ST e onda $\mathrm{T}^{2}$.

Por outro lado, a aplicação de rotina de um teste com especificidade limitada para algumas doenças pode levar à ocorrência de resultados falso-positivos em pacientes que não apresentam doenças cardíacas. Por exemplo, alterações do segmento ST e da onda T podem ser vistos tanto em indivíduos normais como em pacientes com doenças coronarianas ${ }^{3}$. Alterações eletrocardiográficas são causas de preocupação da equipe cirúrgica e motivam o pedido de consulta ao especialista. Pacientes com alterações eletrocardiográficas diversas tem mais frequentemente a operação cancelada do que os pacientes com ECG normal, muitas vezes desnecessariamente ${ }^{4}$.

\section{Recomendações para solicitação de ECG: Grau de Recomendação I:}

- Todos os pacientes com idade maior do que 40 anos, ou independente da idade para pacientes com história e/ou anormalidades ao exame físico sugestivas de doença cardiovascular;

- Pacientes com episódio recente de dor torácica isquêmica ou considerados de alto risco no algoritmo ou pelo médico assistente;

- Pacientes com diabetes mellitus;

\section{Referências}

1. Ikeoka DT, Caramelli B. Aplicações clínicas do eletrocardiograma na avaliação perioperatória de cirurgia não-cardíaca. Rev Soc Cardiol Estado de São Paulo 1999, 9: 424-7.

2. Eagle KA, Brundage BH, Chaitman BR et al. Guidelines for preoperative cardiovascular evaluation for non-cardiac surgery. Report of the American College of Cardiology / American Heart Association task force on guidelines (Committee on perioperative cardiovascular evaluation for non-cardiac surgery). Circulation 1996; 93:1280-1316.

3. Goldenberger AL, O'Konski M. Utility of the routine eletrocardiogram before

\section{E) Algoritmos de avaliação perioperatória}

Um algoritmo utilizado para avaliação perioperatória de risco cardiovascular para procedimentos cirúrgicos não cardíacos deverá contemplar em seqüência as seguintes etapas ${ }^{1}$ :

\section{Grau de Recomendação Ila:}

- Assintomáticos obesos;

Grau de Recomendação III:

- Rotina em indivíduos assintomáticos que serão submetidos a procedimentos cirúrgicos de baixo risco;

\section{II) Radiografia de Tórax ${ }^{5,6}$}

\section{Grau de recomendação I, Nível de evidência $D$}

- Pacientes com anormalidades, relacionadas ao tórax, na história e no exame físico;

\section{III) Hemograma completo 5,6}

\section{Grau de recomendação I, Nível de evidência $D$}

- Idosos (>65 anos);

- Suspeita clínica de anemia ao exame físico ou presença de doenças crônicas associadas à anemia;

- Intervenções de médio e grande porte, com previsão de necessidade de transfusão;

\section{IV) Hemostasia/testes da coagulação ${ }^{5,6}$}

\section{Grau de recomendação I, Nível de evidência D}

- Pacientes anticoagulados;

- Pacientes com insuficiência hepática;

- Portadores de distúrbios de coagulação;

- Intervenções de médio e grande porte;

V) Dosagem da creatinina sérica ${ }^{5,6}$

\section{Grau de recomendação I, Nível de evidência $D$}

- Pacientes com idade superior a 40 anos;

- Portadores de nefropatia, diabetes mellitus, hipertensão arterial sistêmica, insuficiência hepática, insuficiência cardíaca se não tiver um resultado deste exame nos últimos 12 meses;

- Intervenções de médio e grande porte;

surgery and on general admission: critical review and new guidelines. Ann Intern Med 1996; 105: 552-7.

4. Heinisch RH, Nunes Fo. JR, Heinisch LMM. O eletrocardiograma na avaliação de risco cirúrgico para cirurgia não cardíaca. Arq Bras Cardiol 2003; 81: 124.

5. Eagle KA, Berger PB, Calkins H, et al. ACC/AHA Guidelines update for perioperative cardiovascular evaluation for noncardiac surgery - executive summary. J Am Coll Cardiol 2002; 39:542-53.

6. Garcia-Miguel FJ, Serrano-Aguilar PG, López-Bastida J. Preoperative assessment. Lancet 2003, 362: 1749-57.

- As condições clínicas do paciente;

- A capacidade funcional cardiovascular;

- Os riscos intrínsecos associados ao procedimento cirúrgico; 


\section{Diretriz}

- A necessidade de realizar métodos diagnósticos cardiovasculares não invasivos ou invasivos;

- Proposição de mudança de estratégia devido ao risco elevado;

- A checagem da otimização do tratamento farmacológico;

- Necessidade de medidas terapêuticas complementares que diminuam morbimortalidade cardiovascular;

- A necessidade de acompanhamento cardiológico global no perioperatório;

- A necessidade de orientação e acompanhamento após o término do período perioperatório;

Existem vários algoritmos de avaliação perioperatória na literatura que podem ser utilizados. Todos possuem pontos positivos e críticos. A título de exemplo, ilustraremos a seguir um dos algoritmos recomendados pela Diretriz, o do American College of Physicians (ACP), suas vantagens e desvantagens ${ }^{2}$ :

\section{I) Vantagens do algoritmo do ACP}

- A grande maioria das variáveis usadas são bem associadas aos eventos cardíacos perioperatórios em vários estudos;

- Este algoritmo foi validado em um estudo realizado no Hospital das Clínicas da FMUSP. Neste estudo, a probabilidade de eventos cardíacos é de $61,1 \%, 11,6 \%$ e 2,2\% para classe II-III, Classe I (risco intermediário) e classe I (risco baixo) respectivamente. $\mathrm{O}$ estudo mostrou que este algoritmo apresenta uma probabilidade pós-teste melhor quando comparado com outros índices ${ }^{3}$.

- Utiliza um grande número de variáveis clínicas, o que possibilita uma melhor estratificação;

- Estratificação da doença cardíaca estável (risco intermediário) e da instável (risco alto);

- Considera as variáveis obtidas do eletrocardiograma;

- Considera algumas variáveis clínicas não cardiológicas, bem como operação de emergência;

- Considera o tipo cirúrgico, havendo uma real graduação entre o tipo cirúrgico vascular arterial e não vascular;

- Critérios bem definidos para solicitação de teste não invasivo para isquemia do miocárdio. Estes critérios se baseiam na probabilidade pré-teste do exame bem como de seu valor preditivo positivo ${ }^{4}$ e não em valor preditivo negativo como a maioria dos algoritmos; conseqüentemente, há uma melhor seleção dos pacientes;

\section{II) Desvantagens do algoritmo do ACP}

- Não considera a capacidade funcional;

- Não considera o porte da operação;

\section{III) Considerações Finais}

- Os algoritmos não devem ser empregados em pacientes que necessitam de cirurgia de emergência com intuito de adiar procedimento e sim de quantificar risco e orientar estratégias que minimizem estes riscos;

- O algoritmo recomendado por esta Diretriz é aquele utilizado pelo ACP;

- Há casos que fogem completamente do algoritmo e outros dados devem ser usados para pesar risco e beneficio do procedimento;

- O algoritmo complementa a avaliação e a opinião pessoal do médico avaliador. Quando houver diferença entre a opinião pessoal e o resultado da avaliação pelo algoritmo, este fato deve ser mencionado. Por exemplo, pacientes com limitação funcional importante que serão submetidos à intervenções não-vasculares de grande porte podem ter seu risco subestimado pelo algoritmo.

\section{Algoritmo de avaliação pré-operatória do American} College of Physicians:

- $1^{\circ}$ passo: quantificar os pontos de acordo com as variáveis abaixo

- $2^{\circ}$ passo: Definir se o paciente encontra-se no $1^{\circ}$ ou $2^{\circ}$ cenário

$1^{\circ}$ passo: quantificar os pontos de acordo com as variáveis abaixo

- $\mathrm{IAM}<6 \mathrm{~m}$ (10 pontos) ou

- IAM $>6 \mathrm{~m}$ (5 pontos)

- Angina Classe III (10 pontos) ou

- Angina Classe IV (20 pontos)

- EAP na última semana (10 pontos) ou

- EAP alguma vez na vida (5 pontos)
- Suspeita de Estenose aórtica crítica (20 pontos)

- Ritmo não sinusal ou RS c/ ESSV no ECG (5 pontos) ou

$>5$ ESV no ECG (5 pontos)

- $\mathrm{PO} 2<60, \mathrm{pCO} 2>50, \mathrm{~K}<3, \mathrm{U}>50, \mathrm{C}>3,0$ ou restrito ao leito (5 pontos)

- $\quad$ Idade $>70$ anos (5 pontos)

- Cirurgia de emergência (10 pontos)

Total de pontos:

- Classe I = 0-15pontos

- Classe II = 20-30 pontos

- Classe III $=>30$ pontos 


\section{$2^{\circ}$ passo:}

\begin{tabular}{|l|}
\multicolumn{1}{|c|}{$\mathbf{1}^{\circ}$ Cenário (Classe I) } \\
Checar variáveis de risCo \\
- Idade> 70 anos \\
- História de angina \\
- Ondabetes \\
- História de infarto do miocárdio \\
- Alteração isquêmica do ST \\
- HAS com HVE severa \\
\hline
\end{tabular}

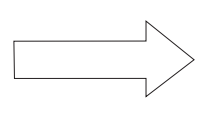

Analisar o no de variáveis de risco
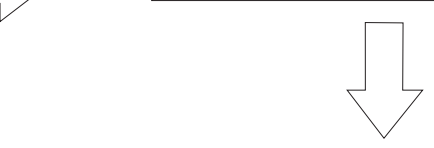

1 a Situação

0 a 1 Variável $\Rightarrow$ BAIXO RISCO $(<3 \%$ EC) $\Rightarrow$ OPERAR

$2^{\mathbf{a}}$ Situação
2 ou + variáveis $\Rightarrow$ RISCO INTERMEDIÁRIO (3 a 15\% EC)

OPERAR

Cirurgia não vascular

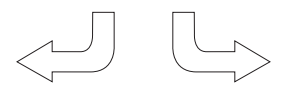

Cirurgia vascular

OPERAR

Negativo

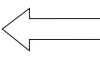

Realizar TN

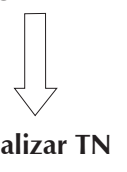

$2^{\circ}$ Cenário (Classe II e III)

(Alto risco $>15 \%$ de EC)

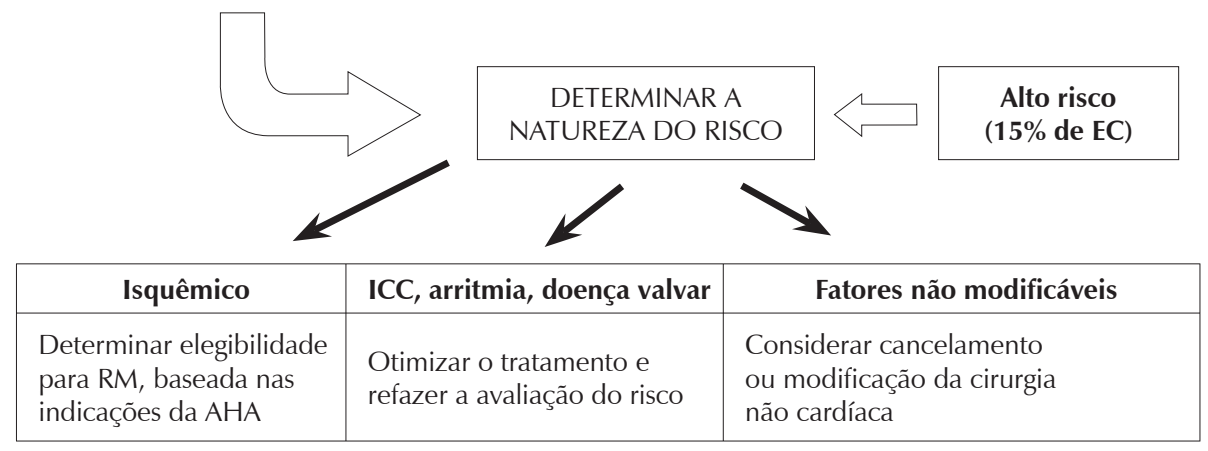

IAM - infarto do miocárdio; ESSV - extra-sístoles supraventriculares; ESV - extra-sístole ventricular; HAS - hipertensão arterial sistêmica; HVE - hipertrofia ventricular esquerda; AHA - American Heart Association; EAP - Edema agudo dos pulmões; RM - revascularização do miocárdio; EC - eventos cardíacos; TN - teste não invasivo; ICC - insuficiência cardíaca congestiva.

\section{Referências}

1. Pinho,C e Caramelli,B. A consulta clínica pré-operatória In: Tratado de Cardiologia-SOCESP.1a Ed, São Paulo. Editora Manole, 2006, pág:154552 .

2. Palda AV, Detsky AS. Guidelines for Assessing and Managing the Perioperative Risk from Coronary Artery Disease Associates with Major Noncardiac Surgery. Report of the American College of Physicians. Ann Intern Med 1997; 127:309-328.
3. Machado FS. Determinantes Clínicos das Complicações Cardíacas Pósoperatórias e de Mortalidade Geral em até 30 dias após Cirurgia Não Cardíaca. Tese (Doutorado) - Faculdade de Medicina da Universidade de São Paulo. USP/FM/SBD-054/2001.

4. Pinho C, Grandini PC, Gualandro DM, Calderaro D, Monachini MC Caramelli B. Multicenter Study of perioperative evaluation for noncardiac surgeries in Brazil (EMAPO). Clinics 2007; 62(1): 17-22. 


\section{3) AVALIAÇÃO ESPECÍFICA}

\section{A) Doença Aterosclerótica Coronária (DAC)}

\section{I) Pacientes com DAC diagnosticada}

Discriminar objetivamente o risco cirúrgico para cada condição específica de DAC é fundamental para a prevenção e menor morbidade de eventos perioperatórios. Há cerca de 4 décadas a análise de risco perioperatório do coronariopata consistia estritamente em aferir a relação temporal entre determinado evento isquêmico cardíaco e a operação proposta $^{1,2}$. No entanto, atualmente contemplamos, além do intervalo referido, todos os fatores relevantes no prognóstico de pacientes portadores de DAC, independentemente do contexto perioperatório: presença de angina, insuficiência cardíaca, sinais eletrocardiográficos, extensão e limiar da isquemia, além da anatomia coronária, nos casos pertinentes ${ }^{3,4}$.

Não há benefício comprovado, mesmo nesta população que já tem o diagnóstico de DAC, da realização rotineira e indiscriminada de exames subsidiários, notadamente provas funcionais e cineangiocoronariografia. Uma cautelosa anamnese, associada à propedêutica direcionada para o aparelho circulatório e a exames subsidiários básicos, como o eletrocardiograma de repouso e a radiografia de tórax, é muitas vezes suficiente para determinar o risco cirúrgico de pacientes coronariopatas.

\section{II) Pacientes com fatores de risco para DAC}

Não há evidências para recomendar prova funcional para todos os pacientes com fatores de risco para DAC. Porém, é fundamental avaliar esta população com um maior grau de suspeita e vigilância clínica, analisar criticamente o eletrocardiograma e estimar a capacidade funcional para evitar confiar na percepção de sintomas em indivíduos que podem estar muito limitados por outras doenças. Além disto, ponderar o porte do procedimento proposto é fundamental. Igualmente importante é avaliar a natureza do procedimento proposto, pois notadamente nos casos de operação vascular, a doença que levou à proposta cirúrgica não apenas compartilha a mesma fisiopatologia da DAC (aterosclerose), como também é marcador de gravidade. Na presença de vários destes fatores pode-se optar pela realização de prova funcional para avaliação de isquemia miocárdica, conforme sugerem os algoritmos de avaliação de risco cardíaco da American Heart Association/American College of Cardiology ${ }^{1}$ e do American College of Physicians ${ }^{2}$.

\section{Referências}

1. ACC/AHA Guideline Update on Perioperative Cardiovascular Evaluation for Noncardiac Surgery. J Am Coll Cardiol 2002; 39: 542-553.

2. American College of Physicians. Clinical Guideline, Part I. Guidelinesfor Assessing and Managing the Perioperative Risk from Coronary Artery Disease Associated with Major Noncardiac Surgery. Ann Intern Med. 1997; 127: 309-312.
3. Tarhan S., Moffitt E.A., Taylor W.F., Giuliani E.R. Myocardial Infarction After General Anesthesia. JAMA 1972; 220: 1451-1454.

4. Goldman L., Caldera D., Nussbaum S.R., Southwick F.S., et al. Multifactorial Index of Cardiac Risk in Noncardiac Surgical Procedures. N Engl J Med 1977; 297:845-850.

\section{B) Hipertensão Arterial Sistêmica}

A hipertensão estágio 3 (PAS $\geq 180 \mathrm{mmHg}$ e $\mathrm{PAD} \geq 110$ $\mathrm{mmHg}$ ) deve ser controlada antes da operação, porém na hipertensão leve ou moderada sem alterações metabólicas ou cardiovasculares associadas, não há evidências de que seja benéfico retardar a operação, embora esta ainda seja uma importante causa de suspensão do procedimento'.

Os pacientes com algum grau de disfunção autonômica, incluindo os hipertensos, são mais suscetíveis à hipotensão durante a indução anestésica e o intraoperatório do que pacientes normotensos; isto é particularmente verdadeiro para os pacientes que fazem uso de inibidores da enzima de conversão da angiotensina (IECA) no pré-operatório. Na maior parte das vezes, isto pode estar relacionado com a redução no volume intravascular, sendo fundamental evitar hipovolemia no perioperatório. A suspensão abrupta destes medicamentos, entretanto, não deve ser realizada porque o descontrole da pressão arterial e descompensação da insuficiência cardíaca aumentam o risco de complicações. A alteração da autorregulação do fluxo sangüíneo cerebral que ocorre no paciente hipertenso torna esse indivíduo

mais suscetível a apresentar sofrimento cerebral mediante as variações na pressão arterial.

O crescente aumento no conhecimento da fisiopatologia da hipertensão, na terapêutica anti-hipertensiva e o desenvolvimento de novos anestésicos e relaxantes musculares com efeitos hemodinâmicos mínimos, tem contribuído no sentido de minimizar as complicações relacionadas com o perioperatório do paciente hipertenso. A clonidina quando utilizada no perioperatório de pacientes hipertensos, mostrou redução significativa da variação da pressão arterial e freqüência cardíaca, além de reduzir a necessidade de anestésico (isoflurano) e de suplementação de narcóticos nesses pacientes ${ }^{2}$.

Nos indivíduos com doença coronária diagnosticada previamente, a variação dos níveis de pressão arterial no intraoperatório já foi associada com alterações isquêmicas no eletrocardiograma. Vários estudos mostraram que a introdução de beta-bloqueadores no pré-operatório resulta no melhor controle das grandes variações da pressão arterial e episódios isquêmicos no perioperatório. Além disso, em pacientes com doença coronariana ou com risco para doença 
coronariana submetidos à intervenções cirúrgicas, os betabloqueadores reduzem a mortalidade hospitalar e a incidência de complicações cardiovasculares ${ }^{3,4}$. Durante o procedimento cirúrgico, a monitorização hemodinâmica do paciente hipertenso é fundamental para detectar variações da pressão arterial e sinais de isquemia o mais precocemente possível. A hipertensão arterial, além de ser um fator de risco para a doença coronária, está associada com a hipertrofia ventricular, sabidamente um fator de risco cardiovascular independente. Esse aspecto deve ser levado em consideração no manuseio de volume no perioperatório dos pacientes hipertensos que têm a geometria ventricular e elasticidade arterial alteradas, principalmente os idosos ${ }^{5}$.

\section{Recomendações:}

- Se a pressão arterial não está controlada e existe tempo hábil para tal, a terapêutica deve ser utilizada para reduzir os níveis de pressão; Grau de recomendação I, Nível de evidência $D$.

\section{Referências \\ 1. Eagle KA, Brundage BH, Chaitman BR, et al. Guidelines for perioperative cardiovascular evaluation for noncardiac surgery. Report of the American College of Cardiology/American Heart Association Task Force on Practice Guidelines. Committee on Perioperative Cardiovascular Evaluation for Noncardiac Surgery. Circulation 1996; 93:1278-317. \\ 2. Ghignone M, Calvillo O, Quintin L. Anesthesia and hypertension: the effect of clonidine on perioperative hemodynamics and isoflurane requirements. Anesthesiology 1987; 67:3-10. \\ 3. Mangano DT, Layug EL, Wallace A, Tateo I. Effect of atenolol on mortality}

\section{C) Insuficiência Cardíaca Congestiva}

Pacientes que demonstram sinais e sintomas de IC descompensada devam ser considerados como de alto risco para complicações cardiovasculares perioperatórias ${ }^{1-3}$. Tais pacientes devem ser cuidadosamente tratados com o objetivo de otimizar seu equilíbrio hemodinâmico e realizar com maior segurança a cirurgia. $\mathrm{O}$ uso de medidas farmacológicas e dietéticas no sentido de melhorar o estado clínico é de grande valor, mas não anula os efeitos fisiopatológicos da doença de base. A administração de fluidos deve ser feita com cautela tanto durante como após a cirurgia. Quanto ao uso de agentes anestésicos, preferência deve ser dada àqueles com menor efeito depressor do miocárdio.

Pacientes claramente sintomáticos (em classe funcional III e IV da NYHA), se submetidos a cirurgia em caráter de urgência, devem ser observados com cautela no período pós operatório, de preferência em unidades de terapia intensiva. Para este grupo também está indicado o uso de cateter de artéria pulmonar fluxo-dirigido para monitoração dos parâmetros hemodinâmicos nos períodos intra e pós-operatório. Muito embora não haja evidências que indiquem melhora da
- As medicações anti-hipertensivas (incluindo IECA) devem ser mantidas no pré-operatório, inclusive no dia da operação; Grau de recomendação I, Nível de evidência $D$.

- Se o paciente está com a pressão elevada e não há tempo para tal, deve-se utilizar bloqueador B-adrenérgico de curta ação (esmolol) para evitar a elevação da pressão no ato da intubação; nos pacientes em que o B-bloqueador está contra-indicado a clonidina por via oral pode ser usada; Grau de recomendação I, Nível de evidência C.

- A hipocalemia, se presente, deve ser corrigida antes da operação; Grau de recomendação I, Nível de evidência D.

- O re-início da terapêutica anti-hipertensiva no pósoperatório, de preferência a que o paciente utilizava antes da cirurgia, deve ser realizado o mais rápido possível; Grau de recomendação I, Nível de evidência D.

- A otimização da volemia deve ser realizada durante todo o perioperatório; Grau de recomendação l, Nível de evidência $C$.

and cardiovascular morbidity after noncardiac surgery. Multicenter Study of Perioperative Ischemia Research Group. N Engl J Med 1996; 335:1713-20.

4. Poldermans D, Boersma E, Bax II, etal. The effect of bisoprolol on perioperative mortality and myocardial infarction in high-risk patients undergoing vascular surgery. Dutch Echocardiographic Cardiac Risk Evaluation Applying Stress Echocardiography Study Group. N Engl J Med 1999; 341:1789-94.

5. Deague JA, Wilson CM, Grigg LE, Harrap SB. Physiological relationships between central vascular haemodynamics and left ventricular structure. Clin Sci (Lond) 2001; 101:79-85.

sobrevida, esta prática possibilita um manuseio mais adequado de fluidos e drogas vasoativas nestas circunstâncias ${ }^{4}$.

\section{Recomendações:}

\section{Grau de Recomendação I, Nível de evidência D}

- Pacientes com sintomas de ICC devem ser avaliados com relação à etiologia e repercussão funcional da disfunção miocárdica;

- O tratamento deve estar otimizado previamente a cirurgia, mantendo as medicações no perioperatório (inclusive no dia da cirurgia);

- Os agentes anestésicos depressores da contratilidade miocárdica devem ser evitados nos portadores de ICC;

- O manejo de volume deve ser criterioso e nos portadores de função cardíaca importantemente deprimida o uso de monitorização invasiva pode ser útil tanto no intra operatório como no pós-operatório imediato;

- Deve ser feita avaliação criteriosa do equilíbrio hidroeletrolítico; 


\section{Referências}

1. Goldman L, Caldera DL, Nussbaum SR, Southwick FS, Krogstad D, Murray SR at al. Multifactorial index of cardiac risk in noncardiac surgical procedures. N Eng J Med 1977; 297(16):845-50.

2. Detsky AS, Abrams HB, McLaughlin JR, Drucker DJ, Sasson Z, Johnston N, Scott JG, Forbath N, Hilliard JR. Predicting cardiac complications in patients undergoing non-cardiac surgery. J Gen Intern Med 1986 Jul-

$$
\text { Aug;1(4):211-9. }
$$

3. Cooperman M, Pflug B, Martin EW Jr, Evans WE. Cardiovascular risk factors in patients with peripheral vascular disease. Surgery 1978 Oct;84(4):505-9.

4. Task force on guidelines for pulmonary artery catheterization (American Society of Anesthesiologists). Anesthesiology 1993;78(2):380-394.

\section{D) Valvopatias}

Pacientes portadores de doenças cardíacas valvares possuem elevado risco de desenvolver endocardite infecciosa relacionada à procedimentos capazes de desenvolver bacteremia. Na presença de sopro cardíaco é fundamental que o clínico faça uma avaliação correta para confirmar a presença de lesão orgânica orovalvar o que em geral sugere a necessidade de profilaxia antimicrobiana para endocardite infecciosa.

Embora os riscos anestésicos e cirúrgicos tenham diminuído muito nas últimas décadas, ainda ocorrem complicações no perioperatório de pacientes com doença cardíaca valvar submetidos à intervenções cirúrgicas: descompensação da insuficiência cardíaca podendo chegar até ao choque cardiogênico, infarto do miocárdio, fenômenos tromboembólicos, arritmias e infecções.

De maneira geral, entre os pacientes portadores de doença cardíaca valvar, aqueles com maior restrição da sua capacidade funcional, ou seja, Classe funcional III ou IV tem um risco cirúrgico e anestésico alto com maior chance de apresentar complicações ${ }^{1,2}$. A melhora do estado clínico funcional, a otimização do tratamento, o controle da freqüência cardíaca e da volemia no pré-operatório, podem reduzir o risco de complicações cardíacas.

No caso específico dos portadores de Estenose Aórtica (EAo) sintomáticos, há um risco muito elevado de ocorrência de edema agudo dos pulmões ou morte súbita. Nesta condição, desde que possível, a intervenção cirúrgica cardíaca valvar deve anteceder a operação não cardíaca $^{3,4}$. Não é recomendada a realização de valvoplastia por cateter-balão para a EAo degenerativa como opção ao tratamento cirúrgico devido aos maus resultados obtidos com esta técnica.

A estenose mitral (EM) ainda é a doença cardíaca valvar mais freqüente no Brasil. A taquicardia e a administração excessiva de fluidos durante o perioperatório causa redução brusca do período de enchimento diastólico e o aumento da pré-carga, devendo ser evitados. Para os portadores de EM com redução importante do orifício valvar e extremamente sintomáticos, uma avaliação da anatomia valvar por meio da Ecodopplercardiografia pode selecionar candidatos ideais para a realização de valvoplastia por cateter-balão antes da intervenção cirúrgica proposta ${ }^{5}$.

A morbidade perioperatória na presença de insuficiência aórtica (IAO) e insuficiência mitral (IM) está relacionada à presença de congestão pulmonar. A presença de estertores

pulmonares e de terceira bulha denotam que o controle da insuficiência cardíaca será crucial no desfecho do procedimento operatório. A utilização de cardiotônicos, diuréticos e vasodilatadores podem ajudar na tarefa de reduzir a pré e a pós-carga, além de melhorar a contratilidade cardíaca.

Pacientes portadores de próteses valvares cardíacas devem receber profilaxia para endocardite infecciosa e aqueles com prótese mecânica merecem uma atenção especial em relação à anticoagulação ${ }^{6}$. Devido à possibilidade de sangramento pelo uso de anticoagulantes e antiagregantes recomenda-se, para a realização de procedimentos cirúrgicos de porte médio ou grande, a suspensão por pelo menos cinco dias da terapia anticoagulante ${ }^{6}$. No entanto, pacientes de alto risco como os portadores de prótese mecânica em posição mitral, prótese de Bjork-Shiley, prótese de Star-Edwards, embolia ou trombose recente $(<$ de 1 ano) ou pelo menos 3 fatores de risco (fibrilação atrial, embolia prévia, hipercoagulabilidade, prótese mecânica e fração de ejeção < 30\%) devem receber tratamento com heparina venosa ou de baixo peso molecular e podem ser operados após a redução do tempo de protrombina - INR abaixo de 1,5. Maiores detalhes sobre anticoagulação no perioperatório estão no item 5D.

\section{Recomendações:}

- Para pacientes portadores de valvopatias deve-se considerar a avaliação do cardiologista previamente ao procedimento cirúrgico; Grau de recomendação I, Nível de evidência $D$.

- Portadores de lesão oro-valvar com indicação de correção cirúrgica, com destaque para a estenose aórtica, devem na medida do possível ter prioridade para a correção da doença cardíaca previamente à intervenção proposta; Grau de recomendação I, Nível de evidência C.

- O controle volêmico e o equilíbrio eletrolítico (uso de diuréticos) devem ter atenção especial durante todo o perioperatório; Grau de recomendação I, Nível de evidência D.

- A avaliação da necessidade de prevenção de endocardite infecciosa deve ser rotina; Grau de recomendação I, Nível de evidência $D$.

- A adequação do nível de anticoagulação a novos patamares para evitar sangramento de difícil controle e o uso de proteção por meio de heparinas deve seguir as diretrizes vigentes para tal fim; Grau de recomendação I, Nível de evidência $C$. 


\section{Referências}

1. Goldman L, Caldera DL, Southwick FS et al. Cardiac risk factors and complications in non-cardiac surgery. Ann Surg 1989;210:637.

2. Forrest JB, Rehder K, Cahalan MK, Goldsmith CH. Multicenter study of general anesthesia. III. Predictors of severe perioperative adverse outcomes. Anesthesiology 1992,76:3.

3. Torsher LC, Shub C, Rettle FR, Brown DL. Risk of patients with severe aortic stenosis undergoing noncardiac surgery. Am J Cardiol 1998;81:448-52.
4. Goldman L, Caldera DL, Nussbaum SR et al. Multifactorial index of cardiac risk in noncardiac surgical procedures. N Engl J Med 1977;297:845-50.

5. Reyes VP, Raju BS, Wynne J et al. Percutaneous balloon valvuloplasty compared with open surgical commissurotomy for mitral stenosis. N Engl J Med 1994;331:961-7.

6. Proceeding of the American College of Chest Physicians. $5^{\text {th }}$ Consensus on Antithrombotic Therapy. Chest 1998;114:439S-769S.

\section{E) Arritmias Cardíacas e Distúrbios da Condução}

\section{I) Arritmias cardíacas}

A necessidade de intervenções cirúrgicas é maior em pacientes idosos, sendo que a incidência de arritmias cardíacas e doenças crônico-degenerativas também aumenta com a idade no adulto. O médico consultor deve definir a ocorrência de sintomatologia relacionada aos distúrbios do ritmo cardíaco e a presença ou não de doenças cardíacas estruturais associadas.

A presença de extra-sistoles isoladas pode ser decorrente simplesmente do estresse emocional ocasionado pela necessidade do tratamento cirúrgico ou estarem associadas à presença de doença aterosclerótica das coronárias ou a graus variados de miocardiopatia ${ }^{1,2}$.

A presença de extra-sistolia ventricular (EV), mesmo sob formas repetitivas, como EEVV pareadas ou em salva (taquicardia ventricular não sustentada), desde que assintomáticas não leva ao aumento de complicações cardiovasculares. Em presença de sintomas ou doença cardíaca estrutural associada, com isquemia miocárdica residual e déficit contrátil, o consultante deve sempre tomar medidas terapêuticas preventivas para diminuir a chance de complicações cardiovasculares ${ }^{1,2}$. Os portadores de arritmias cardíacas tipo extra-sistoles isoladas, quer de origem atrial ou ventricular, sem evidência de cardiopatia estrutural devem apenas ser submetidos a um eletrocardiograma de repouso, não necessitando de propedêutica mais complexa.

Nos portadores de fibrilação atrial permanente recomendase ter certeza do controle da freqüência cardíaca numa faixa inferior a $90 \mathrm{bpm}$, pois na dependência do procedimento cirúrgico realizado, haverá aumento da FC e este poderá diminuir a eficiência sistólica da bomba cardíaca ${ }^{1,2}$.

Lembrar que distúrbios metabólicos, eletrolíticos (uso de diuréticos), hipoxemia e toxicidade de drogas podem ser exteriorizados por meio de distúrbios do ritmo cardíaco.

Em situações de urgência/emergência, quando da impossibilidade de uma pesquisa mais detalhada do distúrbio do ritmo, deve ser utilizado preventivamente, se não houver contra-indicação, o beta-bloqueador.

Situações nas quais deve ser fortemente considerada a avaliação do cardiologista antes da operação em virtude da presença de arritmias cardíacas:

\section{- Na presença de sintomas}

- relacionados a baixo débito ou quadro sincopal, na presença de cardiopatia estrutural associada a comprometimento da função sistólica ventricular esquerda e/ou isquemia miocárdica. Grau de recomendação I, Nível de evidência $D$.

- relacionados a taquiarritmias em portadores de síndrome de pré-excitação ventricular (WPW), sendo estas de início e término súbitos, bem definidos, associados ou não a baixo débito, sem propedêutica pregressa ou tratamento adequado. Grau de recomendação I, Nível de evidência $D$.

- relacionados a taquiarritmias, independentes de cardiopatia estrutural, em portadores de sintomatologia de crises de taquicardia de início e término súbitos, bem definidos, freqüentes, com ocorrência pregressa recente. Grau de recomendação lla, Nível de evidência D.

- relacionados a baixo débito ou quadro sincopal, em idosos, portadores de freqüência cardíaca basal inferior a 50 bpm. Grau de recomendação lla, Nível de evidência $D$.

- Na ausência de sintomas

- em portadores de fibrilação atrial permanente para avaliar controle do ritmo cardíaco. Grau de recomendação lla, Nível de evidência $D$.

- em portadores de grande densidade de arritmias ventriculares isoladas ou na presença de formas repetitivas quando associados à doença cardíaca estrutural. Grau de recomendação lla, Nível de evidência $D$.

\section{II) Distúrbios da condução atrioventricular e intraventricular}

Os distúrbios da condução atrioventricular ou intraventricular são condições menos freqüentes do que as arritmias cardíacas secundárias a origem do impulso, e apesar de poderem ser sugeridas pelo exame clinico, são diagnosticadas pelo eletrocardiograma. Estes distúrbios não costumam ocasionar complicações no perioperatório. As situações de risco já teriam sido diagnosticadas previamente e estariam sob tratamento específico como, por exemplo, o uso de marcapassos.

Os portadores de bloqueios atrioventriculares (BAV) de baixo risco como BAV I grau, BAV II grau tipo Mobitz I durante o sono, portadores de bloqueios IV uni ou bifasciculares, assintomáticos não necessitam ser encaminhados para propedêutica complexa e têm risco muito baixo para complicações arrítmicas ${ }^{1,2}$. 


\section{Diretriz}

Situações nas quais deve ser fortemente considerada a avaliação do cardiologista antes da operação:

- Presença de bloqueios atrioventriculares:

- BAV de alto risco: BAV segundo grau tipo II, BAV2:1, BAVT paroxístico, definitivo ou dissociação AV. Grau de recomendação I, Nível de evidência $D$.

- BAV de baixo risco no ECG de repouso, mas com sintomas sugestivos de baixo débito ou síncope. Grau de recomendação
Ila, Nível de evidência $D$.

- Presença de bloqueios intraventriculares:

- Bloqueio trifascicular. Grau de recomendação Ila, Nível de evidência $D$.

- Bloqueio bifascicular no ECG de repouso, mas com sintomas sugestivos de baixo débito ou síncope. Grau de recomendação lla, Nível de evidência $D$.

\section{Referências}

1. Figueiredo MJO, PinhoC, Bittencourt LAK. Abordagem pré-operatória de pacientes com distúrbios da condução e do ritmo cardíaco. Rev Soc Cardiol Estado de São Paulo,2000; 3:392-6.

2. Pinho C, Figueiredo MJO. Abordagem perioperatória dos distúrbios do ritmo cardíaco In Machado FS, Martins MA, Caramelli B. PerioperatórioProcedimentos Clínicos. 1a Ed, São Paulo, Ed Sarvier, 2004, pág 61-71.

F) Marcapasso Definitivo e Cardiodesfibrilador Implantável (CDI)

A estimulação cardíaca artificial tem apresentado uma enorme evolução nos últimos anos, surgindo uma grande variedade de dispositivos implantáveis capazes de interagir com o ritmo cardíaco. Uma preocupação que geralmente acompanha o portador desses dispositivos implantáveis é a possibilidade da interferência eletromagnética no marcapasso com o uso do bisturi elétrico durante a operação.

\section{I) Portadores de marcapassos cardíacos convencionais (unicamerais ou bicamerais)}

\section{1) Marcapassos implantados há menos de sessenta dias}

Grande parte dos eletrodos de marcapassos atuais apresentam fixação ativa (dispositivos na ponta dos mesmos, capazes de fixá-los de forma ativa no endocárdio) sendo que estes raramente sofrem deslocamentos, complicação possível nesta fase. O local onde é implantado o gerador está em processo de recuperação cirúrgica, podendo ocorrer fenômenos inflamatórios, hematomas, edemas, rejeições e até mesmo infecções que poderiam estar subclínicas ainda nesta fase. O marcapasso e os eletrodos são susceptíveis a infecções oriundas de outros focos do organismo e mesmo de manipulações cirúrgicas de qualquer natureza. Para minimizar o risco de complicações, recomenda-se, se possível, aguardar até o final do $2^{\circ}$ mês do implante para realizar a operação eletiva.

\section{2) Marcapassos que estão próximos ao fim de vida}

Os marcapassos que estão no final de vida devido ao desgaste avançado da bateria deverão ser substituídos por unidades novas e mais modernas antes das cirurgias eletivas. Isto por que estes aparelhos podem apresentar comportamento adverso quando submetidos a condições extremas de funcionamento as quais poderão ser requeridas durante a cirurgia proposta.

\section{3) Fase segura da estimulação cardíaca}

Para operações eletivas, estes pacientes deverão também passar por uma avaliação junto ao médico que acompanha o controle do marcapasso que irá fazer uma completa avaliação do sistema de estimulação, determinando a necessidade de uma programação especial e emitindo um relatório com os cuidados que deverão ser tomados pelo cirurgião e anestesista e com a descrição dos possíveis comportamentos do marcapasso durante a intervenção cirúrgica.

Normalmente, a maior preocupação consiste naqueles pacientes que serão submetidos a operações de grande porte, com o uso do bisturi elétrico. Nestes casos, deverá ser realizada uma programação de segurança, sempre em uma unidade de avaliação de marcapassos e por um médico habilitado. Se não for possível substituir o bisturi elétrico ${ }^{1,2,3}$ pelo ultrassônico, o relatório deverá conter pelo menos as recomendações descritas abaixo:

- Monitorização cardiológica contínua com monitor de ECG e também com oxímetro de pulso (por onde podemos acompanhar o ritmo cardíaco mesmo durante a aplicação do bisturi elétrico);

- Usar bisturi elétrico bipolar. Na impossibilidade deste, usar o unipolar, colocando a placa longe do marcapasso, e preparando bem a pele na região, colocando-se pasta eletrolítica;

- Aterrar bem o aparelho de bisturi elétrico, conectando-o a um bom fio terra;

- Usar o bisturi elétrico o mínimo possível, e por intervalos curtos, avaliando o ECG ou o pulso;

- Caso ocorra bradicardia ou taquicardia durante a aplicação do bisturi elétrico (devido a interferência eletromagnética), colocar um ímã sobre o marcapasso, somente nos momentos da aplicação do bisturi elétrico, retirando-o logo em seguida. Observar que ao colocar o ímã corretamente, o marcapasso estimula com uma freqüência fixa;

- Evitar o uso de drogas arritmogênicas durante a anestesia (simpaticomiméticos e/ou atropínicos); 
- Evitar sobrecarga de volume e, se possível, manter decúbito discretamente elevado;

O paciente deverá ser orientado a retornar à clínica de avaliação do marcapasso após o período de recuperação pós-operatória para que a programação normal do gerador seja restabelecida e para que as funções do marcapasso sejam reavaliadas.

\section{II) Portadores de marcapassos multisítio (ressincronizadores)}

A presença de um maior número de eletrodos no coração inegavelmente aumenta a possibilidade de complicações por interferências externas sobre o sistema de estimulação. A maior parte dos eletrodos de estimulação utilizados no sistema venoso do ventrículo esquerdo são unipolares e eles são mais susceptíveis às interferências externas em especial às produzidas pelo bisturi elétrico.

\section{III) Portadores de CDI}

A complexidade e a diversidade de comportamento destas próteses e o risco de arritmias graves durante a operação, além da possibilidade da interação com interferências eletromagnéticas como as do bisturi elétrico nos levam a recomendar que seja considerada, se possível, a presença do especialista junto com o equipamento de programação do CDI, na sala de operação, permitindo o ajuste do mesmo durante a intervenção e de acordo com as necessidades metabólicas do paciente. A função antitaquicardia deverá ser desligada e o paciente devidamente monitorizado. Ao desligar esta função, o médico deverá estar preparado para tratar uma arritmia de alto risco, por meio de um desfibrilador externo e de drogas aplicáveis. O uso de drogas antiarrítmicas poderá também ser necessário. Não raramente e de acordo com a orientação do especialista, este tipo de paciente necessitará de UTI no perioperatório, onde permanecerá monitorizado na fase crítica, principalmente enquanto a função antitaquicardia do CDI estiver desligada.

\section{IV) Cardioversão ou Desfibrilação elétrica de emergência}

Durante o período perioperatório, o paciente portador de um marcapasso ou desfibrilador implantável poderá apresentar complicações que demandarão a necessidade da aplicação de uma cardioversão elétrica ou desfibrilação. Embora os geradores possam teoricamente suportar os choques, na prática é aconselhável evitá-los, sempre que possível. Quando imprescindível, alguns cuidados devem ser tomados ${ }^{4}$ para preservar o marca-passo ou desfibrilador, os eletrodos e a interface eletrodo-coração, conforme descritos abaixo.

- Se o paciente é portador de desfibrilador implantável, a cardioversão interna é recomendável, devido ao uso de uma menor quantidade de energia, de pulso bifásico, e à utilização dos recursos internos de segurança do próprio aparelho;

- Dar preferência aos cardioversores que utilizam placas adesivas, colocando-as em posição antero-posterior, respeitando a polaridade orientada pelo fabricante. Deve-se evitar a disposição clássica das placas (entre base e ponta do coração - paralela aos eletrodos) devido ao risco da lesão do miocárdio em contato com a ponta do eletrodo.

- Ao aderir as placas, distanciá-las o máximo possível do gerador e dos eletrodos;

- Usar a menor quantidade de energia possível para o caso. Os modernos cardioversores bifásicos devem ser preferidos;

- Colocação do ímã sobre o gerador, exceto nos desfibriladores que podem desligar a função antitaquicardia se o ímã permanece sobre ele por mais de 30 segundos. Os marca-passos mais antigos, invariavelmente apresentavam o desligamento do circuito de sensibilidade ao colocar um ímã sobre eles e tornavam-se assincrônicos. Nos aparelhos atuais, a resposta magnética é programável, podendo apresentar comportamento diverso. Por isto, a colocação do ímã sobre o gerador não é garantia de proteção durante uma cardioversão

- Após o procedimento, reavaliar os limiares de sensibilidade e comando. Considerar uma nova reavaliação em $24 \mathrm{~h}$ mantendo o paciente monitorado nesse período.

\section{V) Recomendações}

\section{1) No pré-operatório:}

- Estabelecer se o paciente é portador de marcapasso (unicameral ou bicameral), ressincronizador, desfibrilador ou múltiplas próteses; Grau de recomendação I, Nível de evidência $D$.

- Definir o tipo de aparelho por meio do cartão de identificação, pelo seu código de identificação radiológica ou avaliando os registros hospitalares; Grau de recomendação I, Nível de evidência $D$.

- Determinar se o paciente é dependente do aparelho utilizando para isto, dados de anamnese (síncopes e/ou tonturas antes do implante), informações das avaliações anteriores ou programando o dispositivo para a freqüência mínima de estimulação observando a presença de foco de escape e sua estabilidade; Grau de recomendação I, Nível de evidência $D$.

- Determinar a função do aparelho. Para isto, é necessária uma avaliação com o especialista para ajustar a programação; na impossibilidade desta, pelo menos avaliar se existe espícula de marcapasso efetiva (que gera comando) no eletrocardiograma; Grau de recomendação IIb, Nível de evidência $D$.

\section{2) No intra-operatório}

- Todos os pacientes deverão ser monitorados por ECG contínuo e pletismografia (ou ausculta, palpação do pulso ou ultra-som), independente do tipo de anestesia; Grau de recomendação I, Nível de evidência C.

- Eletrocautério - usar as recomendações descritas no item I.3; Grau de recomendação I, Nível de evidência D.

- Ablação por por radiofrequência - colocar a placa dispersiva distante do gerador e eletrodos e evitar o contato direto do cateter de ablação com os eletrodos do aparelho; Grau de recomendação I, Nível de evidência C.

- Litotripsia ${ }^{5}$ - direcionar o foco para fora da área que compreende o aparelho e eletrodos; desligar a estimulação atrial quando a litotripsia for sincronizada pelo ECG; Grau de 


\section{Diretriz}

recomendação lla, Nível de evidência $D$.

- Cardioversão ou desfibrilação - seguir as orientações dexritas no item IV; Grau de recomendação I, Nível de evidência $D$.

\section{3) No pós-operatório}

\section{Grau de recomendação I, Nível de evidência $D$.}

- A freqüência cardíaca e o ritmo cardíaco deverão ser monitorados continuamente no período pós-operatório;

- Equipamento para cardioversão/desfibrilação e suporte para estimulação cardíaca deverão estar disponíveis;

- Caso as funções do aparelho tenham sido alteradas por ocasião do procedimento cirúrgico, a condição normal deverá ser restabelecida assim que for possível por meio da reprogramação do mesmo;

\section{Referências}

1. Levine PA, Balady GL, LazarHL, Belott PH, Roberts AJ. Electrocautery and pacemakers: management of the paced patient subject to electrocautery. Ann Thorac Surg 1986; 41:313-7.

2. Ahern TS, Luckett C, Ehrlich S, Pena EA. Use of bipolar electrocautery in patients whit implantable cardioverter-defibrilators: No reason to inactivate detection or therapies. PACE 1999;22:778.

3. Wong DT, Middleton W. Electrocautery onduced tachycardia in a rate-

\section{G) Transplantes}

O transplante de órgãos compreende diversas situações clínicas diferentes pois inclui desde o uso de tecidos desvitalizados, como as córneas, até órgãos vitais, sem os quais, mesmo com o uso de aparelhos, é impossível manter um indivíduo por dias ou mesmo horas, como é o caso do fígado e coração.

Por se tratarem de grupos de pacientes bastante heterogêneos, não há um protocolo único de avaliação perioperatória para os diversos tipos de transplantes. Adicionalmente, há carência de estudos prospectivos e controlados nesta área. Em sua maior parte, os métodos de avaliação disponíveis refletem as opiniões de especialistas e fundamentam-se mais nas comorbidades do que na doença que indicou o transplante $\mathrm{e}^{1-5}$.

\section{Recomendações:}

- A presença de fatores de risco para doença

\section{Referências}

1. Kasiske BL. The evaluation of prospective renal transplant recipients and living donors. In: Surgical Clinics of North America, WB Saunders, 1998, vol 78 , número 1, pág. 27-39.

2. Danovitch GM, Hariharan S, Pirsch JD, Rush D, Roth D, Ramos E, Starling RC, Cangro C, Weir MR. Management of the waiting list for cadaveric kidney transplants: report of survey and recommendations by the Clinical Practice Guidelines Committee of the American Society of Transplantation. J Am Soc Nephrol 2002; 13:528-35.

\section{H) Cardiopatia e Gravidez}

Os procedimentos cirúrgicos realizados durante a gravidez apresentam maior morbidade e mortalidade materna porque são intercorrências agudas ou decorrentes

responsive pacemaker. Anesthesiology 2001; 94:10-1.

4. Kenneth A, Ellenbogen SL, Pinski RGT. Interference with cardiac pacing. Cardiology Clinics 2000; 18:219-39.

5. Drach GW, Weber C, Donovan JM. Treatment of pacemaker patients with extracorporeal shock wave lithotripsy: experience from 2 continents. J Urol 1990; 143:895-6 aterosclerótica coronária no receptor de rim e fígado deve levar à pesquisa de cardiopatia isquêmica por meio de métodos não invasivos; Grau de recomendação Ila, Nível de evidência $D$.

- Quando houver coronariopatia aterosclerótica com indicação de revascularização, esta deve preceder o transplante de órgãos; Grau de recomendação Ila, Nível de evidência $D$.

- Receptores de transplante hepático devem receber propedêutica de hipertensão pulmonar previamente ao procedimento; Grau de recomendação Ila, Nível de evidência $D$.

- A presença de grave co-morbidade com prognóstico desfavorável a curto prazo deve levar à rediscussão da indicação do transplante; Grau de recomendação I, Nível de evidência $D$.

3. Ramos EL, Kasiske BL, Alexander SR, Danovitch GM, Harmon WE, Kahana L, KiresukTJ, Neylan JF. The evaluation of candidates for renal transplantation. The current practice of U.S. transplant centers. Transplantation 1994; 57:490-7.

4. Donovan JP, Zetterman RK, Burnett DA, Sorrell MF. Preoperative evaluation, preparation, and timing of orthotopic liver transplantation in the adult. Semin Liver Dis 1989; 9:168-75.

5. Van Thiel DH, Shade RR, Gavaler JS, et al. Medical aspects of liver transplantation. Hepatology 1984; 4:79S-83S.

do agravamento do quadro clínico refratário à terapêutica não intervencionista. O prognóstico fetal está relacionado ao materno e depende da fase da gestação em que é realizada a intervenção cirúrgica. No primeiro trimestre, 
os riscos de teratogênese e de aborto espontâneo são maiores, enquanto no terceiro se relacionam com a prematuridade $^{1}$.

A diferenciação dos sintomas muitas vezes é difícil, motivo pelo qual exames complementares são freqüentemente utilizados. Os dados isolados de exames complementares não devem determinar conduta terapêutica na gestação. Os exames mais freqüentes usados na gestação de mulheres cardiopatas são o eletrocardiograma, o ecocardiograma e eventualmente o eletrocardiograma dinâmico (Holter), geralmente suficientes para definir o diagnóstico e o risco das cardiopatias na cirurgia não cardíaca.

Na gravidez normal ocorrem modificações nos exames subsidiários que devem ser conhecidas no intuito de diferenciar de anomalias cardíacas tais como a presença de ondas q na derivação D3, desvio de eixo ÂQRS para a esquerda e alteração de repolarização ventricular no eletrocardiograma; no ecodopplercardiograma pode ocorrer a exacerbação de gradiente transvalvar ou intramiocárdico de lesões obstrutivas, aumento dos diâmetros das cavidades cardíacas ou refluxo trícuspide.

Recomendações para a utilização de exames subsidiários ${ }^{2}$ :

- ECG de repouso ou dinâmico e ecodoplercardiograma podem ser usados sem risco materno fetal. Grau de recomendação I, Nível de evidência $D$.

- A radiografia de tórax não deve ser indicada como exame de rotina durante a gravidez e usada somente em condições especiais. Grau de recomendação I, Nível de evidência $C$.

- A cintilografia miocárdica é desaconselhável pelo risco de exposição fetal à irradiação ionizante, especialmente no $1^{\circ}$ trimestre; se indispensável usar o Tecnetium $99 \mathrm{~m}$ e cintilografia com Talio 201; Grau de recomendação Ilb, Nível de evidência $C$.

- A cintilografia com gálio 97 é sempre contra-indicada durante a gravidez; Grau de recomendação I, Nível de evidência $C$

- Estudo hemodinâmico quando indicado deve ser realizado com proteção abdominal. Grau de recomendação I, Nível de evidência $C$.

- A ressonância nuclear magnética não é contra indicada na gravidez. Grau de recomendação I, Nível de evidência C.

Recomendações Específicas do Planejamento da Cirurgia Geral na Gravidez:

- Retardo na indicação e realização da cirurgia é o principal fator de morbiletalidade;

- O segundo trimestre é a fase da gestação mais segura para a mãe e o feto;

- Técnicas cirúrgicas convencionais não devem ser modificadas em função da gravidez;

- Avaliação seriada do balanço hidroeletrolítico, do hematócrito e da hemoglobina;
- Quando possível, o procedimento deve ser realizado com coxin dorsal para favorecer a lateralização esquerda do útero;

- Analgesia eficaz para se evitar o parto prematuro;

- Descompressão gastrintestinal para prevenir vômito e aspiração;

- Oxigenação deve ser efetiva antes da indução e da intubação;

- Prevenção de íleo adinâmico;

- Evitar quantidades excessivas de solução cristalóide na infusão intra-operatória;

- Evitar solução glicosada quando o parto for iminente, pelo risco de hipoglicemia neonatal

- Cateterização vesical com sonda de Folley para prevenir a retenção urinária;

- Manutenção da rotina antibiótica;

- Recomenda-se atenção quando houver edema de membros inferiores que aumenta o risco de flebite por estase e de tromboembolismo no pós-operatório;

- Não se recomenda deambulação precoce pelo risco de parto prematuro;

- Deve-se prevenir as contrações prematuras do útero com uso de progesterona (250 mg/dia/via vaginal);

\section{Prevenção do tromboembolismo}

A gravidez por si só predispõe à trombose devido a combinação da estase sangüínea e da hipercoagulabilidade por aumento dos fatores de coagulação, redução da fibrinólise e de proteínas fibrinolíticas ${ }^{3}$. Outros fatores podem concorrer para o incremento do risco de tromboembolismo como obesidade, hospitalização prolongada, idade gestacional, paridade e intercorrências cirúrgicas.

A prevenção do tromboembolismo na gestante cardiopata exige estabelecer o risco/benefício da anticoagulação ${ }^{4}$, devendo-se avaliar o risco de tromboembolismo de acordo com a situação clínica da paciente. Considera-se moderado risco as gestantes com fibrilação atrial crônica, antecedentes de tromboembolismo, trombo intracavitário e cardiomiopatia dilatada $^{5}$, enquanto que as de alto risco são as gestantes portadoras de próteses mecânicas ${ }^{5}$.

\section{Recomendações:}

- A heparina é o anticoagulante eletivo durante gravidez pois não atravessa a barreira placentária ${ }^{5}$, não é nocivo ao concepto; Grau de recomendação I, Nível de evidência A.

- Embora ainda controverso, o esquema pré-operatório de anticoagulação recomendado para pacientes de alto risco é heparina não fracionada intravenosa (IV) na dose de $12 \mathrm{UI} / \mathrm{Kg} /$ hora controlada pelo tempo de tromboplastina parcial ativada em $1 \times$ e $1 / 2$ do valor normal ou heparina de baixo peso molecular (enoxaparina na dose de $1 \mathrm{mg} / \mathrm{kg}$ / dia a cada 12 horas). Para pacientes de moderado risco, recomenda-se a heparina não fracionada subcutânea na dose de 10.000UI/ a cada 12 horas ou heparina de baixo peso molecular (enoxaparina) subcutânea na dose de 40mg/dia. 


\section{Diretriz}

Os dois esquemas devem ser suspensos entre 5 a 12 horas antes da operação, para a HNF e HBPM, respectivamente e reintroduzidos seis horas após ${ }^{5}$. Grau de recomendação $I / b$, Nível de evidência C.

\section{Referências}

1. Brodsky JB, Cohen EN, Brown BW, Wu ML, Whitcher C. Surgery During pregnancy and fetal outcome. Am J Obstet Gynaecol 1980;138:1165-7.

2. NCRP Report no 91. Recommendations on limits for exposure to ionizing radiation. Washington, DC: National Commission on Radiation Protection, 1987

3. Bonnar J. Venous Thromboembolism and pregnancy. Clin Obstet Gynaecol
$1981 ; 8: 455-73$.

4. Ginsberg JS, Hirsh J Turner DC, Levine MN, Burrows R. Risks to the fetus on anticoagulant therapy during pregnancy. Thromb Haemostasis 1989;61:197-203.

5. Consenso Brasileiro sobre Cardiopatia e Gravidez, Sociedade Brasileira de Cardiologia. Arq Bras Cardiol 1999; 72 (suppl 3).

\section{I) Procedimentos odontológicos}

A incidência e a gravidade das bacteremias odontogênicas aumentam significativamente na presença de focos infecciosos, como infecções periodontais e endodônticas. No entanto, essas podem estar presentes em ações rotineiras do corpo, como durante a mastigação e a escovação dos dentes ${ }^{1}$. Por esse motivo, é recomendável a averiguação da saúde bucal previamente a procedimentos cirúrgicos em cardiopatas ou não, visando diminuir as complicações perioperatórias.

O uso de anestésicos locais com vasoconstritor em pacientes cardiopatas tem gerado controvérsias. A administração de vasoconstritores em combinação com anestésicos locais aumenta a qualidade e duração do controle da dor, e reduz o sangramento ${ }^{2}$. Anestésico local sem vasoconstritor tem curta duração, rápida absorção (alto potencial tóxico), inadequado controle da dor e pode gerar alterações hemodinâmicas e até arritmias cardíacas, além de promover uma leve vasodilatação, aumentando o sangramento. Lidocaína com epinefrina tem sido o anestésico local mais utilizado em todo o mundo ${ }^{2}$.

Epinefrina ou outro vasoconstritor são contra-indicados em casos de arritmias ventriculares repetitivas não tratadas ou supraventriculares com resposta ventricular elevada e devem ser usados com atenção em pacientes com marcapassos e desfibriladores implantados ${ }^{3}$. O uso de vasoconstritor também é contra indicado para pacientes com angina instável e o hospital pode ser o local mais apropriado para a realização deste tratamento odontológico ${ }^{3}$. Em pacientes com cardiomiopatia hipertrófica o uso de epinefrina deverá ser feito com cuidado ${ }^{3}$.

A aplicação de epinefrina em pacientes hipertensos não controlados foi associada a um ligeiro aumento da pressão sanguínea sistólica e diastólica, porém isso não foi significativo ${ }^{3}$. Vasoconstritores podem também ser contraindicados para pacientes com episódio recente de infarto, congestão cardíaca grave, hipertireodismo não controlado ${ }^{3}$ e uso de drogas ilícitas.

\section{Recomendações:}

- Pacientes cardiopatas controlados, sob medicação otimizada, podem ser submetidos a procedimentos odontológicos com segurança com os cuidados habituais de rotina; Grau de recomendação I, Nível de evidência D.

- O uso de anestésico com vasocontrictor deve ser evitado nas fases agudas de eventos coronários, arritmias cardíacas com resposta ventricular elevada, quadros hiperadrenérgicos ou com obstrução da via de saída do VE; Grau de recomendação I, Nível de evidência $D$.

- Indivíduos portadores de marcapasso e desfibrilador automático implantável não sofrem alterações com o uso dos motores alta ou baixa-rotação, amalgamador, teste pulpar elétrico, laser, escova dental elétrica, ultrassom endodôntico, ultrassom periodontal e radiografia. O uso de bisturi elétrico têm orientações específicas (vide item 3F); Grau de recomendação I, Nível de evidência $C$.

\section{I) Procedimentos odontológicos em uso de anticoagulantes}

O paciente com o RNI abaixo de 3,0 pode se submeter a qualquer tipo de tratamento odontológico pouco traumático (extração dentária simples ou múltipla, alveoloplastia, biopsia, frenectomia) sem suspensão do anticoagulante, desde que os recursos hemostáticos sejam utilizados. Isto inclui: cirurgia atraumática, suturas adequadas para o fechamento das feridas, aplicação de pressão pós-cirurgia, uso tópico de agentes coagulantes, como trombina, esponja gelatinosa, celulose regenerada oxidada, colágeno sintético, compressão com gaze embebida com ácido tranexâmico por 30-60 minutos e uso de antifibrinolíticos nos períodos pré e pós-cirúrgico ${ }^{3,4}$.

A administração de antifibrinolíticos via oral deve ser iniciada 24 horas antes do procedimento cirúrgico. A dose recomendada de ácido epsilon-amino capróico é de 200mg/ $\mathrm{kg}$, dividida a cada 6 horas (das 24 horas) no pré-cirurgico e mantida no pós-cirúrgico por até 7 dias. O ácido tranexâmico é mais potente que o ácido E-amino capróico e a dose recomendada é de $25-30 \mathrm{mg} / \mathrm{kg}$ de 8 em 8 horas durante o mesmo período (24 horas antes e 7 dias após o procedimento). A alternativa para impedir eventos hemorrágicos sem a interrupção da terapia anticoagulante é a realização de bochechos de ácido tranexâmico em solução aquosa a 4,8\% durante e após 7 dias a cirurgia, com $10 \mathrm{ml} 4$ vezes ao dia por 2 minutos ou bochechos com ácido E-amino capróico 5 .

Procedimentos com risco elevado de sangramento 
devem seguir as mesmas orientações para intervenções não odontológicas.

\section{Recomendações:}

- Pacientes que não são considerados de alto risco para sangramento, recomenda-se não suspender a varfarina; Grau de recomendação I, Nível de evidência C.

- Pacientes com alto risco para sangramento é recomendada a suspensão temporária da varfarina até RNI em torno de 1,5 associado ou não ao uso de heparinas na dependência do risco de trombose; Grau de recomendação I, Nível de evidência $C$.

- Pacientes submetidos a tratamento dental com sangramento local poderão realizar bochechos com ácido tranexâmico ou ácido epsilon-amino capróico, para controle do sangramento, sem interrupção da terapia anticoagulante; Grau de recomendação I, Nível de evidência C.

\section{II) Procedimentos odontológicos e prevenção de} endocardite infecciosa

Nesta situação devemos situar as duas vertentes: a primeira delas é a predisposição do paciente para endocardite infecciosa e a segunda é a potencialidade do procedimento gerar bacteremia por agente capaz de ocasionar quadro de endocardite infecciosa.

Os procedimentos odontológicos de maior risco para bacteremia são os seguintes: colocação subgengival de fibras ou fitas com antibióticos, exodontias, implantes ou reimplantes dentários, procedimentos endodônticos e periodônticos, colocação de bandas ortodônticas e procedimentos com sangramento significativo. Os pacientes de risco elevado sempre que submetidos a estes procedimentos, devem receber profilaxia antibiótica.

Pacientes que realizam hemodiálise com "shunts" arteriovenosos necessitam de profilaxia antibiótica, quando submetidos à procedimentos odontológicos ${ }^{3}$. Para pacientes que colocaram stent vascular é prudente a realização de profilaxia antibiótica durante uma intervenção odontológica de emergência nas primeiras 4 a 6 semanas pós-operatório ${ }^{3,6}$.

Indivíduos que receberem um transplante de órgão na vigência de infecções dentárias devem ser tratados com antibiótico, antes e depois do transplante, até o fim do tratamento.

As opções terapêuticas para prevenção de endocardite infecciosa estão descritas no item 5E.

\section{Referências}

1. Dajani AS, Taubert KA, Wilson W, et al. Prevention of bacterial endocarditis. Recommendations by the American Heart Association. JAMA 1997; 277:1794-801.

2. Brown R, Rhodus N. Epinephrine and local anesthesia revisited. Oral Surg Oral Med Oral Pathol Oral Radiol Endod 2005; 100:401-8.

3. Academy Report. Periodontal Management of Patients with Cardiovascular Diseases. J Periodontol 2002; 73:954-68.

4. Jeske AH, Suchko GD; ADA Council on Scientific Affairs and Division of Science; Journal of the American Dental Association. Lack of a scientific basis for routine discontinuation of oral anticoagulation therapy before dental treatment. J Am Dent Assoc. 2003 Nov;134(11):1492-7.

5. Jack Ansell, MD; Jack Hirsh, MD, FCCP; Leon Poller, MD; Henry Bussey, PharmD, FCCP; Alan Jacobson, MD and Elaine Hylek, MD. The Pharmacology and Management of the Vitamin K Antagonists. The Seventh ACCP Conference on Antithrombotic and Thrombolytic Therapy. 2004 Sep;126(3 Suppl):204S-233S.

6. Tong DC, Rothwell BR. Antibiotic Prophylaxis in dentistry: a review and pratice recommendations. JADA 2000; 131:366-374.

\section{4) AVALIAÇÃO PERIOPERATÓRIA SUPLEMENTAR}

\section{A) Atalho para fazer um teste não invasivo na presença de fatores de risco para complicações (pular os passos recomendados pelos algoritmos)}

Nenhum fator de risco isoladamente é indicativo da avaliação funcional. As maiores evidências do benefício destas provas se encontram no grupo de pacientes com risco intermediário e que serão submetidos a intervenções vasculares (grau de recomendação I, evidência D). Assim, a realização de prova funcional não está indicada nem no grupo de pacientes de baixo risco, pois nestes não traria nenhum benefício adicional, nem naqueles pacientes de alto risco, uma vez que estes geralmente necessitam de uma estratificação invasiva.

A avaliação de isquemia miocárdica no contexto perioperatório preferencialmente deve ser realizada por meio de uma prova funcional associada a um método de imagem. A cintilografia miocárdica com estresse físico (preferencial aos métodos farmacológicos), com dipiridamol ou dobutamina (quando há limitação física) e o ecocardiograma de estresse são testes com excelentes taxas de acurácia, com alto valor preditivo negativo e são comparáveis entre si.

O teste ergométrico convencional não apresenta a mesma acurácia dos testes associados a imagem, e apresenta limitações em pacientes com alterações no eletrocardiograma basal, tais como bloqueio de ramos, sobrecargas ventriculares e alterações de repolarização ventricular. Entretanto, num grupo seleto de pacientes que consegue atingir $85 \%$ da freqüência cardíaca máxima prevista, o resultado do teste tem um valor preditivo negativo alto e permite a avaliação objetiva da capacidade funcional ${ }^{1-4}$.

Os pacientes que foram submetidos a alguma forma de avaliação funcional nos dois últimos anos, sem alterações na 


\section{Diretriz}

sintomatologia desde então, não têm necessidade de repetir o teste. O mesmo conceito se aplica aos pacientes com revascularização miocárdica cirúrgica completa realizada há menos de cinco anos e estáveis clinicamente.

\section{Recomendações para realização de teste não invasivo Grau de recomendação I}

- Indicado para os pacientes com preditores clínicos intermediários de risco e que serão submetidos a intervenções vasculares;

\section{Grau de recomendação Ila}

- Indicada na presença de dois de três fatores mencionados abaixo:

1) Presença de: angina classe funcional I ou II, história prévia de infarto do miocárdio ou onda $\mathrm{Q}$ patológica, insuficiência cardíaca prévia ou compensada, diabetes mellitus

\section{Referências}

1. Eagle et al. ACC/AHA Guideline Update on Perioperative Cardiovascular Evaluation for Noncardiac Surgery 2002

2. Grayburn PA, Hillis LD. Cardiac events in patients undergoing noncardiac surgery: shifting the paradigm from noninvasive risk stratification to therapy. Ann Intern Med 2003;138(6):506-11.

\section{B) Avaliação da função ventricular em repouso}

A função ventricular esquerda pode ser avaliada por ecocardiografia transtorácica, ventriculografia radioisotópica ou por ventriculografia contrastada. Usualmente, a ecocardiografia bidimensional é o exame escolhido, por também avaliar a estrutura e dinâmica das válvulas ou presença de hipertrofia ventricular. A avaliação da função ventricular esquerda obtida de rotina no pré-operatório é questionável, embora se deva considerar o contexto clínico de cada caso $^{1-5}$.

\section{Recomendações: \\ Grau de recomendação I}

ou insuficiência renal;

2) Baixa capacidade funcional: menos de 4 METs;

3) Procedimento cirúrgico de alto risco: cirurgias vasculares periféricas ou de aorta, procedimentos cirúrgicos prolongados com grandes perdas sangüíneas ou de shifts de fluidos;

\section{Grau de recomendação IIb}

- Indicado em pacientes sem avaliação funcional nos últimos dois anos e

1) Sabidamente coronariopatas ou

2) Com no mínimo dois fatores de risco para DAC (HAS, tabagismo, dislipidemia, DM, história familiar positiva);

\section{Grau de recomendação III}

- Em pacientes não candidatos a revascularização miocárdica, sem possibilidade de modificação do plano cirúrgico não cardíaco de acordo com resultado da prova funcional;
3. Tetzlaff JE, Farid I. Cardiac Testing for Noncardiac Surgery: Past, Present, and Future. Journal of Clin Anesth 2002;14(5): 321-323.

4. Lustik SJ, Eichelberger JP, Chhibber AK. Preoperative Stress Testing: New Guidelines. Journal of Clin Anesth, Aug 2002,14(5), pag 375-380.

- Suspeita clínica de estenose aórtica importante; Nível de evidência $B$.

\section{Grau de recomendação Ila}

- Pacientes com ICC sem avaliação prévia da função ventricular; Nível de evidência $D$.

- Presença de obesidade grau 3; Nível de evidência D.

- Avaliação pré-operatória de transplante hepático; Nível de evidência $D$.

\section{Grau de recomendação IIlb}

- Detecção de valvopatias; Nível de evidência B.

Grau de recomendação III

- Rotina para todos os pacientes; Nível de evidência D.

\section{Referências}

1. Halm EA, Browner WS, Tubau JF, Tateo IM, Mangano DT. Echocardiography for assessing cardiac risk in patients having noncardiac surgery. Ann Intern Med 1996:25:433-441.

2. McPhail NV, Ruddy TD, Calvin JE, Barber CG, Cole CW, Davies RA, Gulenchyn KY. Comparison of left ventricular function and myocardial perfusion for evaluating perioperative cardiac risk of abdominal aortic surgery. Can J Sur 1998;33:224-228.

3. Kontos MC, Brath LK, Akosah KO, Mohanty PK. Cardiac complications in noncardiac surgery: relative value of resting two-dimensional echocardiography and dipyridamole thallium imaging. Am Heart
$1996 ; 132: 559-566$

4. Rohde LE, Polanczyk CA, Cook EF, Lee RT, Mangione C, Goldman L, Lee TH. Usefulness Of Transthoracic Echocardiography As A Tool For Risk Stratification Of Patients Undergoing Major Noncardiac Surgery. Am J Cardiol 2001;87:505-509.

5. Lee TH, Marcantonio EM, Mangione CM, Thomas EJ, Polanczyk CA, Cook F, Sugarbaker DJ, Donaldson MC, Poss R, Ho KKL, Ludwig LE, Pedan A, Goldman L. Derivation and prospective validation of a simple index for prediction of cardiac risk of major noncardiac surgery. Circulation 1999; 100:1043-1049. 


\section{C) Eletrocardiograma de esforço}

A importância do uso suplementar do teste ergométrico na avaliação perioperatória é fornecer uma medida objetiva da capacidade funcional, identificar a presença de isquemia grave e arritmias, além de estimar o risco cardíaco perioperatório e o prognóstico a longo prazo.

Uma importante limitação do teste ergométrico para avaliação perioperatória de cirurgia não cardíaca é o fato de que $30 \%$ a $50 \%$ dos pacientes encaminhados ao cardiologista para avaliação pré-cirúrgica de grande porte ou de cirurgias vasculares, não podem atingir carga suficiente durante o esforço para avaliar a reserva cardíaca ${ }^{1-3}$.

Um estudo prospectivo avaliou 204 pacientes com doença coronária ou com risco aumentado de desenvolvêla, que se submeteram à cirurgia não cardíaca necessitando de anestesia geral. Todos foram submetidos a teste ergométrico pré-operatório com uso da medicação habitual. O infradesnivelamento do segmento ST maior ou igual a 1,0 $\mathrm{mm}$ foi considerado um preditor independente para eventos cardíacos no pós-operatório, sendo que o valor preditivo positivo do teste foi de apenas $20 \%{ }^{4}$.

O teste ergométrico na avaliação perioperatória é um exame de baixo custo, fácil execução e alta reprodutibilidade e, mesmo inferior aos teste com imagem, é adequado à realidade de vários municípios do país ${ }^{5}$.

\section{Referências}

1. Von Knorring J, Lepantalo M: Prediction of perioperative cardiac complications by electrocardiographic monitoring during treadmill exercise testing before peripheral vascular surgery. Surgery 1986; 99: 610-613.

2. Arous EJ, Baum PL, Cuttler BS: The ischemic exercise test in patients with peripheral vascular disease: Implications for management. Arch Surg 1984;199: 780-783

3. McPhail N, Calvin JE, Shariatmadar A, et al. The use of preoperative exercise
Recomendações para o Teste Ergométrico no contexto perioperatório:

\section{Grau de recomendaçõa Ila}

- Indicada na presença dos dois fatores abaixo:

1) Presença de preditores clínicos intermediários: angina classe funcional I ou II, história prévia de infarto de miocárdio ou onda $Q$ patológica, insuficiência cardíaca prévia ou compensada, diabetes mellitus ou insuficiência renal;

2) Procedimento cirúrgico de alto risco: cirurgias vasculares periféricas ou de aorta, procedimentos cirúrgicos prolongados com grandes perdas sangüíneas ou de shifts de fluidos;

\section{Grau de recomendação IIb}

- Indicado em pacientes sem avaliação funcional nos últimos dois anos e

1) Sabidamente coronariopatas ou

2) Com no mínimo dois fatores de risco para DAC (HAS, tabagismo, dislipidemia, DM, história familiar positiva);

\section{Grau de recomendação III}

- Em pacientes não candidatos a revascularização miocárdica, sem possibilidade de modificação do plano cirúrgico não cardíaca de acordo com resultado da prova funcional;

- Rotina para todos os pacientes; testing to predict cardiac complications after arterial reconstruction. J Vasc Surg 1988; 7: 60-68.

4. Chaitman BR, Miller DD. Perioperative cardiac evaluation for noncardiac surgery noninvasive cardiac testing.Prog Cardiovasc Dis 1998: 40 (5): 405-418.

5. Diretrizes da Sociedade Brasileira de Cardiologia sobre Teste Ergométrico. Arq Bras. Cardiol 2002; 78(suplemento II): 1-16.
D) Cintilografia de perfusão miocárdica com estresse farmacológico e não farmacológico

No contexto do perioperatório, as indicações e interpretações da cintilografia são as mesmas que as usuais. O exame com estresse físico deve ser preferido, ficando o estresse farmacológico para os casos de limitação funcional.

Nos pacientes que serão submetidos a cirurgias vasculares, deve-se utilizar estresse farmacológico pela dificuldade de exercício relacionada à doença de base. Pacientes com aneurismas de aorta não devem realizar estresse com dobutamina nem exercício físico. Já o dipiridamol deve ser evitado na presença de obstrução de carótida maior que 70\% bilateral, pelo risco de isquemia cerebral.

\section{E) Ecocardiograma de estresse com dobutamina}

A ecocardiografia sob estresse é eficaz para identificar pacientes com doença arterial coronária, seguro e tem importante papel como preditor de eventos $\operatorname{cardíacos}^{1,2}$. A ecocardiografia sob estresse pela dobutamina e pelo exercício apresentam acurácia diagnóstica semelhante e superior ao estresse com dipiridamol ${ }^{3}$. Se o ecocardiograma sob estresse pela dobutamina não demonstrar a presença de isquemia residual no paciente previamente infartado, o prognóstico é bom e a probabilidade de reinfarto é baixa após a intervenção cirúrgica ${ }^{4}$.

O uso da ecocardiografia sob estresse pela dobutamina na avaliação do risco perioperatório já está bem documentado na literatura, apresentando valor preditivo positivo variando de $21 \%$ a $95 \%$ e valor preditivo negativo de $93 \%$ a $100 \%$ para eventos cardíacos em pacientes submetidos à intervenções cirúrgicas ${ }^{5}$. Os resultados geralmente foram utilizados para influenciar a conduta clínica préoperatória, especialmente a decisão da realização da cinecoronariografia ou revascularização miocárdica antes ou após a cirurgia eletiva. 


\section{Diretriz}

L'Italien e cols ${ }^{6}$ avaliaram a influência dos marcadores clínicos sobre a estimativa do risco cardiovascular a longo prazo em pacientes submetidos à cirurgia vascular. $\mathrm{O}$ resumo das evidências suporta que os pacientes que apresentam marcadores clínicos de baixo risco não serão beneficiados com a realização de testes não invasivos, a menos que tenham baixa capacidade funcional ( $<4$ METs) e sejam candidatos a procedimentos cirúrgicos de alto risco (nível de evidência $B$ ). Por outro lado, os pacientes que possuem 3 ou mais marcadores clínicos de baixo risco devem ser estratificados como tendo risco intermediário (nível de evidência D). Nos pacientes identificados como risco intermediário para eventos cardíacos, a ecocardiografia sob estresse deve ser realizada em todos os casos que possuem baixa capacidade funcional $(<$ 4 METs) e naqueles casos com boa ou excelente capacidade funcional ( $>4 \mathrm{METs}$ ) que serão submetidos a procedimentos cirúrgicos de alto risco (nível de evidência B). Devemos considerar a realização da cinecoronariografia nos pacientes que apresentam risco alto para eventos cardiovasculares (nível de evidência $B$ ).

\section{Referências}

1. Mathias W Jr, Arruda A, Santos FC, Arruda AL, Mattos E, Osorio A Campos $\mathrm{O}$, Andrade JL, Carvalho AC Safety of dobutamine-atropine stress echocardiography: a prospective experience of 4033 consecutive studies. J Am Soc Echocardiogr 1999; 12: 785-791.

2. Chuah SC, Pellikka PA, Roger VL, McCully RB, Seward JB. Role of Dobutamine stress echocardiography in predicting outcome in 860 patients with known or suspected coronary artery disease. Circulation 1998; 97: 1474-1480.

3. Dagianti A, Penco M, Agati L, Scionner S, Dagianti A, Rosanio S, Fedele F. Stress echocardiography: comparison of exercise, dipyridamole and dobutamine in detecting and predicting the extent of coronary artery disease. J Am Coll Cardiol 1995; 26: 18-25.

Recomendações para utilização da ecocardiografia sob estresse/cintilografia de perfusão miocárdica com estresse:

\section{Grau de recomendação I}

- Indicado para os pacientes com risco intermediário que serão submetidos a intervenções vasculares;

\section{Grau de recomendação Ila}

- Indicada na presença de dois de três fatores mencionados abaixo:

1) Presença de: angina classe funcional I ou II, história prévia de infarto do miocárdio ou onda $\mathrm{Q}$ patológica, insuficiência cardíaca prévia ou compensada, diabetes mellitus ou insuficiência renal;

2) Baixa capacidade funcional: menos de 4 METs;

3) Procedimento cirúrgico de alto risco: cirurgias vasculares periféricas ou de aorta, procedimentos cirúrgicos prolongados com grandes perdas sangüíneas ou de shifts de fluidos;

\section{Grau de recomendação IIb}

- Indicado em pacientes sem avaliação funcional nos últimos dois anos e

1) Sabidamente coronariopatas ou

2) Com no mínimo dois fatores de risco para DAC (HAS, tabagismo, dislipidemia, DM, história familiar positiva);

\section{Grau de recomendação III}

- Em pacientes não candidatos a revascularização miocárdica, sem possibilidade de modificação do plano cirúrgico não cardíaca de acordo com resultado da prova funcional.

- Rotina para todos os pacientes
4. Bigi R, Cortigiani L, Mariani PR, Bax JJ. Sustained favorable long-term prognosis of negative stress echocardiography follwing uncomplicated myocardial infarction. Am J Cardiol 2002; 90: 149-152.

5. Ballal RS, Kapadia S, Secknus MA, Rubin D, Arheart K, Marwick TH. Prognosis of patients with vascular disease after clinical evaluation and dobutamine stress echocardiography. Am Heart J 1999; 137: 469-475.

6. L'Italien G, Paul SD, Hendel RC, Cohen MC, Fleischer LA, Brown KA, Zarich SW, Leppo JA, Eagle KA. Cardiac risk assessement following vascular surgery: independent validation of Bayesian prediction model. J Am Coll Cardiol 1996; $27: 317 \mathrm{~A}$.

\section{F) Holter}

O holter pode ser utilizado para avaliação de arritmias ou para identificação de isquemia silenciosa por meio da análise do segmento ST. O seu uso rotineiro no contexto perioperatório não é recomendado, sendo reservado para casos específicos baseado no quadro clínico do paciente.

\section{G) Cineangiocoronariografia}

A realização de cineangiocoronariografia na avaliação préoperatória de uma operação não cardíaca tem como objetivo obter uma melhor avaliação e estratificação da isquemia miocárdica e propor estratégias de intervenção para redução de risco cardíaco perioperatório. As indicações para realização de exame no contexto perioperatório são as mesmas da prática clínica, não devendo ser recomendada de forma rotineira na avaliação perioperatória.

Devemos lembrar que nos casos onde a realização do procedimento cirúrgico for uma urgência, a indicação do exame pode ser postergada considerando o risco e benefício global.

Recomendações para realização de cineangiocoronariografia no pré-operatório:

\section{Grau de recomendação I}

- Teste não invasivo de alto risco;

- Presença de preditores clínicos de alto risco;

- Síndrome coronária aguda de alto risco;

- Teste não invasivo positivo com isquemia comprovada e com disfunção de VE; 


\section{Grau de recomendação Ila}

- Teste não invasivo positivo, porem não de alto risco, com função ventricular preservada;

\section{Grau de recomendação III}

- Pacientes não candidatos à revascularização miocárdica;

\section{5) MEDIDAS PARA REDUÇÃO DO RISCO CIRÚRGICO}

\section{A)Terapia medicamentosa perioperatória}

\section{I) Beta-bloqueadores}

Ao longo dos últimos 20 anos os betabloqueadores passaram da classe das medicações com recomendação de suspensão perioperatória para se tornarem uma das principais armas farmacológicas no controle clínico e redução de risco perioperatório. Acreditava-se antigamente que o uso recente de beta-bloqueador poderia impedir resposta hemodinâmica apropriada ao estresse cirúrgico, conceito este já refutado por importantes evidências sobre a sua segurança ${ }^{1}$. Existem dois principais estudos randomizados que estabeleceram o impacto benéfico do beta-bloqueio perioperatório: o primeiro deles incluiu alguns indivíduos até mesmo de baixo risco para complicações cardiovasculares mas que apresentavam pelo menos 2 fatores de risco para $\mathrm{DAC}^{2}$ e o segundo, selecionou uma população de risco intermediário a alto para cirurgia vascular e que apresentava isquemia ao ecocardigrama de estresse ${ }^{3}$.

Mangano mostrou uma redução de $65 \%$ na mortalidade cardiovascular aos 2 anos de seguimento e menor morbidade cardiovascular no grupo que recebeu beta-bloqueador $(17 \% \times 32 \%, p=0,008)$. O maior benefício ocorreu principalmente nos primeiros 8 meses de seguimento ${ }^{2}$. No segundo estudo, Poldermans demonstrou em sua população, já nos primeiros 30 dias de seguimento, redução da taxa de infarto não fatal e morte por causa cardíaca de 91\% (3,4\% X $34 \%, p<0,001)^{3}$.

A indicação de beta-bloqueador no perioperatório de intervenções cirúrgicas, para pacientes com risco baixo ou intermediário de complicações cardiovasculares tem recebido críticas devido às limitações dos ensaios clínicos.

O objetivo deve ser o controle da freqüência cardíaca para próximo de $60 \mathrm{bpm}$. O medicamento deve ser iniciado no momento da avaliação pré-operatória e mantido até o 7o pós-operatório. É importante ressaltar que o uso de beta-bloqueador, caso não tenha sido iniciado com maior antecedência, pode ser feito até mesmo na sala cirúrgica, com preparações para administração venosa.

Recomendações para uso de beta-bloqueador perioperatório:

\section{Grau de Recomendação I}

- Pacientes de alto risco (Classes II e III da ACP) e coronariopatas; Nível de evidência A.

Grau de Recomendação IIb
- Dois ou mais fatores de risco cardiovasculares ( $>65$ anos, HAS, tabagismo, diabetes e colesterol total $>240 \mathrm{mg} / \mathrm{dl})^{2}$; Nível de evidência $B$.

\section{Grau de Recomendação III}

- Pacientes com contra-indicações para uso de betabloqueadores; Nível de evidência $B$.

\section{II) Estatinas}

Em um estudo recente realizado no Brasil, foram randomizados 98 pacientes submetidos eletivamente a operações vasculares para receberem atorvastatina (20mg) ou placebo. Houve redução de $68 \%$ dos eventos cardiovasculares maiores, através do uso de atorvastatina, ao final de 6 meses de seguimento. Tal efeito ocorreu independentemente dos níveis basais de colesterol e foi adicional ao benefício advindo do uso de beta-bloqueadores (semelhante entre os grupos) ${ }^{4}$.

Posteriormente, outro estudo também avaliou o benefício do uso de estatinas na redução de mortalidade no perioperatório de operações vasculares. Foram retrospectivamente avaliados 2816 pacientes, cuja taxa de mortalidade foi de 5,8\% ${ }^{5}$. O benefício conferido pelo uso de estatinas foi redução de 4,5 vezes da taxa de mortalidade em relação aos pacientes que não receberam esta medicação (OR 0,22 IC: 0,10 - 0,47). Embora o tamanho amostral seja grande, foram incluídos pacientes operados desde 1991, época em que o uso perioperatório de beta-bloqueador não estava tão bem estabelecido. Além disso, o uso de beta-bloqueadores foi mais freqüente entre os pacientes que sobreviveram, o que pode superestimar o impacto benéfico das estatinas.

Recomendações para o uso perioperatório das estatinas: Grau de Recomendação I

- Operações vasculares; Nível de evidência B.

- Coronariopatas ou pacientes que já usavam estatinas previamente; Nível de evidência $D$.

\section{Grau de Recomendação IIb}

- Pacientes de alto risco (classes II e III da ACP); Nível de evidência $D$.

\section{III) Alfa-agonistas}

Com o intuito de moderar a resposta de catecolaminas aos procedimentos cirúrgico e anestésico, diminuindo o risco de complicações miocárdicas em coronariopatas, alguns autores estudaram a ação destes medicamentos, especialmente clonidina, no contexto perioperatório. Os resultados, porém, são conflitantes.

\section{IV) Aspirina}

O Ácido acetilsalicílico (AAS) é um potente antiagregante plaquetário. Sua ação benéfica em reduzir morbi-mortalidade em coronariopatas é bastante conhecido.

\section{Recomendações:}

- Para pacientes com uso contínuo, o AAS não deve 


\section{Diretriz}

ser suspenso antes da intervenção, exceto nas cirurgias neurológicas e na prostatectomia transuretral ${ }^{6}$; Grau de recomendação I, Nível de evidência $B$.

\section{Referências}

1. Goldman L. Cardiac risks and complications of noncardiac surgery. Ann Intern Med 1983; 98:504-513.

2. Mangano DT, Layug EL, Wallace A, Tateo I. Effect of atenolol on mortality and cardiovascular morbidity after noncardiac surgery. N Engl J Med 1996; 335:1713-1720.

3. Poldermans D, Boersma E, Bax JJ, Thomson IR. The effect of bisoprolol on morbidity and mortality in patients undergoing vascular surgery. N Engl J Med 1999; 341: 1789-1794.

4. Durazzo AE, Machado FS, Ikeoka DT, De Bernoche C, Monachini MC, Puech-
- Quando estiver sendo usada dose mais elevada de aspirina (325 mg), considerar a redução para dose menor; Grau de recomendação lla, Nível de evidência D.

\section{B) Revascularização miocárdica}

A revascularização miocárdica pode ser indicada antes da operação não cardíaca, com o objetivo de reduzir o risco cardiovascular perioperatório ${ }^{1,2}$. A maior parte dos pacientes submetidos à revascularização miocárdica por angioplastia ou cirurgia já tinham previamente a indicação do procedimento. O tempo de espera entre um e outro procedimento é um fator importante, mesmo entre os que realizam angioplastia ${ }^{3-5}$. De um lado o risco de trombose intra-coronariana ou reestenose intra-stent quando este tempo for, respectivamente, muito curto ou longo. De outro lado, o risco de complicações hemorrágicas associadas ao uso de antiagregantes potentes como o clopidogrel. Cabe lembrar que pacientes que foram submetidos à angioplastia com stent farmacológico devem receber clopidogrel durante mais tempo do que aqueles com stent convencional devido ao risco de trombose tardia do stent.

Recomendações para revascularização do miocárdio (cirúrgica ou percutânea) antes de operações não cardíacas:

\section{Grau de recomendação I}

- A angioplastia somente deve ser feita quando houver alguma comprovação de isquemia relacionada àquela artéria e não apenas baseada nos achados anatômicos; Nível de evidência $A$.

- Pacientes com indicação de revascularização do miocárdio independentemente do contexto perioperatório, em programação de operações não cardíacas eletivas; Nível de evidência $D$.

- Pacientes com evidência durante a avaliação perioperatória de grandes áreas isquêmicas, baixo limiar para isquemia e anatomia coronária de alto risco: lesão de tronco de coronária esquerda e padrão triarterial associado à disfunção ventricular; Nível de evidência $D$.

\section{Grau de recomendação Ila}

- Pacientes sem marcadores funcionais ou anatômicos de

Leão P, Caramelli B. Reduction in cardiovascular events after vascular surgery with atorvastatin: a randomized trial. J Vasc Surg. 2004;39:967-76.

5. PoldermansD, Bax J, Kertai M, Krenning B, et al. Statins are associated with a reduced incidence of perioperative mortality in patients undergoing major noncardiac vascular surgery. Circulation 2003; 107: 1848-1851.

6. Burger W, Chemnitius JM, Kneissl GD, Rucker G. Low-dose aspirin for secondary cardiovascular prevention-cardiovascular risks after its perioperative withdraw versus bleeding risks with its continuation- review and meta-analysis. J Intern Med 2005; 257: 399-414. alto risco de complicação cardíaca perioperatória porém com indicação de revascularização miocárdica, antes de operações não cardíacas de grande porte (vasculares, intra-peritoneais ou intra-torácicos); Nível de evidência $D$.

\section{Grau de recomendação IIb}

- Pacientes sem marcadores funcionais ou anatômicos de alto risco de complicação cardíaca perioperatória porém com indicação de revascularização miocárdica, antes de operações não cardíacas de pequeno ou médio porte; Nível de evidência $D$.

\section{Grau de recomendação III}

- Pacientes com necessidade de operação não cardíaca de emergência, independentemente da gravidade dos sinais, sintomas e grau de obstrução coronária; Nível de evidência $D$.

- Pacientes com doenças cirúrgicas não cardíacas que aumentam muito o risco de complicação geral no perioperatório da revascularização miocárdica, tais como neoplasias intestinais com sangramento importante, síndromes dispépticas graves, infecções intra ou extra-cavitárias, traumatismo cranio-encefálico ou tumores cerebrais com risco de sangramento; Nível de evidência D.

- Pacientes com grave limitação prognóstica por condições extra-cardíacas, em quem se planeja procedimento cirúrgico não cardíaco paliativo, tais como gastrostomias, derivações digestivas, traqueostomias, etc.

Recomendações para o intervalo de segurança entre a revascularização miocárdica e cirurgia não cardíaca:

\section{Grau de Recomendação I}

- Após revascularização miocárdica cirúrgica:

- Tempo ideal: 30 dias; Nível de evidência D.

- Tempo mínimo: variável conforme as condições clínicas do paciente; Nível de evidência $D$.

- Após angioplastia com balão sem uso de stent: 
- Tempo ideal: 14 dias; Nível de evidência $B$.

- Tempo mínimo: 7 dias; Nível de evidência $B$.

- Após angioplastia com uso do stent:

- Tempo ideal: 6 semanas; Nível de evidência B.
- Tempo mínimo: 14 dias; Nível de evidência B.

- Após angioplastia com stent farmacológico:

- Tempo ideal: não estabelecido; Nível de evidência $D$.

- Tempo mínimo: 30 dias $^{6}$; Nível de evidência D.

\section{Referências}

1. Eagle K., Rihal CS., Mickel MC., Holmes DR., et al. Cardiac Risk of Noncardiac Surgery- Influence of Coronary Disease and Type of Surgery in 3368 Operations. Circulation 1997; 96: 1882-1887.

2. Hassan SA., Hlatky MA., Boothroyd DB., Winston C., et al. Outcomes of noncardiac surgery after coronary bypass surgery or coronary angioplasty in the bypass angioplasty revascularization investigation (BARI). Am J Med 2001; 110:260-266.

3. Gottlieb A., Banoub M., Sprung J., Levy PJ., et al. Perioperative cardiovascular morbidity in patients with coronary artery disease undergoing vascular surgery after percutaneous transluminal coronary angioplasty. Cardiothorac Vasc Anesth 1998; 12: 501-506.

\section{C) Profilaxia para Tromboembolismo Venoso}

A adequada profilaxia para cada paciente depende do conhecimento adequado de seus fatores de risco. Nos pacientes cirúrgicos há ainda os fatores de risco inerentes ao próprio procedimento ${ }^{1}$.

Os fatores de risco para tromboembolismo venoso (TEV) são: idade avançada, imobilidade prolongada ou paralisia, tromboembolismo venoso prévio, câncer e os seus tratamentos, intervenções de grande porte (envolvendo principalmente abdome, pelve e membros inferiores), trauma (particularmente os de pelve, quadril e membros inferiores), obesidade, insuficiência venosa periférica, disfunção cardíaca, acidente vascular cerebral, cateteres venosos centrais, doença inflamatória intestinal, síndrome nefrótica, gravidez e uso de estrógenos.

I) Classificação do risco de TEV conforme características do paciente e do procedimento

- Risco Baixo: cirurgia de pequeno porte, paciente com
4. Elmore JR., Hallett Jr JW., Gibbons RJ., Naessens JM, et al. Myocardial revascularization before abdominal aortic aneurysmorrhaphy: effect of coronary angioplasty. Mayo Clin Proc 1993; 68: 637-641.

5. Kaluza GL., Joseph J., Lee JR., Raizner ME., et al. Catastrophic outcomes of noncardiac surgery soon after coronary stenting. J Am Coll Cardiol 2000; 35: 1288-1294.

6. Daemen J, Wenaweser P, Tsuchida K, Abrecht L, Vaina S, et al. Early and late coronary stent thrombosis of sirolimus-eluting and paclitaxel-eluting stents in routine clinical practice: data from a large two-institutional cohort study. Lancet 2007; 369: 667-678.

menos de 40 anos e sem fatores de risco.

- Risco Moderado:

- Cirurgia de pequeno porte e pacientes com fatores de risco;

- Cirurgia de porte intermediário, pacientes entre 40-60 anos, sem fatores de risco;

- Cirurgias de grande porte, pacientes com menos de 40 anos sem fatores de risco;

- Risco Alto:

- Cirurgias de porte intermediário, pacientes > 60 anos ou c/ fatores de risco;

- Cirugias de grande porte, pacientes $>40$ anos ou c/ fatores de risco;

- Risco Muito Alto:

- Cirurgias de grande porte, pacientes $>40$ anos associado a TEV prévio, câncer ou hipercoagulabilidade;

- Pacientes com múltiplos fatores de risco;

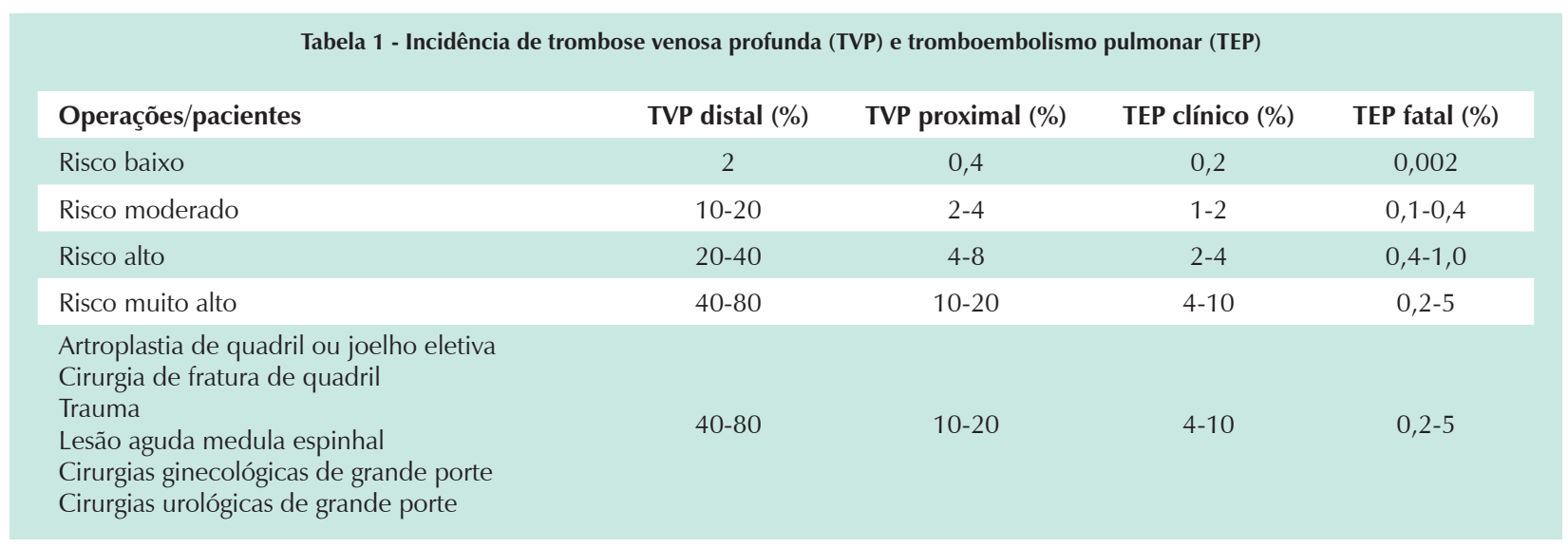




\section{Diretriz}

II) Recomendações para profilaxia perioperatória de tromboembolismo venoso ${ }^{1}$

\section{1) Risco Baixo}

- Mobilização precoce; Grau de recomendação I, Nível de evidência C.

\section{2) Risco Moderado}

- Heparina 5000 U SC cada 12 hs, iniciando 1-2 h antes da operação; Grau de recomendação l, Nível de evidência A.

- Enoxaparina 20 mg SC 1-2 h antes da cirurgia e 1x/dia no pós-operatório; Grau de recomendação I, Nível de evidência A.

- Meia elástica - início imediatamente antes da cirurgia até acompanhamento ambulatorial ou compressão pneumática intermitente $(\mathrm{CPI})$ - início imediatamente antes da cirurgia até a alta hospitalar; Grau de recomendação I, Nível de evidência A.

\section{3) Risco Alto}

- Heparina 5000Ul sc cada 8 horas, iniciando 1-2h antes da cirurgia; Grau de recomendação I, Nível de evidência A.

- Enoxaparina 40mg SC 1-2 h antes da cirurgia e 1x/dia no pós-operatório; Grau de recomendação I, Nivel de evidência A.

- CPI - início imediatamente antes da cirurgia até a alta hospitalar; Grau de recomendação I, Nível de evidência A.

\section{4) Risco Muito Alto}

- Enoxaparina 40mg SC 1-2 h antes da cirurgia e 1x/dia no pós-operatório combinado com $\mathrm{CPI} /$ meia elástica; Grau de Recomendação I, Nível de evidência C.

- Heparina 5000 U SC cada 8 h, iniciando 1-2 h antes de cirurgia combinado com $\mathrm{CPI} /$ meia elástica; Grau de Recomendaçãol, Nível de evidência C.

- Varfarina em pacientes selecionados - início com 5mg/d no dia ou no dia após a cirurgia, ajustando a dose para manter um INR de 2-3; Grau de recomendação lla, Nível de evidência C.

\section{5) Artroplastia de quadril eletiva}

- Enoxaparina 40 mg SC 12 h antes ou 12-24 h depois da cirurgia, ou 20 mg SC 4-6 h depois da cirurgia mantendo 40 mg/d nos dias subseqüentes; Grau de recomendação I, Nível de evidência $A$

- Varfarina com ajuste da dose para manter o INR entre 2-3 iniciando-se no pré-operatório ou imediatamente após a cirurgia; Grau de recomendação I, Nível de evidência A.

- Heparina SC cada 8h, dose inicial de 3500 U ajustando-se $\pm 500 \cup$ por dose para se manter TTPA nos níveis superiores da normalidade; Grau de recomendação lla, Nível de evidência A.

- Associação das medidas de profilaxia com CPI ou meio elástica; Grau de recomendação lla, Nível de evidência C.

- Duração da profilaxia por pelo menos 7 dias; Grau de recomendação I, Nível de evidência $A$

\section{6) Artroplastia de joelho eletiva}

- Enoxaparina 40 mg SC 12 h antes ou 12-24 hs depois da cirurgia, ou 20 mg SC 4-6 h depois da cirurgia mantendo $40 \mathrm{mg} / \mathrm{d}$ nos dias subseqüentes; Grau de recomendação I, Nível de evidência $A$.

- Varfarina com ajuste da dose para manter o INR entre 2-3 iniciando-se no pré-operatório ou imediatamente após a cirurgia; Grau de recomendação l, Nível de evidência A.

- CPI - início imediatamente antes da cirurgia até a alta hospitalar; Grau de recomendação I, Nível de evidência $B$.

- Duração da profilaxia por pelo menos 7 a 10 dias; Grau de recomendação I, Nível de evidência A.

\section{7) Cirurgia de fratura de quadril}

- Enoxaparina 40 mg SC 12 h antes ou 12-24 h depois da cirurgia, ou 20 mg SC 4-6 h depois da cirurgia mantendo 40 mg/d nos dias subseqüentes; Grau de recomendação I, Nível de evidência $B$.

- Varfarina com ajuste da dose para manter o INR entre 2-3 no pré-operatório ou imediatamente após a cirurgia; Grau de recomendação I, Nível de evidência $B$.

- Heparina 5000 U SC cada 8 h, 1-2 h antes; Grau de recomendação lla, Nível de evidência $B$.

\section{8) Neurocirurgia}

- CPI com ou sem meia elástica; Grau de recomendação I, Nível de evidência A.

- Heparina 5000 U SC cada 8 h, 1-2 h antes; Grau de recomendação lla, Nível de evidência $A$.

- Enoxaparina 40mg SC/d no pós-operatório; Grau de recomendação lla, Nível de evidência $A$.

- Associação de meia elástica/CPI e enoxiparina/ heparina profilática; Grau de recomendação I, Nível de evidência $B$.

\section{9) Trauma}

- Enoxaparina $30 \mathrm{mg}$ SC cada $12 \mathrm{~h}$ iniciando 12-36 h após o trauma se hemodinamicamente estável; Grau de recomendação I, Nível de evidência A.

- $\mathrm{CPI} /$ meia elástica se houver contra-indicação ao uso de enoxiparina pelo risco de sangramento; Grau de recomendação I, Nível de evidência C.

- Filtro de veia cava inferior se houver TVP demonstrada e contra-indicação ao uso de anticoagulantes; Grau de recomendação I, Nível de evidência C.

\section{0) Lesão aguda da medula espinhal}

- Enoxaparina 30 mg SC cada 12 h; Grau de recomendação I, Nível de evidência $B$

- CPI e meia elástica em associação com enoxiparina ou heparina profilática, ou se anticoagulantes são contraindicados logo após a lesão; Grau de recomendação lla, Nível de evidência $B$.

- Na fase de reabilitação continuar terapia com enoxiparina ou passar para anticoagulação plena com varfarina (INR entre 2,0-3,0); Grau de recomendação I, Nível de evidência C. 


\section{1) Cirurgias ginecológicas}

A) Pequenas em doenças benignas

- Mobilização precoce; Grau de recomendação I, Nível de evidência C. risco

B) De grande porte em doença benigna sem fatores de

- Heparina 5000 U SC cada 12 h; Grau de recomendação I, Nível de evidência A.

- Enoxaparina 40 mg SC cada 24 h ou CPI antes da cirurgia e no mínimo vários dias do pós-operatório; Grau de recomendação I, Nível de evidência C.

C) Extensas por câncer

- Heparina 5000 U SC cada 8 h; Grau de recomendação I, Nível de evidência $A$.

- Heparina 5000 U SC cada 8 h associado a CPI ou meia elástica na tentativa de promover uma proteção adicional; Grau de recomendação I, Nível de evidência C.

\section{2) Cirurgias urológicas}

A) Baixo risco ou transuretrais

- Mobilização precoce; Grau de recomendação I, Nível de evidência $C$.

B) Grande porte ou com abertura de cavidade

- Heparina 5000 U SC cada 8 h, 1-2 h antes; Grau de recomendação I, Nível de evidência $B$.

- Enoxaparina 40mg SC 1-2 h antes e 1x/dia no pós- operatório; Grau de recomendação I, Nível de evidência B.

- CPI - imediatamente antes e até a alta hospitalar; Grau de recomendação I, Nível de evidência $B$

- Meia elástica - início imediatamente antes da cirurgia até acompanhamento ambulatorial; Grau de recomendação I, Nível de evidência $B$.

C) Pacientes de alto risco

- Associação de $\mathrm{CPI} /$ meia elástica com enoxaparina/heparina profilática; Grau de recomendação I, Nível de evidência C.

\section{III) Pacientes já em uso de anticoagulação oral por TEV} prévio

Com relação aos pacientes em uso de anticoagulação oral por história de TEV prévio ou recorrente, o tratamento no período perioperatório depende da consideração conjunta dos riscos da doença e da terapia anticoagulante. Estima-se que suspender a anticoagulação no primeiro mês após um evento agudo esteja associado a um risco muito alto de recorrência do TEV (40\% em um intervalo de um mês). Foi descrito um patamar intermediário quando suspensa a anticoagulação entre o segundo e terceiro mês ( $10 \%$ em um intervalo de 2 meses) $)^{2}$. Para pacientes em uso de anticoagulação oral permanente por história de TEV recorrente, estados hereditários de hipercoagulabilidade ou câncer a suspensão da anticoagulação oral está associada a um risco muito menor de TEV $(15 \% \text { ao ano })^{3}$. Este esquema encontra-se exposto na Tabela 2. Consensos atuais admitem o uso de heparina de baixo peso molecular em dose plena ao invés de heparina venosa em dose plena nos pacientes com história de TEV prévio no período perioperatório ${ }^{4,5}$.

Tabela 2: Recomendação para manejo da anticoagulação pré e pós-operatória para pacientes que estão fazendo uso de anticoagulação oral por história de TEV prévio*

\begin{tabular}{lll}
\hline Indicação & Antes da cirurgia & Após a cirurgia \\
\hline TEV agudo - mês 1 & Heparina EV \# (suspender $6 \mathrm{~h}$ antes) & $\begin{array}{l}\text { Heparina EV \# (reiniciar 12 h após operações de grande } \\
\text { porte ou mais tarde caso haja risco de sangramento); }\end{array}$ \\
\hline TEV - mês 2 e 3 & Sem alteração $\beta$ & Heparina EV (até atingir INR de 2,0 com uso de warfarina) \\
\hline TEV - após 3 meses & Sem alteração $\beta$ & HBPM SC \\
\hline TEV recorrente $£$ & Sem alteração $\beta$ & HBPM SC \\
\hline
\end{tabular}

Grau de Recomendação I, Nível de evidência C. ${ }^{*}$ Heparina EV se refere ao uso de heparina venosa em doses terapêticas e HBPM SC se refere ao uso de heparina de baixo peso molecular subcutâneo em doses profiláticas recomendadas para prevenção de TEV em pacientes de alto risco. \# O uso de filtro de veia cava inferior deve ser considerado quando o TEV agudo tiver ocorrido há menos de duas semanas ou se o risco de sangramento com o uso de heparina EV for alto. $\beta$ Para paciente hospitalizado, usar HBPM SC profilática. Contudo a hospitalização não é recomendada somente para este propósito. £Para pacientes cujo último episódio de TEV ocorreu há mais de 3 meses, mas que requerem anticoagulação oral por longo prazo devido ao alto risco de recorrência.

\section{Referências}

1. Geerts W, Heit J, Clagett P, Pineo G, Colwell C, Anderson F, Wheeler B. Prevention of Venous Thromboembolism. Chest 2001; 119: 132S175 S.

2. Kearon C, Hirsh J. Management of anticoagulation before and after elective surgery. N Engl J Med 1997; 336:1506-11.

3. Hull RD, Carter CJ, Jay JM, et al. The diagnosis of acute, recurrent, deep-vein thrombosis: a diagnostic challenge. Circulation 1983; 67:901-6.

4. Hewitt RL, Chun KL, Flint LM. Current Clinical Concepts in Perioperative Anticoagulation. Am Surg 1999 Mar.;65(3):270-3.

5. Hirsh J, Fuster V, Ansell J, Halperin JL. American Heart Association/American College of Cardiology Foundation Guide to Warfarin Therapy. Circulation 2003; 107:1692-1711. 


\section{Diretriz}

\section{D) Anticoagulação no perioperatório}

O manejo de pacientes em uso de anticoagulantes no perioperatório depende do risco do paciente em apresentar eventos tromboembólicos ao descontinuar o anticoagulante e do risco de sangramento no perioperatório. A anticoagulação no perioperatório está associada a um aumento de 3\% de sangramentos graves. Há um consenso que INR $<1,5$ não está associado a sangramento no perioperatório. Portanto é importante um ajuste adequado da anticoagulação para minimizar os eventos trombóticos e hemorrágicos. ${ }^{1}$

\section{I) Risco de tromboembolismo $0^{1,2}$}

- Pacientes de alto risco - tromboembolismo venoso há menos de 3 meses, próteses valvares mecânicas, fibrilação atrial com acidente vascular cerebral (AVC) prévio ou com múltiplos fatores de risco para AVC ou associada a valvopatias, estados de hipercoagulabilidade (fator $V$ de Leiden, deficiências de proteína $\mathrm{C}$ e S) com trombose recorrente ou recente.

- Pacientes de risco intermediário - fibrilação atrial sem AVC prévio e com apenas 1 fator de risco para AVC (idade $>65$ anos, diabetes mellitus, HAS, ICC).

- Pacientes de baixo risco - tromboembolismo venoso há mais de 3 meses, fibrilação atrial sem fatores de risco para AVC, estados de hipercoagulabilidade sem complicação trombótica recente, história de trombose recorrente.

\section{II) Procedimentos com baixo risco de sangramento}

- Cirurgia oftalmológica - catarata, trabeculectomia, cirurgia vitrorretinal

- Procedimentos dentários - higiene, extração simples, restauração, procedimentos endodônticos e protéticos.

\section{III) Recomendações}

\section{1) Pacientes de baixo risco para tromboembolismo}

- Interromper a varfarina 4 dias antes da operação, aguardar INR retornar a valores quase normais $(<1,5)$; Grau de recomendação lla, Nível de evidência $C$.

- No pré-operatório pode ser usada heparina não fracionada (HNF) ou de baixo peso (HBPM) profilática se

\section{Referências}

1. Machado FS. Perioperatório do paciente em uso de anticoagulante. In: Machado FS, Martins MA, Caramelli B. Perioperatório: procedimentos clínicos.1ed, São Paulo, Ed Savier; 2004.p105-9.

\section{E) Profilaxia de Endocardite Infecciosa (EI)}

A profilaxia antimicrobiana deve ser realizada considerando a cardiopatia pré-existente e o tipo de procedimento ${ }^{1,2}$.

\section{I) Cardiopatia pré-existente}

- Alto risco - Próteses valvares, endocardite infecciosa indicado; Grau de recomendação lla, Nível de evidência C.

- No pós-operatório, usar HNF ou HBPM profilática se indicado pelo tipo de procedimento e reiniciar a varfarina simultaneamente; Grau de recomendação Ila, Nível de evidência C.

\section{2) Pacientes de alto risco para tromboembolismo}

- Interromper a varfarina 4 dias antes da operação, aguardar INR normalizar; Grau de recomendação Ila, Nível de evidência $C$.

- Iniciar HNF ou HBPM dose plena quando INR < 2,0; Grau de recomendação Ila, Nível de evidência C.

- Suspender HNF endovenosa 5 horas antes do procedimento e a HBPM ou HNF subcutânea 12-24horas antes; Grau de recomendação lla, Nível de evidência C.

- No pós-operatório, reiniciar HNF ou HBPM em doses plena e a varfarina simultaneamente até o INR estar dentro da faixa terapêutica; Grau de recomendação lla, Nível de evidência C.

\section{3) Pacientes de risco intermediário para} tromboembolismo

- Dependendo da avaliação individual de cada paciente, podem ser seguidas as orientações tanto para o alto como para o baixo risco, a critério do médico assistente; Grau de recomendação Ila, Nível de evidência $C$.

\section{4) Procedimentos de baixo risco de sangramento}

- Realizar o procedimento com INR ao redor de 2,0 - não é necessário suspensão do anticoagulante; Grau de recomendação I, Nível de evidência $D$.

- Se o INR > 3, descontinuar o anticoagulante por um a dois dias antes da cirurgia e reiniciar na noite depois da cirurgia; Grau de recomendação I, Nível de evidência D.

\section{5) Procedimentos de urgência ${ }^{1}$}

- Vitamina K e plasma fresco poderão ser usados para reversão da anticoagulação, evitando altas doses de vitamina $\mathrm{K}$ que podem dificultar anticoagulação posterior;

2. Ansell J, Hirsh J, Poller L, Bussey H, Jacobson A, Hylek E. The Pharmacology and
Management of the Vitamin KAntagonists: The Seventh ACCP Conference on Management of the Vitamin KAntagonists: The Seventh ACCP Conference
Antithrombotic and Thrombolytic Therapy. Chest 2004; 126(3): 214-15.

prévia, cardiopatias congênitas cianóticas, shunts arteriovenosos produzidos cirurgicamente.

- Risco moderado - outras cardiopatias congênitas, disfunções valvares reumáticas ou de outras etiologias, cardiomiopatias hipertróficas, prolapso de valva mitral com insuficiência. 


\section{II) Procedimento cirúrgico}

Por outro lado, os procedimentos cirúrgicos que devem ser precedidos por profilaxia antimicrobiana são aqueles associados a alta incidência de bacteremia transitória: tratamento odontológico (extração dentária, procedimentos periodônticos ou endodônticos), intervenções cirúrgicas no trato gastrointestinal (esclerose de varizes de esôfago, dilatação de estenose de esôfago, colangiografia endoscópica retrógrada, operações sobre o trato biliar ou a mucosa intestinal), trato respiratório (amigdalectomia, adenoidectomia, broncoscopia com broncoscópico rígido e operações envolvendo a mucosa respiratória), trato urinário (cirurgia de próstata, cistoscopia, e dilatação uretral).

III) Recomendações de profilaxia antibiótica para $\mathrm{El}^{1-3}$

\begin{tabular}{|c|c|c|}
\hline \multicolumn{3}{|c|}{ Procedimentos dentários, trato respiratório e esôfago } \\
\hline Situação & Antibiótico & Regime \\
\hline Geral & $\begin{array}{l}\text { Amoxicilina } \\
\text { ou } \\
\text { Ampicilina }\end{array}$ & $\begin{array}{l}2 \mathrm{~g} \text { ou } 50 \mathrm{mg} / \mathrm{Kg} \mathrm{VO} / 1 \text { hora antes do procedimento (AP) } \\
\text { ou } \\
2 \mathrm{~g}(\mathrm{IM} / \mathrm{EV}) \text { ou } 50 \mathrm{mg} / \mathrm{kg} 30 \text { minutos AP }\end{array}$ \\
\hline Alérgicos & $\begin{array}{l}\text { Clindamicina } \\
\text { ou } \\
\text { Cefalexina } \\
\text { Azitromicina ou Claritromicina }\end{array}$ & $\begin{array}{l}600 \mathrm{mg} \text { ou } 20 \mathrm{mg} / \mathrm{Kg} \mathrm{VO} / 1 \text { hora AP ou IM } 30 \text { minutos AP } \\
\text { ou } \\
2 \mathrm{~g} \text { ou } 50 \mathrm{mg} / \mathrm{Kg} \text { VO/ } 1 \text { hora AP } \\
500 \mathrm{mg} 1 \text { hora AP }\end{array}$ \\
\hline \multicolumn{3}{|c|}{ Procedimentos gastrointestinais (exceto esôfago) e genitourinários } \\
\hline Alto risco & $\begin{array}{l}\text { Ampicilina } \\
+ \\
\text { Gentamicina }\end{array}$ & $\begin{array}{l}2 \mathrm{~g}(\mathrm{IM} / \mathrm{EV} \text { ) ou } 50 \mathrm{mg} / \mathrm{Kg} 30 \mathrm{~min} \text { AP }+6 \text { horas após } 1 \mathrm{~g} \text { ou } \\
25 \mathrm{mg} / \mathrm{kg} \text { (ou Amoxicilina } 1 \mathrm{~g} \mathrm{VO}) \\
1,5 \mathrm{mg} / \mathrm{Kg} \text { (até } 120 \mathrm{mg} \text { ) IM/EV } 30 \mathrm{~min} \text { AP }\end{array}$ \\
\hline Alto risco e alérgico & $\begin{array}{l}\text { Vancomicina } \\
+ \\
\text { Gentamicina }\end{array}$ & $\begin{array}{l}\text { 1g ou } 20 \mathrm{mg} / \mathrm{kg} \text { EV (infusão em } 1 \text { hora) } 30 \text { min AP } \\
+ \\
1,5 \mathrm{mg} / \mathrm{Kg} \text { (até } 120 \mathrm{mg} \text { ) IM/EV } 30 \mathrm{~min} \text { AP }\end{array}$ \\
\hline Risco moderado & $\begin{array}{l}\text { Amoxicilina } \\
\text { ou } \\
\text { Ampicilina }\end{array}$ & $\begin{array}{l}2 \mathrm{~g} \text { ou } 50 \mathrm{mg} / \mathrm{Kg} \text { VO } 1 \text { hora AP } \\
\text { ou } \\
2 \mathrm{~g}(\mathrm{IM} / \mathrm{EV}) \text { ou } 50 \mathrm{mg} / \mathrm{kg} 30 \mathrm{~min} \text { AP }\end{array}$ \\
\hline $\begin{array}{l}\text { Risco moderado e } \\
\text { alérgicos }\end{array}$ & Vancomicina & 1g ou 20mg/kg EV (infusão em 1hora) 30 min AP \\
\hline
\end{tabular}

\section{IV) Profilaxia para EI NÃO está recomendada}

- Comunicação Interatrial (CIA) isolada;

- CIA, Comunicação Interventricular ou Persistência do Canal Arterial corrigidas e sem fluxo residual;

- Cirurgia de revascularização miocárdica prévia;

\section{Referências}

1. Dajani AS, Taubert KA, Wilson W et al. Prevention of Bacterial Endocarditis. Recommendations by the American Heart Association. Circulation 1997;96:358-66.

2. Durack DT. Prevention of infective endocarditis. N Engl J Med

\section{F) Controle glicêmico}

Até pouco tempo era tolerada hiperglicemia leve a moderada em pacientes submetidos a estresse cirúrgico por se acreditar que ela poderia ser benéfica ao servir de nutriente para células nervosas e sangüíneas, sendo aceito manter glicemias discretamente elevadas no perioperatório,
- Prolapso de válvula mitral sem regurgitação;

- Sopros cardíacos inocentes;

- Portadores de marca-passo ou CDI;

- História de doença de Kawasaki ou febre reumática sem disfunção valvar;

\section{$1995 ; 332: 38-44$}

3. Dajani AS, Bawdon RE, Berry MC. Oral amoxicillin as prophylaxis for endocarditis: what is the optimal dose? Clin Infect Dis $1994 ; 18: 157$ 160.

com o intuito de evitar possíveis complicações agudas da hipoglicemia. Sabe-se hoje que a hiperglicemia pode ter efeitos maléficos nos desfechos clínicos de pacientes submetidos a cirurgia, especialmente quanto à possibilidade de infecções ${ }^{1}$. Além disso, a hiperglicemia provoca, direta ou indiretamente, disfunção endotelial, aumento da trombogênese, prejuízo 


\section{Diretriz}

na cicatrização por síntese deficiente de colágeno, distúrbios hidro-eletrolíticos com diurese osmótica, alterações no sistema imune, entre outros. Estudos têm demonstrado que o nível de glicose plasmática na admissão é um preditor independente de prognóstico após síndrome coronariana aguda, acidente vascular encefálico isquêmico e revascularização miocárdica, independentemente da história prévia de diabetes mellitus² Estes efeitos maléficos da hiperglicemia sustentam a indicação de manutenção de rigoroso controle glicêmico perioperatório.

\section{I) Pré-operatório}

Recomenda-se estrito controle glicêmico desde o préoperatório, particularmente na semana que antecede a intervenção. Idealmente, as glicemias e hemoglobina glicosilada devem estar em níveis normais. As drogas hipoglicemiantes usadas por via oral são suspensas até 72 horas antes, a depender da meia-vida da droga, e substituídas por insulina regular subcutânea na medida necessária para adequado controle glicêmico, somente sendo reintroduzidas após adequada estabilidade hemodinâmica e respiratória e restabelecido perfeito funcionamento do sistema gastrointestinal. O objetivo é manter a glicemia no pré-operatório entre 80 e $120 \mathrm{mg} / \mathrm{dl}$ no período pré-prandial ${ }^{3}$.

\section{Recomendações:}

- Todos os pacientes devem ser investigados por meio de uma boa anamnese e exame físico para identificação de fatores de risco para diabetes mellitus (DM); Grau de recomendação I, Nível de evidência $D$.

- Aqueles que tiverem idade maior que 45 anos, sobrepeso ou sintomas sugestivos de DM devem ter ao menos uma glicemia em jejum mensurada; Grau de recomendação I, Nível de evidência $D$.

- Glicemia < 100 mg/dL - Paciente irá para o procedimento cirúrgico sem qualquer preparo especial pré-operatório; Grau de recomendação I, Nível de evidência $D$.

- Glicemia entre 100 e 125 mg/dL - Paciente deverá ter uma creatinina nos últimos 12 meses, eletrocardiograma basal, atenção maior no controle pressórico. Após a cirurgia, considerar encaminhamento ao endocrinologista; Grau de recomendação I, Nível de evidência $D$.

- Glicemia > $125 \mathrm{mg} / \mathrm{dL}$ ou diagnóstico conhecido de DM - Paciente deverá ter uma creatinina nos últimos 12 meses, eletrocardiograma basal, atenção maior no controle pressórico, inclusive investigação de disautonomia (PA e FC sentado e após 3 minutos em pé). Após a cirurgia, considerar encaminhamento ao endocrinologista; Grau de recomendação I, Nível de evidência $D$.

- Glicemia > 220mg/dL, considerar adiamento da intervenção após melhor controle glicêmico; Grau de recomendação I, Nível de evidência $D$.

- Momento ideal de suspender as medicações orais antes da operação (Grau de recomendação l, Nível de evidência D):

Biguanidas: 24 a 48 horas antes

Sulfoniluréias: de 1a geração - 48 a 72 horas antes;

de $2^{\underline{a}}$ e $3^{\underline{a}}$ geração - no dia da operação.

Glitazonas: 24 a 48 horas antes

Tiazolidinedionas: no dia da intervenção

Acarbose: 24 horas antes

Glinidas: no dia da cirurgia

Insulina NPH: dose noturna pode ser mantida; na manhã seguinte administrar $1 / 3$ a 2/3 da dose dependendo do horário da operação.

- Se houver muita dificuldade no controle glicêmico, considerar acompanhamento simultâneo com o endocrinologista;

\section{II) Intra e Pós-operatório}

A hiperglicemia e a resistência insulínica são achados comuns em pacientes submetidos a estresse cirúrgico, graças às alterações metabólicas onde ocorre aumento de secreção de substâncias contra-reguladoras hiperglicemiantes e diminuição da secreção de insulina pela célula beta pancreática ${ }^{4}$. O tratamento agressivo da glicemia parece ter importante implicação na redução de infecções em intervenções cirúrgicas ${ }^{5}$. Van den Berghe e colaboradores ${ }^{6}$ estudaram prospectivamente 1548 pacientes de uma unidade de terapia intensiva (UTI) voltada primariamente para cuidados pós-cirúrgicos randomizados para receber tratamento convencional (tratar se glicemia $>215 \mathrm{mg} / \mathrm{dl}$ ) ou tratamento intensivo da glicemia (manter entre 80 e 110 $\mathrm{mg} / \mathrm{dl})$, dos quais $63 \%$ encontravam-se em pós-operatório de cirurgia cardíaca e $87 \%$ eram não diabéticos. Este estudo foi interrompido precocemente porque a mortalidade na UTI era significativamente inferior no grupo de tratamento intensivo do que no grupo de tratamento convencional $(4,6 \%$ X 8, $0 \%$; $\mathrm{p}<0,04)$, principalmente devido à redução de falência de múltiplos órgãos por sepse. Também a mortalidade intrahospitalar bem como a incidência de morbidades, tais como sepse, insuficiência renal aguda e polineuropatia, foram significativamente menores no grupo de tratamento intensivo. Embora episódios de hipoglicemia tenham sido muito mais freqüentes no grupo de tratamento intensivo, não houve nenhum episódio que se acompanhasse de instabilidade hemodinâmica ou convulsões ${ }^{1}$.

A administração venosa de insulina no intra-operatório oferece vantagens sobre sua aplicação subcutânea por ter absorção mais previsível e possibilidade de ajustes mais rápidos para melhor e mais seguro controle glicêmico. Uma outra solução contendo dextrose com eletrólitos pode ser administrada concomitantemente com objetivo de prevenção de hipoglicemia e hipocalemia. Recomendamos o controle pós operatório em unidades onde a monitorização intensiva seja efetiva e sugerimos seguimento intra e pós-operatório da glicemia capilar ou arterial de acordo com a experiência do centro e dos perfis dos pacientes.

\section{Recomendações:}

- Se a cirurgia for prolongada (tempo de cirurgia maior que 1 hora) ou se o paciente for de alto risco (classes II e III da ACP), deverá ter uma glicemia capilar mensurada na 
indução anestésica; Grau de recomendação Ila, Nível de evidência $D$.

- Administração venosa de insulina a todos os diabéticos tipo 1 (independentemente do porte cirúrgico) e aos diabéticos tipo 2 submetidos a cirurgia com duração prevista superior a 1 hora ou quando a glicemia estiver muito descontrolada; Grau de recomendação lla, Nível de evidência D.

- Controle rigoroso de glicemia com insulina regular em bomba de infusão, objetivando manter glicemia capilar entre 80 e $110 \mathrm{mg} / \mathrm{dL}$, repetindo glicemia capilar freqüentemente, conforme julgamento clínico. Convém mensurar o potássio sérico caso a glicemia esteja superior a 110mg/dL e monitorálo pelo menos diariamente; Grau de recomendação Ila, Nível de evidência $B$.

- A transição do controle glicêmico por via venosa para medicações por via oral pode ser feito fora da unidade de terapia intensiva, mantendo o mesmo alvo de controle (glicemia entre 80 e $110 \mathrm{mg} / \mathrm{dL}$ ) e considerando acompanhamento do endocrinologista. A glicemia capilar deve ser mensurada 1 hora após a retirada da bomba de insulina seguida por, no mínimo, 3 glicemias pré-prandiais ao dia ou de 6/6horas quando em jejum; Grau de recomendação Ila, Nível de evidência $B$.

\section{Referências}

1. Van den Berghe G, Wouters P, Bouillon R, Weekers F, et al. Outcome benefit of intensive insulin therapy in the critically ill: Insulin dose versus glycemic control. Crit Care Med 2003;31(2):359-66.

2. Umpierrez GE, Isaacs SD, Bazargan N, You X, Thaler LM, Kitabchi AE. Hyperglycemia: na independent marker of in-hospital mortality in patients with undiagnosed diabetes. J Clin Endocrinol Metab 2002;87:978-82.

3. American Diabetes Association: Standards of medical care for patients with diabetes mellitus (Position Statement).Diabetes Care 2001; 24(1):

\section{G) Considerações anestésicas e o intraoperatório}

\section{I) Escolha da técnica anestésica}

A escolha da técnica anestésica deve ter como objetivo final melhorar a evolução do paciente a longo prazo. O surgimento da técnica de Fast Track onde o paciente permanece menor tempo no hospital, refletiu na anestesia com o surgimento de prática direcionada à proteção miocárdica e despertar precoce.

Diversos estudos tentaram demonstrar a superioridade de uma técnica em detrimento da outra. Rodgers e colaboradores ${ }^{1}$, demonstraram em uma meta-análise que incluiu 9559 pacientes em 141 estudos clínicos, que o uso da anestesia regional reduziu a mortalidade em 30 dias em 30\%, a trombose venosa profunda em $44 \%$, a embolia pulmonar em 55\%, a necessidade de transfusão em $50 \%$, a pneumonia em 39\%, a depressão respiratória em 59\%, o infarto do miocárdio em 33\% e a falência renal em $43 \%$. Numa outra meta-análise que incluiu 17 estudos, dos quais 11 foram randomizados, com 1173 pacientes, Beattie e colaboradores² demonstraram que a utilização da analgesia epidural por mais de 24 horas está associada à redução estatisticamente significativa $(p<0,05)$ de isquemia miocárdica pós-operatória e tendência à redução de mortalidade $(\mathrm{p}<0,09)$.

O uso da anestesia regional pressupõe maior estabilidade hemodinâmica e está associada à excelente analgesia intra e pós-operatória. A doença pulmonar obstrutiva crônica aumenta o risco de mortalidade perioperatória em 5-13 vezes e procedimentos abdominais estão associados ao maior risco de complicações respiratórias. Estudos apontam para efeitos benéficos do bloqueio do neuroeixo em pacientes com alto risco de complicações respiratórias em detrimento

S33-S43.

4. McCowen KC, Malhotra A, Bistrian BR. Stress-induced hyperglycemia. Crit Care Clin 2001; 17:107-124.

5. Pomposelli JJ, Baxter JK III, Babineau TJ, et al. Early postoperative glucose control predicts nosocomial infection rate in diabetic patients. J Parenter Enteral Nutr 1998;22:77-81.

6. Van den Berghe $G$, Wouters $P$, Weekers $F$, et al. Intensive insulin therapy in critically ill patients. N Engl J Med 2001;345:1359-67. de anestesia geral. Portanto a anestesia regional pode ter influência benéfica na redução de morbi-mortalidade.

\section{Recomendação:}

- Quando possível, o bloqueio do neuroeixo deve ser preferível à anestesia geral. Grau de recomendação Ila, Nível de evidência $A$.

\section{II) Escolha do agente anestésico}

Recomenda-se que a indução anestésica seja sempre realizada de forma lenta, evitando-se instabilidade hemodinâmica com ocorrência de isquemia coronariana e cerebral. A substituição do midazolam por propofol ou etomidato, a substituição do fentanil por sufentanil em baixas doses e a não utilização de relaxantes musculares de eliminação renal em pacientes com comprometimento da depuração de creatinina permitem a extubação precoce em torno de 4 horas, minimizando o risco de isquemia miocárdica durante o período de despertar pós-operatório com adequada analgesia e sedação.

Em pacientes com instabilidade hemodinâmica ou com reduzida reserva cardiovascular, o etomidato é o agente de escolha para indução anestésica por menor interferência hemodinâmica. Por outro lado, a utilização de propofol foi associada à hipotensão intra-operatória.

\section{Recomendação:}

- Medicamentos de rápido início de ação, reduzida duração e com reduzido efeito residual devem ser preferencialmente 


\section{Diretriz}

utilizados em todos os procedimentos anestésicos. Grau de recomendação I, Nível de evidência $B$.

\section{III) Manutenção da temperatura corporal}

A ocorrência de hipotermia intra-operatória está relacionada ao aumento da resposta ao estresse, hipertensão e ocorrência de eventos isquêmicos coronarianos. Dois estudos clínicos demonstraram que a hipotermia não intencional estava relacionada à isquemia miocárdica pós-operatória em pacientes submetidos a procedimentos vasculares e não vasculares, com número significativamente maior de alterações eletrocardiográficas em pacientes com temperatura $<35$ graus e menor incidência de angina instável, parada cardio-respiratória e infarto do miocárdio em pacientes mantidos em normotermia ${ }^{3}$.

\section{Recomendação:}

- Manutenção de normotermia perioperatória para a prevenção de eventos cardíacos. Grau de recomendação I, Nível de evidência A.

\section{IV) Nitroglicerina intraoperatória}

A nitroglicerina é um fármaco vasodilatador predominantemente venoso e com propriedades dilatadoras coronarianas. No entanto nenhum estudo demonstrou prevenção de infarto perioperatório com o uso de nitroglicerina profilática venosa ${ }^{4}$

\section{Recomendação:}

- A nitroglicerina intra-operatória deve ser utilizada apenas para controle pressórico em pacientes coronariopatas, sem o objetivo de prevenção de isquemia perioperatória. Grau de recomendação I, Nível de evidência C.

\section{V) Cateteres}

\section{1) Cateter de artéria pulmonar}

A presença de cateter de artéria pulmonar permite medidas hemodinâmicas que ajudam no manejo intra-operatório de pacientes com cardiopatia submetidos à intervenções cirúrgicas. Entretanto, de acordo com as evidências na literatura, a sua utilização não está relacionada à redução de complicações cardiovasculares perioperatórias.

Dois trabalhos prospectivos que avaliaram o uso perioperatório de cateter de artéria pulmonar, encontraram aumento de incidência de eventos não cardíacos, sem redução de taxa de complicações cardiovasculares. O primeiro deles foi um estudo prospectivo, não randomizado, envolvendo 4059 pacientes submetidos a cirurgias eletivas e de grande porte, com exceção de cirurgias de aneurisma de aorta abdominal. Neste estudo, foi observado maior incidência de eventos não cardíacos, tais como embolia pulmonar e acidente vascular cerebral, bem como maior tempo de hospitalização ${ }^{5}$. O segundo trabalho prospectivo e randomizado, de 1994 pacientes de alto risco submetidos à intervenções cirúrgicas, não demonstrou benefício na utilização de cateter de artéria pulmonar no perioperatório e a sua presença foi relacionada a maior incidência de embolia pulmonar ${ }^{6}$.

A utilização de cateter de artéria pulmonar tem seu papel bem estabelecido no perioperatório de operações vasculares de alto risco, principalmente nas correções de aneurisma de aorta abdominal. Nos pacientes com disfunção ventricular importante (insuficiência cardíaca classes funcionais III e IV) e que serão submetidos a operações com grande potencial de causar labilidade volêmica ou pressórica, podem se beneficiar da monitorização hemodinâmica invasiva.

\section{Recomendações para o uso de cateter de artéia pulmonar no perioperatório:}

- Cirurgia de correção de aneurisma de aorta abdominal; Grau de recomendação lla, Nível de evidência $D$.

- Pacientes com cardiopatia descompensada a ser submetido a um procedimento cirúrgico de grande porte; Grau de recomendação lla, Nível de evidência $B$.

- Pacientes com disfunção miocárdica que serão submetidos à cirurgias de grande porte; Grau de recomendação IIb,Nível de eviência $B$.

\section{2) Pressão arterial invasiva}

A monitorização invasiva de pressão arterial no perioperatório de cirurgias não cardíacas segue as mesmas indicações de monitorização e de cuidados intensivos em pacientes graves.

No contexto perioperatório, a indicação de monitorização invasiva de pressão arterial é baseada em fatores dependentes do paciente e do tipo de cirurgia a ser realizada. As operações prolongadas e de grande porte como as cardíacas, craniotomias, torácicas e abdominais devem ter monitorização invasiva em todo o intra-operatório e pós-operatório imediato.

Há uma situação peculiar onde a monitorização de pressão arterial invasiva pode ser útil e deve ser considerada: nos pacientes portadores de marcapasso definitivo. Nesta população específica, devido à presença de marcapasso, a monitorização eletrocardiográfica no intra-operatório pode sofrer interferências com uso de bisturi elétrico e a monitorização de pressão arterial invasiva permite uma monitorização hemodinâmica mais fidedigna.

\section{Recomendações:}

- Pacientes com instabilidade hemodinâmica, cardiopatia grave e/ou operações de grande porte; Grau de recomendação I, Nível de evidência $D$.

- Pacientes portadores de marcapasso definitivo; Grau de recomendação Ilb, Nível de evidência $D$.

\section{VI) Balão intra-aórtico}

Existem poucos dados na literatura em relação à indicação de balão intra-aórtico no perioperatório de intervenções cirúrgicas e a sua utilização está limitada em situações especiais.

O uso de balão intra-aórtico no perioperatório de cirurgias não cardíacas poderia ser benéfico num grupo seleto de pacientes onde o risco cardíaco perioperatório é muito elevado: pacientes com síndrome coronariana 
aguda, disfunção ventricular associada à isquemia ou doença coronariana com anatomia grave (multi-arterial ou com lesão de tronco) e que será submetido à operações de grande porte, entre elas, as intra-torácicas e intra-abdominais.

\section{Referências}

1. Rodgers A, Walker N, Schug S, et al. Reduction of postoperative mortality and morbidity with epidural or spinal anaesthesia: results from overview of randomised trials. Bmj 2000; 321:1493.

2. Beattie WS, Badner N, Choi P. Epidural analgesia reduces postoperative myocardial infarction: a meta-analysis. Anesth Analg 2001; 93(4):853-8.

3. Sea F. Perioperative maintenance of normothermia reduces the incidence of morbid cardiac events. A randomized clinical trial. JAMA 1997; 277: 1127-34.

\section{H) Monitorização perioperatória}

\section{I) Monitorização do segmento ST}

A utilidade da monitorização do segmento ST no perioperatório é controversa. Muitos dos conceitos aplicados neste contexto são derivados da prática da ergometria convencional e da monitorização ambulatorial do eletrocardiograma dinâmico, de forma que, se já existem restrições quanto à acurácia das alterações do segmento ST em predizer isquemia miocárdica naquelas situações, o mesmo se aplica no perioperatório, adicionando-se ainda algumas considerações específicas. Os estudos que avaliaram as alterações do segmento ST no perioperatório não são uniformes no que diz respeito à metodologia aplicada (derivações, período de monitorização, sistema de análise exclusivamente visual ou computadorizado) ou aos critérios definitivos para isquemia utilizados ${ }^{1}$. Cabe ainda lembrar que além de haver diferença comprovada de acurácia entre os diferentes sistemas de análise automatizada do segmento $\mathrm{ST}^{2}$, ela é ainda maior quando se compara a análise do observador na sala de operação com a análise automatizada; em uma das séries relatadas a equipe médica que assistia aos pacientes identificou apenas $20 \%$ das alterações detectadas pela análise informatizada ${ }^{1}$.

Além dos fatores classicamente admitidos como limitantes da análise do segmento ST, algumas características específicas do perioperatório devem ser consideradas como potencialmente

\section{Recomendação:}

- Suporte para pacientes de alto risco cardíaco e operação de grande porte; Grau de recomendação IIb, Nível de evidência $D$.
4. Coriat P. Prevention of intraoperative myocardial ischemia during noncardiac surgery with intravenous nitroglycerin. Anesthesiology 1984; 61:193-196.

5. Polanczyk CA, Rohde LE, Goldman L, et al. Right heart catheterization and cardiac complications in patients undergoing noncardiac surgery: an observational study. JAMA 2001; 286(3): 309-14.

6. Sandham JD,Hull RD,Brant RF, et al.Canadian Critical Care Clinical Trials Group. A randomized, controlled trial of the use of pulmonary-artery catheters in high-risk surgical patients. N Engl J Med 2003; 348(1): 5-14. interferentes na análise do segmento ST, como a hipotermia, hipocalemia, hipocalcemia, hipomagnesemia, além de arterfatos produzidos pela localização distorcida das derivações eletrocardiográficas, em virtude da proximidade com o campo cirúrgico, ou mesmo pela interferência elétrica de bisturis.

Ainda assim, devemos considerar a monitorização com análise informatizada do segmento ST como um instrumento potencialmente adjuvante na avaliação perioperatória de pacientes de alto risco, para os quais o valor preditivo positivo dos achados é maior, com implicação prognóstica ${ }^{3,4}$, embora não existam evidências suficientes para recomendar seu uso de rotina. É importante lembrar que a maioria destas alterações não ocorre no intra-operatório, mas sim no pósoperatório, sendo que a maior correlação prognóstica se observa com a presença e duração da alteração no período pós-operatório ${ }^{4,5}$. Para pacientes que não apresentam preditores clínicos ou cirúrgicos de alto risco, há dados que sugerem baixa especificidade das alterações do segmento ST no perioperatório, de forma que não há potencial benefício da técnica ${ }^{6}$.

\section{Recomendação:}

- Monitorização do segmento ST automatizada no perioperatório de pacientes de alto risco; Grau de recomendação IIb, Nível de evidência C.

\section{Referências}

1. London MJ, Hollenberg M, Wong MG, Levenson L, et al. Intraoperative myocardial ischemia: localization by continuous 12-lead electrocardiography. Anesthesiology 1988: 69:232-241.

2. Slogoff S., Keats AS, David Y, Igo SR. Incidence of perioperative myocardial ischemia detected by different electrocardiographic systems. Anesthesiology 1990; 73:1074-1081.

3. Mangano DT, Hollenberg M, Fegert G, et al. Perioperative myocarial ischemia in patients undergoing noncardiac surgery-I incidence and severity during the 4 day perioperative period. The Study of Perioperative Ischemia (SPI) Research Group. J Am Coll Cardiol 1991; 17:843-850.

4. Fleisher LA. Anesthetic management and perioperative surveillance. Progress in Cardiovascular Diseases 1998; 40(5): 441-452.

5. Landesberg G, Luria MH, Cotev S, et al. Importance of long-duration postoperative ST-segment depression in cardiac morbidity after vascular surgery. Lancet 1993; 341: 715-719.

6. Fleisher LA, Zielski MM, Schulman SP. Perioperative ST-segment depression is rare and may not indicate myocardial ischemia in moderate-risk patients undergoing noncardiac surgery. J Cardiothorac Vasc Anesth 1997; 11(2): 155-159. 


\section{II) Infarto Agudo do Miocárdio (IAM) perioperatório}

OIAM é a complicação cardíaca mais temida no perioperatório, com incidência em torno de 1 a 1,8\% e mortalidade de $23 \%$ a 40-50\% ${ }^{1-3}$. A existência de co-morbidades é um importante fator prognóstico e a limitação para o uso do arsenal farmacológico terapêutico anti-trombótico e anti-plaquetário classicamente utilizado nas síndromes coronarianas agudas, corroboram para esta pior evolução. Embora as conseqüências clínicas do infarto perioperatório sejam gravíssimas, seu diagnóstico na maioria das vezes não é evidente e requer alto grau de suspeita clínica e monitorização. Os critérios diagnósticos (dor compatível, eletrocardiograma e marcadores de necrose miocárdica) sofrem modificações inerentes ao contexto perioperatório.

O quadro clínico clássico de dor torácica precordial freqüentemente está ausente, quer por efeito residual de anestésicos e analgésicos, quer pela subvalorização por parte da equipe médica, ao atribuir precipitadamente a dor torácica a outras etiologias mais óbvias, tais como dores incisionais ou relacionadas à posição do paciente. Há relatos de séries de infartos perioperatórios em que a incidência de infarto sem dor foi de $50 \%{ }^{1}$ e até mesmo $61 \%^{2}$. O quadro clínico freqüentemente é de insuficiência cardíaca e arritmias, com congestão pulmonar ou baixo débito, manifesto como alterações do estado de consciência, sintomas gastrointestinais, hipotensão ou piora da função renal que podem corresponder a $64 \%$ dos casos de infarto perioperatório ${ }^{2}$.

Quanto à análise do eletrocardiograma, a grande maioria dos infartos apresenta alterações eletrocardiográficas compatíveis, porém não patognomônicas de infarto. As alterações inespecíficas do ECG no perioperatório são extremamente comuns, porém de baixa especificidade para isquemia miocárdica, muitas vezes decorrentes de distúrbios eletrolíticos, efeitos medicamentosos, hipotermia ou processos inflamatórios sistêmicos freqüentemente presentes nos períodos intra e pós-operatório ${ }^{3}$. Estes achados adquirem maior plausibilidade na avaliação diagnóstica de isquemia miocárdica quando analisados comparadamente a outros registros de eletrocardiograma feitos evolutivamente e antes da intervenção cirúrgica, e devem sempre ser inseridos no contexto clínico e de marcadores de necrose miocárdica.

Finalmente, é a análise de marcadores de necrose miocárdica que parece promissora para redefinir critérios diagnósticos de infarto do miocárdio perioperatório. A especificidade da $\mathrm{CKMB}$, ainda que analisada percentualmente em relação à CPK, é reduzida no contexto perioperatório ${ }^{4}$, questionandose o significado biológico de sua alteração quando ocorre sem correlação com o quadro clínico ou alteração eletrocardiográfica.
Yeager e colaboradores denominam esta situação de "infarto químico" e em seu estudo, os pacientes com este diagnóstico tiveram sobrevida livre de infarto e revascularização miocárdica semelhante à população controle até 4 anos de seguimento ${ }^{5}$. Se tal achado representa resultados falso-positivos da CKMB ou apenas uma questão metodológica, não há elementos para responder. Atualmente, com a incorporação cada vez maior da análise de troponina na avaliação diagnóstica e prognóstica das síndromes coronarianas agudas, a avaliação destes casos fica mais precisa, com evidências do impacto prognóstico das troponinas T e I quando elevadas no perioperatório ${ }^{6}$. Em série nacional o valor preditivo positivo da troponina para infarto agudo do miocárdio ou óbito de causa cardíaca no perioperatório de cirurgia vascular foi de $62 \%$ e a especificidade foi de $93 \%$, enquanto que o valor preditivo positivo da CKMB foi de apenas $22 \%$. Recentemente a importância prognóstica da elevação isolada de troponina foi reiterada, com dados que revelam serem relevantes até mesmo elevações discretas e inferiores aos valores de corte diagnóstico de infarto ${ }^{4}$.

Pacientes com diagnóstico inequívoco de infarto agudo do miocárdio perioperatório devem ser tratados agressivamente, preferencialmente com estratificação de risco invasiva e precoce, necessariamente antes da alta hospitalar. Tal prática é fundamental para controle da alarmante morbi-mortalidade a curto e longo prazos.

A positividade de qualquer um dos critérios citados (eletrocardiograma, CKMB, troponina ou quadro clínico) deve ser sempre valorizada e indicativa de investigação complementar antes da alta hospitalar, desde que a sua monitorização tenha sido bem indicada, ou seja, paciente com estimativa de risco cardíaco moderado a alto. A opção de se realizar estratificação cardíaca invasiva ou não invasiva em pacientes com elevação isolada de troponina deve ser baseada na avaliação específica do cardiologista.

\section{Recomendações:}

- Pacientes com estimativa de risco cardíaco perioperatório intermediário a alto de natureza isquêmica, devem permanecer monitorizados em unidades semi-intensivas ou de terapia intensiva realizando eletrocardiograma e troponina diariamente até o 3 o dia pós-operatório, já que a maioria dos eventos ocorre até este dia. Grau de recomendação I, Nível de evidência A.

- Se a dosagem de troponina não estiver disponível, recomenda-se a substituição por curva de CKMB/CPK de 8/8h. Grau de recomendação I, Nível de evidência $B$.

\section{Referências}

1. Goldman L, Caldera D, Nussbaum SR, Southwick FS, et al. Multifactorial Index of Cardiac Risk in Noncardiac Surgical Procedures. N Engl J Med 1977; 297:845-850

2. Becker RC, Underwood DA. Myocardial infarction in patients undergoing noncardiac surgery. Cleve Clin J Med 1987; 54: 25-28.

3. Liu LL, Dzankic S, Leung JM. Preoperative electrocardiogram abnormalities do not predict postoperative cardiac complications. J Am Geriatr Soc 2002; 50: 1186-1191.

4. Landesberg G, Shatz V, Akopnik I, Wolf YG. Association of cardiac troponin, CK-MB, and postoperative myocardial ischemia with long-term survival after major vascular surgery. J Am Coll Cardiol 2003; 42: 1547-54.

5. Yeager RA, Moneta GL, Edwards JM, Taylor LM, et al. Late survial after perioperative myocardial infarction complicating vascular surgery. J Vasc Surg 1994; 20:598-606.

6. Lopez-Jimenez F, Goldman L, Sacks DB, Thomas EJ, et cols. Prognostic value of cardiac troponin T after noncardiac surgery: 6-month follow-up data. J Am Coll Cardiol 1997; 29: 1241-1245. 


\section{6) CIRURGIA DE URGÊNCIA}

Ao indicar-se uma cirurgia de urgência encontra-se implícita a idéia de que a premência do procedimento, ao menos em princípio, suplanta os eventuais riscos que a operação impõe ao paciente. No entanto, nem por este motivo uma avaliação pré-operatória deve ser negligenciada, já que as chances de complicações cardíacas são de 2 a 5 vezes mais freqüentes neste tipo de intervenções ${ }^{1}$. O risco elevado deve-se tanto à falta de tempo hábil e condições para a realização de uma avaliação satisfatória, quanto à gravidade e co-morbidades associadas à doença que motivou a intervenção. O conhecimento dos antecedentes cardiovasculares do paciente associado a mínimos dados propedêuticos pode permitir a utilização otimizada de recursos de monitoração e terapêutica intra e pós-operatória. Além disso, a grande maioria das síndromes isquêmicas agudas ocorre no período compreendido entre o ato cirúrgico e o 3 ia pós-operatório, permitindo que se programe o tempo durante o qual o paciente deva permanecer em unidade de cuidados intensivos.

\section{Recomendações para monitorização:}

- ECG diariamente (além de antes do procedimento cirúrgico) até o 3o pós-operatório; Grau de recomendação I, Nível de evidência C.

- Marcadores de lesão miocárdica - Recomenda-se a dosagem diária de marcadores de necrose miocárdica até o 3o pós-operatório (de preferência troponina); Grau de recomendação I, Nível de evidência $A$.

\section{Referências}

1. Mangano, DT. Perioperative cardiac morbidity. Anesthesiology 1990; 72:153.

2. Raymer K, Yang H. Patients with aortic stenosis: cardiac complications in non-cardiac surgery. Can J Anesth 1998; 45:855-9.

3. Haering JM, Comunale ME, Parker RA, et al. Cardiac risk of noncardiac
- Cateter de Swan-Ganz - face à controvérsia a respeito dos reais benefícios da utilização deste recurso, o uso deste cateter deve ser restrito a pacientes instáveis hemodinamicamente imediatamente antes do ato operatório de urgência ou que apresentem alto risco de instabilização; Grau de recomendação IIb, Nível de evidência $B$.

- Monitorização do segmento ST no intra-operatório e $\mathrm{PO}$ imediato, com pelo menos 2 derivações precordiais (V4 e V5),em pacientes coronariopatas; Grau de recomendação IIb, Nível de evidência $C$.

- Ecocardiograma transtorácico - devido ao pouco tempo disponível habitualmente para este tipo de avaliação antes de um procedimento de urgência, não deve ser solicitado de rotina, exceto em situações especiais de dúvida diagnóstica, como cardiomiopatia hipertrófica e/ou doença valvar ${ }^{2,3}$. As recomendações/níveis de evidência são as mesmas do item 4B;

- Balão Intra-Aórtico - diante das escassas evidências na literatura, deve-se restringir sua indicação a situações particulares de alta gravidade como já descrito no item 5GVI;

\section{Recomendações para terapêutica:}

- Beta-bloqueadores - a utilização profilática no perioperatório de intervenções de urgência se baseia em estudos com operações eletivas demonstrando redução de infarto agudo e morte e de eventos pós-alta hospitalar; As recomendações/níveis de evidência são as mesmas do item $5 \mathrm{Al}$;

- Nitratos - contra-indicados como profilaxia de isquemia ${ }^{4}$; Grau de recomendação III, Nível de evidência C.

surgery in patients assymetric septal hypertrophy. Anesthesiology 1996; 85: 254-9.

4. Dodds, TM, Stone, JG, Coromilas, J, et al. Prophylatic nitroglycerin infusion during noncardiac surgery does not reduce perioperative ischemia. Anesth Analg 1993; 76: 705. 